\title{
AN ANALYSIS OF URBAN \\ ECOLOGICAL KNOWLEDGE AND BEHAVIOUR IN WELLINGTON, NEW ZEALAND
}

\author{
By \\ John Parker \\ Thesis \\ ENVIRONMENTAL STUDIES 593 \\ 2009
}

A 90 point thesis submitted to Victoria University of Wellington, as partial fulfilment of requirements for the degree of

Master of Environmental Studies

School of Geography, Environment and Earth Sciences

Victoria University of Wellington

September, 2009 


\title{
AN ANALYSIS OF URBAN ECOLOGICAL KNOWLEDGE AND BEHAVIOUR IN WELLINGTON, NEW ZEALAND
}

\author{
John Parker
}

\begin{abstract}
The majority of the worlds' population now live in urban areas, with urban areas growing at a faster rate than other land use types. Most urban residents are concentrated in neighbourhoods of low biodiversity, and there are concerns about urban residents' disconnection from nature. A lack of ecological knowledge and pro-environmental behaviour has conservation implications. I surveyed Wellington households $(\mathrm{n}=453)$ and investigated possible predictors of residents' ecological knowledge about birdlife, bird feeding, and tree planting connected to birdlife. Three measures of knowledge were tested, species freelisting, neighbourhood bird knowledge, and photo identification. Key predictors of higher levels of ecological knowledge were increased frequencies of visiting local and regional parks, higher levels of garden space, and higher educational qualifications. However, all models had low predictive power. Species richness and perceived access to greenspaces were not significant predictors of ecological knowledge. Residents had a lower knowledge of native birdlife compared with exotic species across all measures. Forty-two percent of respondents fed birds, $10 \%$ targeting native species, and 36\% planted trees for birdlife. Knowledge of neighbourhood birds and garden size were key predictors for each. This study shows the importance of urban greenspaces for ecological knowledge and behaviour, and efforts should be made to encourage visits to greenspaces.
\end{abstract}




\section{Acknowledgements}

There are a number of people I would like to thank who have contributed in various ways to the completion of this thesis. First and foremost, I would like to thank my supervisor, Dr Michael Gavin, for all the time, guidance, enthusiasm and encouragement given throughout the year. Thanks especially for your perseverance with me after all seemed lost, and for patiently getting me back on track.

I would like to thank my Ministry of Hard Work colleagues, Mark, Joe, Ed, and Vicki, who all helped make the thesis experience an enjoyable one. I wish the Ministerial team all the best for the future. To the new office crew, I sincerely thank Babs for your empathy and encouragement, and Fei for your friendly company and delicious cooking. Many thanks to all the other graduate students who thankfully reminded me that life existed outside the university walls, especially Emilio, Rob, Chris, Nico, Charlie, and Aaron. Thanks also to Thea, for providing the incentive to finish.

Special thanks must go to Sarah, for your encouragement and offerings of food. It was much appreciated. To Eunica, I thank you for brightening my life when I needed it most. Memories of your company will linger long after this thesis is forgotten.

Very special thanks must go to Bernie, of which there can be no other. For the curry dinners, the late-night encouragement, the badminton, and outlook on life, I thank you. And, of course, thank you to my parents, for making this study possible. 


\section{Table of Contents}

$\begin{array}{ll}\text { Abstract } & 1\end{array}$

$\begin{array}{ll}\text { Acknowledgements } & 2\end{array}$

List of Figures 5

List of Tables $\quad 6$

$\begin{array}{ll}\text { Chapter One : Introduction } & 7\end{array}$

1.1 Impact of Urban Ecosystems on Urban Residents 14

$\begin{array}{ll}1.2 \text { Ecological knowledge } & 20\end{array}$

1.3 Conservation-related behaviour 26

1.4 Research Objectives $\quad 30$

$\begin{array}{ll}\text { Chapter Two: Methodology } & \mathbf{3 1}\end{array}$

2.1 Case Study - Wellington, New Zealand 31

2.2 Site Location - Wellington 33

2.3 Site Location - Survey Design 35

2.4 Survey Design 38

2.5 Survey Questions $\quad 41$

$\begin{array}{lr}\text { Chapter Three: Results and Analysis } & 50\end{array}$

3.1 Urban Wildlife and Ecological Knowledge Survey - Response Rates 50

3.2 Ecological knowledge 51

3.3 Respondent Socio-Demographics $\quad 58$

3.4 Ecological Knowledge Analysis 63

3.5 Bird Feeding and Tree Planting $\quad 72$

3.6 Bird-Related Behaviour Analysis 76

$\begin{array}{ll}3.7 \text { Exotic and Native species } & 80\end{array}$

Chapter Four: Discussion and Conclusion $\quad \mathbf{8 3}$ 
4.1 Ecological knowledge $\quad 83$

4.2 Predictors of ecological knowledge $\quad 84$

$\begin{array}{ll}4.3 \text { Native and exotic bird knowledge } & 90\end{array}$

4.4 Unexplained variance $\quad 92$

4.5 Bird feeding and tree planting 93

4.6 Urban planning considerations $\quad 97$

$\begin{array}{ll}4.7 \text { Research suggestions } & 101\end{array}$

$\begin{array}{ll}4.8 \text { Conclusion } & 103\end{array}$

$\begin{array}{ll}\text { References } & 105\end{array}$

Appendix

1. Questionnaire sent to participants 117

2. Bi-variate correlation analysis 126 


\section{List of Figures}

1.1 Urban Populations as percentage of total population in $2005 \quad 8$

1.2 Urban Population as percentage of total population 8

1.3 Relative importance of anthropogenic agents of fragmentation 9

1.4 Pathways whereby human activities lead to altered biotic structure in urban settings 13

2.1 Population of New Zealanders in rural and urban areas 31

2.2. Map of Wellington showing the greenspaces managed by the Wellington City Council

2.3 Aerial map of Wellington showing study area, landscape types, transect routes, and locations surveyed (numbered points)

3.1 The self-rated level of ecological knowledge of the respondents

3.2 Comparison between the respondents' self-rated level of ecological knowledge and their actual knowledge, measured by the number of birds free listed.

3.3 The number of birds respondents had seen or heard in the neighbourhood measured against their perceived level of knowledge

3.4 Number of bird species freelisted in five minutes 54

3.5 Number of bird species respondents had seen or heard in their neighbourhood within the past year

3.6 Number of birds the respondents correctly identified from photographs 56

3.7 How the respondents answered questions concerning bird identification from photographs

3.8 Frequency of visits to parks and participation in outdoor recreation activities

3.9 The accessibility of local green spaces, as perceived by the respondents 62

3.10 Percentage of respondents feeding birds on their property 73

3.11 Percentage of respondents planting trees on their property 73 


\section{List of Tables}

2.1 Description of the six transect routes (A to F), along which the survey locations were spaced out.

2.2 Definitions of the landscape types used to describe the land cover surrounding each survey location.

3.1 Geographic variation of the response rates

3.2 Comparison of respondents' knowledge level between different measures of ecological knowledge.

3.3 Comparison table of the composition of survey residents with the averages for Wellington City population

3.4 Partial correlations of the variables correlated with knowledge, controlling for other correlated independent variables

3.5 Socio-economic and other predictors of ecological knowledge: results from stepwise linear regression

3.6 Significance of the regression model, ANOVA summary 68

3.7 Socioeconomic and other predictors of ecological knowledge: results from linear regression of native and exotic bird knowledge

3.8 Significance of the regression model, ANOVA summary 71

3.9 Comparison of respondents participating in bird feeding and tree planting versus nonparticipants based on socio-demographic factors.

3.10 Partial correlations of the variables correlated with knowledge, controlling for other correlated independent variables

3.11 Socioeconomic and other predictors of ecological behaviour: results from stepwise logistic regression

3.12 Significance of the ecological behaviour regression models 


\section{Introduction}

The aim of this study is to examine urban ecological knowledge and the links between ecological knowledge and behaviour. I will do so through an examination of the ecological knowledge and behaviour of Wellington residents towards avian wildlife. The study of ecological knowledge in urban areas is an important one, given the rapid growth of urban populations worldwide. The United Nations (2007) predicted that the portion of the world's population living in urban areas will equal the rural population for the first time in 2007. Currently, the percentage of the population living in urban areas is significantly larger in developed countries, reaching $81 \%$ in North America (United Nations, 2007; see Figs 1.1 and 1.2). Urbanisation of the world's population has occurred rapidly during the twentieth century. In 1900, only 13 percent of the world's population was made up of urban-dwellers, increasing to 29 percent in 1950 , and reaching 49 percent in 2005 (United Nations, 2007). The projections are for this to increase to 60 percent (five billion people) by 2030, including 80 percent of the population in developed countries (United Nations, 2007). Urban areas are currently expanding at a faster rate than any other land use type, and the impact of urbanisation is even more acute when we consider that the number of households and urbanised land is outpacing population growth in many regions due to a trend in fewer residents per household (Liu et al., 2003; McKinney, 2002). 


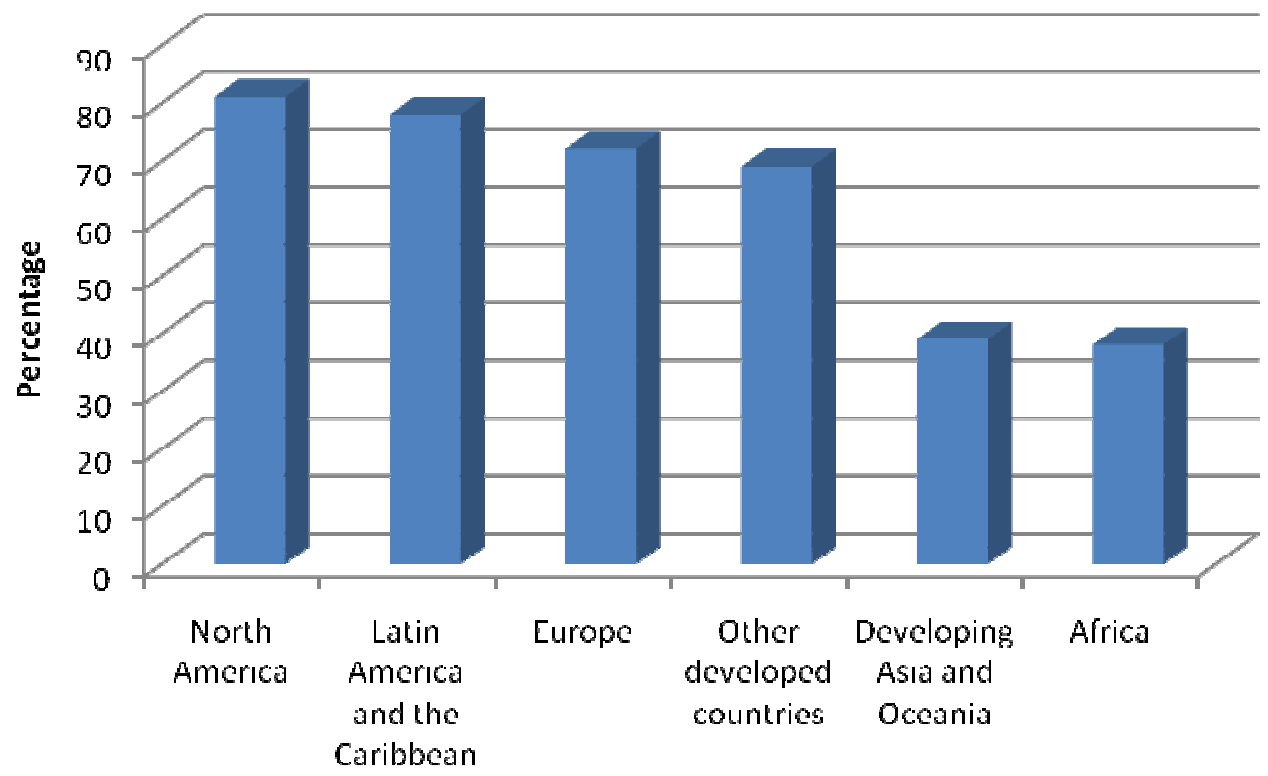

Figure 2.1 Urban Populations as percentage of total population in 2005 (UN, 2007).

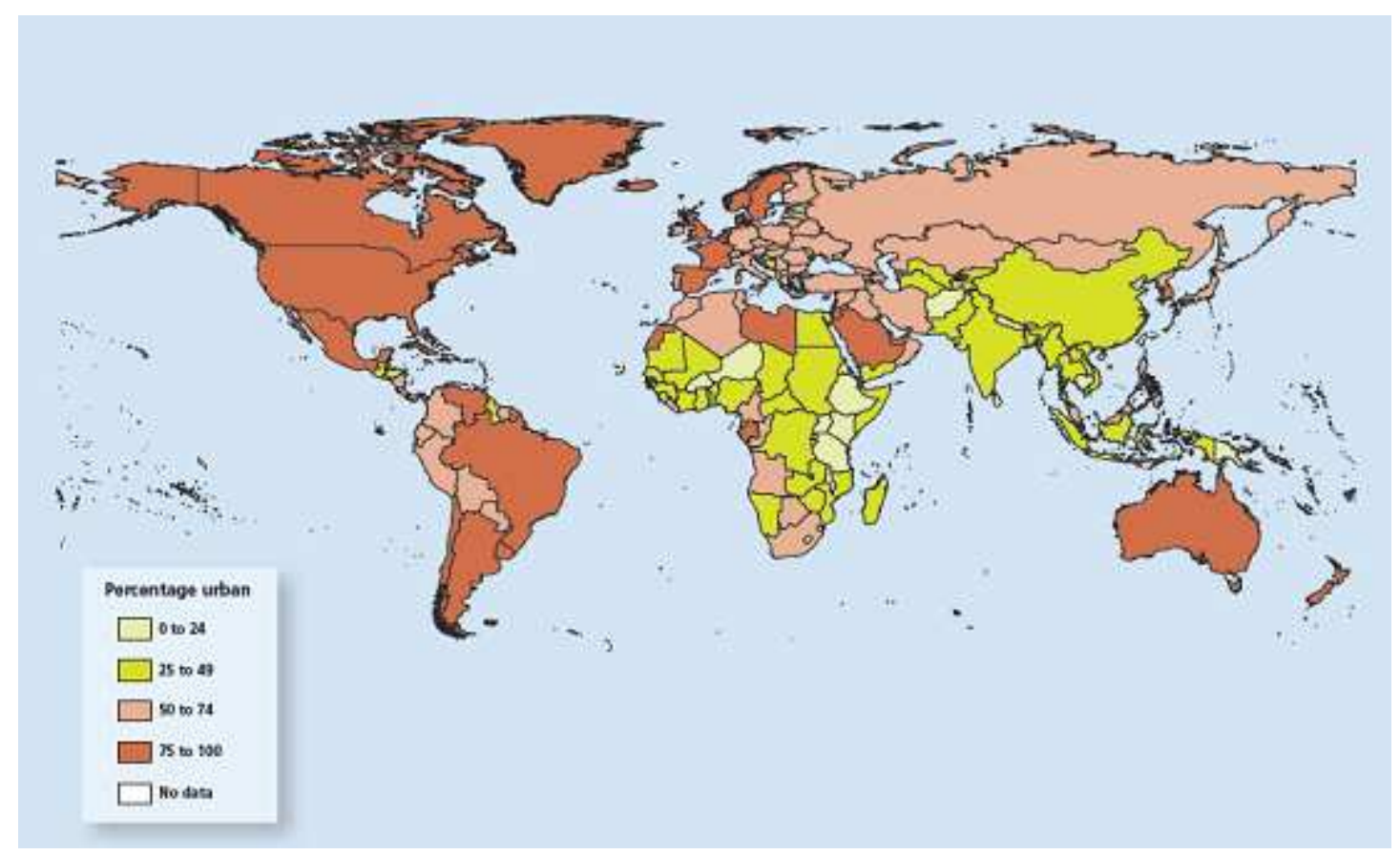

Figure 1.2 Urban Population as percentage of total population (UN, 2007).

As urban areas continue to grow, there are increasing concerns about ecological integrity of urbanized landscapes. The growth of urban areas causes land exploitation 
that often decreases the amount and quality of green space, and the remaining areas of green space become fragmented and isolated (Marzluff and Ewing, 2001; Stenhouse, 2004; Sandstrom et. al., 2006b). This habitat fragmentation generally leads to a major alteration of vegetation and species composition, often with detrimental effects on biodiversity (McKinney, 2006). Fragmentation can have a devastating impact on local ecosystems (Luck et. al., 2009), and urbanisation has thus become a major concern in conservation biology (e.g. Miller, 2002). Of the main anthropogenic activities that fragment natural landscapes, urbanisation has the greatest local effect on wildlife because of its persistence on the landscape and its dissimilarity to natural land cover (Fig. 1.3) (Marzluff and Ewing, 2001). Taken on a global scale, as the extent of urban development increases, urbanisation is likely to overtake agriculture as the dominant agent of fragmentation (Marzluff and Ewing, 2001).

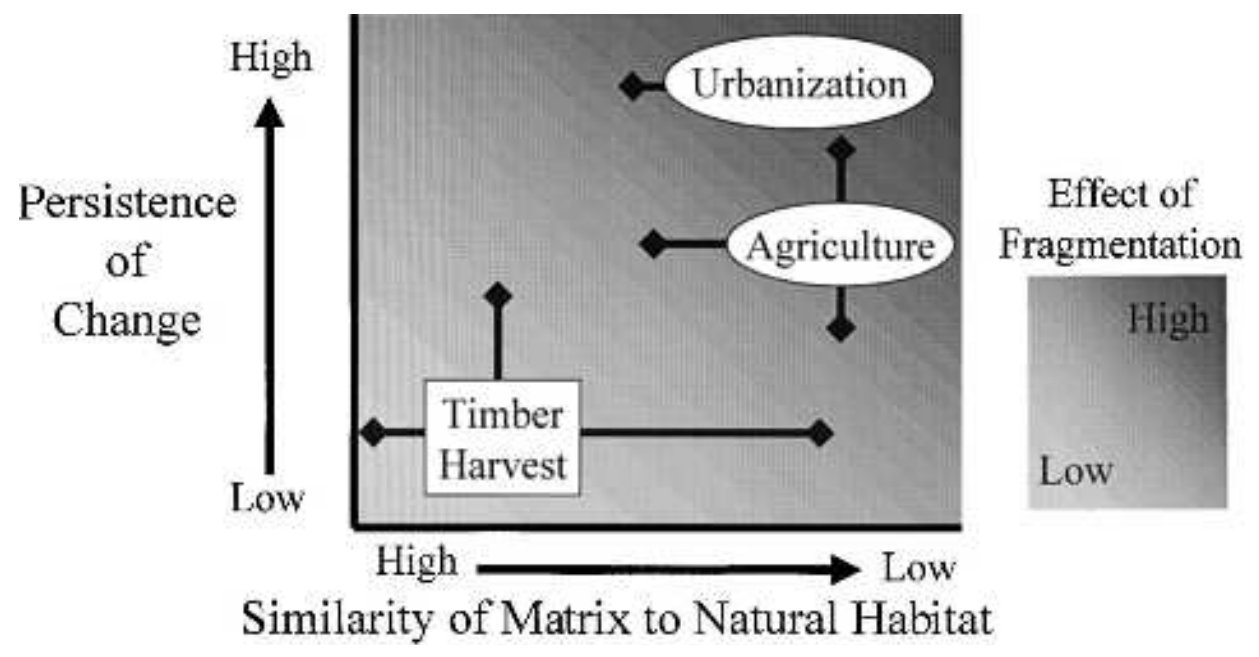

Figure 1.3. Relative importance of anthropogenic agents of fragmentation. Urbanisation is expected to have the greatest local effect on native animals because once an area is urbanised it rarely reverts back to a more natural condition, and the urban matrix is very dissimilar to native land covers. Source: Marzluff and Ewing, 2001. 
Public and private urban greenspaces are generally reducing over time (Grose, 2009). Urban greenspaces can include public parks, reserves, natural heritage areas, and private residential gardens (De Sousa, 2003). In many urban areas, private gardens can represent the largest single proportion of green space (Garston et al., 2005), providing physical linkages between green spaces and green refuges (Mathieu et. al., 2007). The reduction in private garden space is mainly due to increasing suburban densities and greater house sizes (McKinney, 2002). As a quantitative example of greenspace reduction, the city of Tokyo, Japan, experienced a loss of 369 square kilometres of green space between 1975 and 2005, whilst the built up area increased by 659 square kilometres (Takahashi 2008). In Phoenix, Arizona (USA), modelling studies suggest that the urban area will soon be highly fragmented ecologically as large patches of open land are broken up, resulting in a decline in patch diversity and complexity (BerlingWolff and Wu, 2004). Similarly, studies from Perth, Australia found that the smaller reserves in the highly populated inner metropolitan area display high levels of fragmentation, higher levels of weed infestation and path density and low vegetation condition, compared with those reserves in the outer urban area (Stenhouse, 2004). Even in places where urban growth is occurring at a moderate rate, such as Sweden, urbanisation is still increasing the degree of fragmentation and isolation of green spaces (Borgstrom et. al., 2006). The fragmentation of the remnant vegetation may have critical ecological implications. While some species that are able to survive in small remnant patches may adapt well to urban environments (Rickman and Connor, 2003), most taxa are likely to be negatively impacted by the effects of habitat fragmentation due to urbanisation (Connor et al., 2002).

In addition to fragmentation, urbanisation also changes the quality of habitat remaining within urban areas (Rickman and Connor, 2003). The changes in habitat 
quality due to urbanisation can be caused by pesticides, air pollution, changes in light, nutrient and water regimes, soil compaction, and exotic species (Connor et al., 2002). Cities tend to homogenise the physical environment as they are usually designed to meet the needs of one species, humans (McKinney, 2006). Homogenization occurs because a small set of species, which are 'urban adaptable' (e.g., house sparrows, rats, rock doves), become locally abundant and increasingly widespread in cities around the globe (see McKinney, 2006). Although species richness can increase or decrease with urbanisation depending on the taxonomic group, the spatial scale of the analysis, and the intensity of urbanisation, the general trend is for a decline in biodiversity (McKinney, 2008). In urban environments, the most commonly studied taxa are bird species (see McDonnell and Hahs, 2008). For avian populations, urbanisation tends to select for omnivorous, granivorous, and cavity nesting species, with increased urbanisation generally leading to an increase in avian biomass and density but a reduction in richness (Chace and Walsh, 2006; McDonnell and Hahs, 2008).

This reduction in species richness reflects a general loss and decline of native species, which are replaced by fewer exotic species (see Marzluff, 2001; McKinney, 2002; Adams, 2005; Chace and Walsh, 2006; McKinney, 2008). Non-native species richness arises from two basic factors: (1) increasing importation of non-native individuals, and (2) favourable habitat for the establishment of non-native species (McKinney, 2006). The disturbed habitat created by urbanisation promotes non-native species by providing resources, reducing the threat of natural enemies, and altering the physical environment to improve conditions for the non-native invader (Shea and Chesson, 2002). Because of the homogenisation of urban environments, bird communities of highly-urbanised areas are often more similar with other cities than with adjacent natural ecosystems (Blair, 2001). Urban exploiters such as rock doves, 
starlings, and house sparrows are common to all cities from Europe to North America, migrating from city to city rather than being native to a region (McKinney, 2006). Consequently, urban residents are therefore exposed to reduced native diversity.

On the other hand, the urban landscape is becoming increasingly important for maintaining biodiversity (Sandstrom et al., 2006). On a global scale, there is a positive association between human population density and biodiversity, as people tend to live in areas of high diversity (Cincotta et al., 2000). As a result, there is a great potential for conservation of biodiversity in urban areas (Schwartz et al., 2002). Amongst all taxonomic groups, species richness declines in areas with extreme urbanisation, but the effects of moderate levels of urbanisation vary significantly (McKinney, 2008). In some situations, the addition of non-native species may exceed the loss of native species to give a net gain in species richness (McKinney, 2008).

In general though, the trend is for declining urban biodiversity and reduced species richness, with a reduction in native species with increasing urbanisation. Human activities in urban areas influence the biological diversity and species richness, summarised below in Fig 1.4. However, the resulting urban environmental change also impacts on humans as well, affecting how urban residents interact with the environment. 


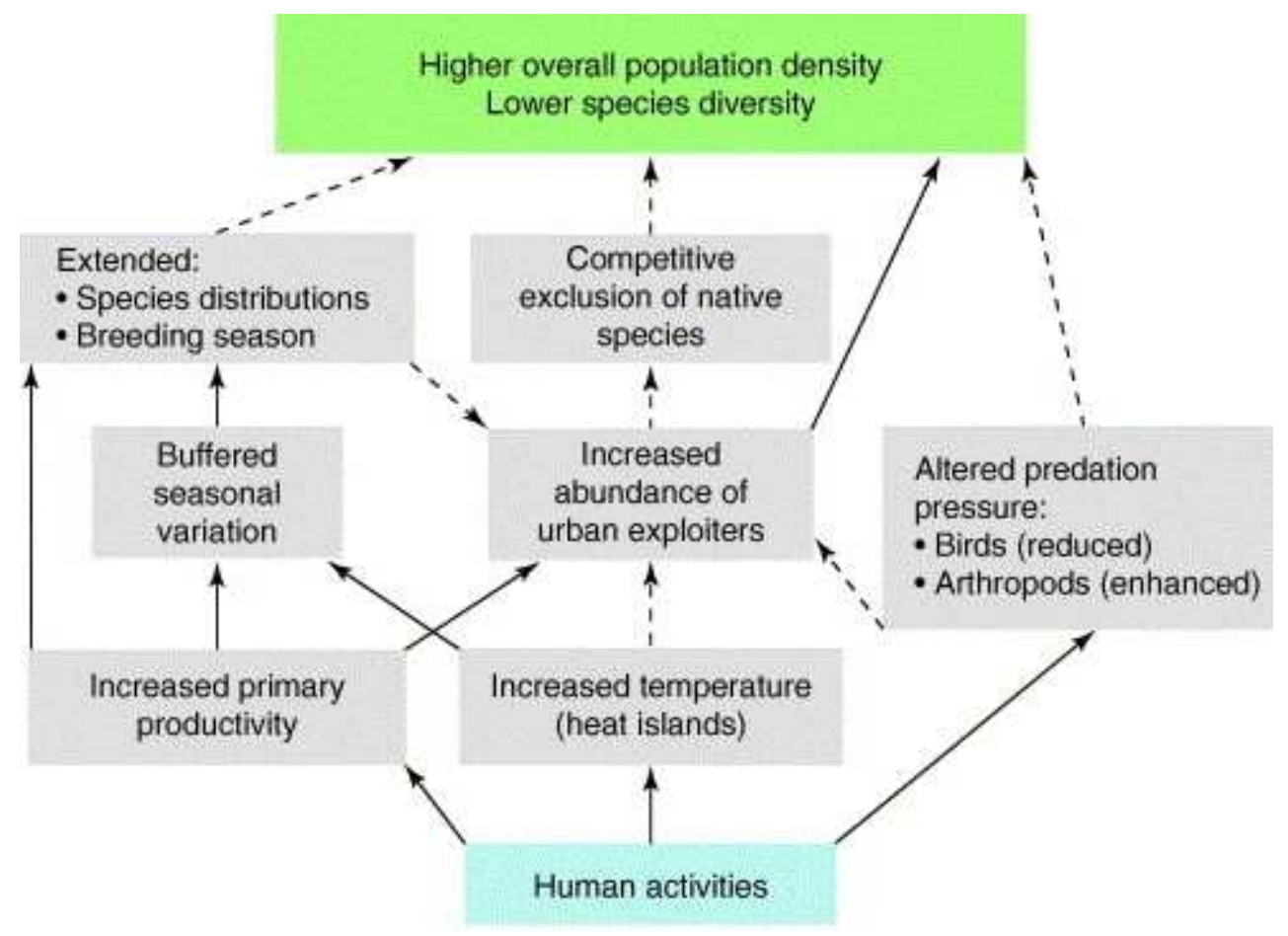

Figure 1.4. Pathways whereby human activities lead to altered biotic structure in urban settings. The dashed lines indicate where more research is needed to address the mechanisms. Source: Shochat et al., 2006

While urban landscapes are among the most profoundly altered ecosystems on the planet, they have traditionally been little studied in comparison with non-urban landscapes. Urban ecological studies have a long history, dating back from more than fifty years (Luck and Wu, 2002), yet a study of the papers published in nine leading ecological journals between $1995-2000$ found only 0.4 percent focused on cities or urban species (Collins et. al., 2000). In recent years however, there has been an increase in interest in urban ecology (McIntyre et. al., 2001; Collins et al., 2000; Pickett and Cadenasso, 2006). Urbanization creates a different socio-ecological system compared with other systems, acting on a variety of spatial, temporal, and functional scales (Grimm et. al., 2000; Pickett et. al., 2001; Borgstrom et. al., 2006). 
Some main principles of urban ecology have been developed, and Cadenasso and Pickett (2008) identify the following five principles: 1) cities or urban areas are ecosystems, 2) they are heterogeneous, 3) they are dynamic, 4) human and natural processes interact in cities, and 5) ecological processes remain important in them. For example, urban green spaces have been commonly understood as unchanging and isolated entities in the urban landscape, and not as integrated elements of a larger urban socio-ecological system (Borgstrom et al., 2006). Key attributes of the urban model are learning and feedback between the human and natural components of urban ecosystems (Pickett et. al., 1997). To integrate human activity successfully into an ecological model, it is necessary to realise the importance of human decision-making, culture, and the many factors which influence urban residents' 'quality of life', such as educational activities, recreation, wealth, and community health (Grimm et al., 2000). In other words, urbanisation has significant ecological impacts, which, in turn, can have profound implications for humans.

\subsection{Impact of Urban Ecosystems on Urban Residents}

The loss of green space in cities can have many detrimental impacts for urban residents, and is a growing issue throughout the world (Bonnes et al., 2007). Urban green spaces offer urban residents the opportunity to experience nature within the city, contact they otherwise may not have, as well as providing many other benefits (Chiesura, 2004). Sanderson (2002, p. 162) observed that "in the foreseeable future, most of the world's population will not know nature in any direct way." The fragmentation and loss of green spaces has implications on humans for recreation, health, ecosystem services, and general well-being. 
Urban ecosystems are increasingly seen as critical in providing ecosystem services valuable for human health and well-being (Millennium Ecosystem Assessment, 2005), yet the exploitation and degradation of urban green spaces reduces their ability to sustain these ecosystem services (Ernstson et al., 2008). Such services can include, for example, mitigation of air pollution, noise, and heat (Millenium Ecosystem Assessment, 2005). Additionally, because many urban citizens do not depend on locally functioning ecosystems due to the support for energy, resources, and waste retention being provided by ecosystems elsewhere outside the city (Borgstrom et al., 2006), the degradation of urban ecosystems may not be readily noticed.

Easily accessible urban green areas also provide opportunities for urban dwellers to have contact with nature, learn about and appreciate nature (Yli-Pelkonen and Niemela, 2005). They can help alleviate urban alienation, the process where urban residents become alienated from nature and natural processes (Cranz and Boland, 2004). The appreciation of contact with nature may even be part of a distant effect of the conditions under which early humans evolved (van den Berg et al., 2007). In a broad sense then, the presence of green spaces in cities is a prerequisite for human wellbeing (Frumkin, 2001). Urban green spaces are highly appreciated by residents, and an important factor in residential satisfaction (Burgess et. al., 1988; Bonaiuto et. al., 1999; Bonnes et al., 2007). Studies suggest that the physical properties of urban green spaces, such as their availability and richness in biodiversity, are related to residents' appreciation and frequency of visit to these spaces (Bonnes et al., 2007). As an example of their importance, the lack of green space and parks was the main reason given for people moving out from the city of Leuven, Belgium (van Herzele and Wiedemann, 2003). 
Research also shows that access to green spaces can reduce stress-related illnesses, and improve general health and well-being (Frumkin, 2001; Grahn and Stigsdotter, 2003; de Vries et al., 2003; Pretty et al., 2005; Tzoulas et al., 2007; Maas et al., 2009, Mitchell and Popham). Simply viewing natural settings from the window has been shown to substantially contribute to residents' satisfaction with their neighbourhood and with diverse aspects of their sense of well-being (Kaplan, 2001).

The importance of urban nature for the recreation and well-being of residents should not be underestimated (Kuo et al., 1998, Niemela, 1999). The amount, and quality, of green spaces can affect residents' activity patterns, frequencies of everyday recreation, and the way in which knowledge about the environment is acquired (van Herzele and Wiedemann, 2003). Having green spaces nearby in the neighbourhood has been shown to increase the outdoor recreational activities of urban residents (Neuvonen et. al., 2007; Giles-Corti and Donovan, 2002; Grahn and Stigsdotter, 2003; Giles-Corti et al., 2005), although one study did not find any relationship (Hillsdon et. al., 2006). There are also other positive social benefits to urban green spaces, for they can play an important role in residents' feelings of attachment towards the community, and their interactions with other residents (Kim and Kaplan, 2004). The frequency of visits to urban green areas has been shown to be significantly higher among residents in urban neighbourhoods that have a high quantity of green spaces (Bonnes et al., 2007). Accessibility is important, as studies show that most people are unwilling to walk more than 400m (10 minutes) from home to reach a neighbourhood green space (e.g. Burgess et al., 1988). Urban planning can maximise access by incorporating a continuum of green space sizes from smaller, local parks close to people's homes to larger parks at the urban fringe (Caspersen et al., 2006). 
Despite the many benefits of urban green spaces to local residents, green spaces are often unevenly distributed within cities. Diverse green spaces are often disproportionately located in wealthier city neighbourhoods (e.g. Iverson and Cook, 2000). Research from Baltimore has shown a significant positive relationship between the likelihood of a community to contain areas with trees and grass (green infrastructure) and its level of income and education (Grove and Burch, 1997). The distribution of native and exotic plant species, the density, structure of the understory, and plant diversity have all been linked to the socio-economic status of the neighbourhood (Hope et al., 2003; Martin et al., 2004). In Phoenix, Arizona, USA, neighbourhood vegetation richness increased across a gradient of low to high socioeconomic status (Martin et al., 2004). Socio-economic factors accounted for ninety percent of the neighbourhood vegetation richness variation, with income the most significant factor.

Other aspects of urban nature are also unevenly distributed. For example, bird diversity tends to vary spatially in cities. A Melbourne study found that streetscape vegetation can have a significant effect on bird diversity, with parks and native streetscapes generally supporting fewer introduced species than exotic and recently developed streetscapes (White et al., 2005). In Vancouver, neighbourhoods of higher socioeconomic status tended to have a higher native bird species richness and abundance than ones of lower socioeconomic status (Melles, 2005). This was possibly due in part to land values in urban areas often being heavily influenced by the proximity of parks and other green space (Melles, 2005). A study evaluating bird diversity across different cities worldwide found a pattern of decreased bird diversity in neighbourhoods where most residents are concentrated (Turner et al., 2004). A Chicago study found high-income neighbourhoods to contain a higher number of exotic bird 
species, while low-income neighbourhoods had more native and migratory species (Loss et al., 2009). This contradicts previous studies (e.g. Melles, 2005), and Loss et al. (2009) hypothesised that income could have been linked to fine-scale vegetation characteristics influencing avian richness, such as the proportion of native plant species. The proximity to large natural preserves also enhanced avian richness (Loss et al., 2009). They also found that as neighbourhoods aged, the avian community shifted from being comprised primarily of native species to being increasingly dominated by exotic and migratory species, contrasting earlier studies (e.g. Palomino and Carrascal, 2005). The characteristics of the landscape preceding new housing developments seemed to be important (Loss et al., 2009), and was likely to help explain for the different findings.

A consequence of this unequal distribution of urban nature is that, within cities worldwide, the majority of residents are concentrated in areas of impoverished biodiversity (Turner et al., 2004). This trend occurs in spite of substantial diversity being present in cities overall, and is even more severe when examining native species (Turner et al., 2004). The implications of this are troubling. As mentioned earlier, green spaces can have numerous psychological and restorative benefits, but they also provide residents with a link to the natural world. By the year 2030, it is estimated that the majority of the earth's population is likely to be living in a state of "biological poverty" (Turner et al., 2004). This is defined as when urban citizens experience below-average levels of native species diversity on a daily basis. A consequence of this may be the 'extinction of experience', whereby urban residents experience reduced biological diversity and local flora and fauna, followed by disaffection and apathy, in turn producing more degenerative environments (Miller, 2005). If urban residents are experiencing less diversity and encounter fewer native species, there may be worrying consequences for conservation. 
One consequence of the decline of native species in cities is the 'Pigeon Paradox' (Dunn et al., 2006), a situation where urban dwellers depend on a connection with nature that may be comprised largely of non-native organisms, such as feral pigeons, which are currently viewed as undesirable pests. With thousands of species facing the threat of extinction in the next 50-100 years, the links between urban nature and conservation outside cities may be important (Dunn et al., 2006). If urban residents are unfamiliar and disconnected from their native environment then it may be difficult to persuade them to promote native species conservation, which holds increasing importance as more and more people live in cities worldwide (McKinney, 2002; Turner et al., 2004; Miller, 2005). To illustrate the lack of knowledge about ecological issues, a British study of schoolchildren aged between 4 and 11 showed that the children were more than twice as good at identifying Pokemon characters (a card game) than in identifying common organisms found locally (Balmford et. al., 2002).

The impoverished biodiversity and lack of native species experienced by most urban dwellers may have a big impact on the levels of ecological knowledge and environmental behaviours of urban residents. As well as providing direct benefits such as recreational, psychological, and environmental services, urban nature experiences can provide wider educational services by increasing residents' interest and knowledge in the environment (Yli-Pelkonen and Niemela, 2005). Studies have shown an increasing gap between people and the natural world, and a correspondingly growing ignorance in environmental knowledge (Miller, 2005). These human connections with the natural world could be restored by providing meaningful interaction with nature in close proximity to where people live and work (Miller and Hobbs, 2002). If, for example, local residents are able to observe changes in urban environmental patterns and processes or ecological conditions (e.g. habitat fragmentation, loss of species), this 
may help them understand the same changes taking place elsewhere. The end result may be that their overall awareness of environmental issues is raised (Yli-Pelkonene and Niemela, 2005). This direct experience with nature can promote emotional affinity towards, knowledge about, and interest in nature, which in turn can be a powerful predictor in pro-environmental behaviour (Kals et al., 1999). Lack of knowledge is a factor that can explain the weak relationship between environmental concern and environmentally responsible behaviour (Fransson and Garling, 1999). Indeed if, as hypothesised by Chawla $(1998 ; 1999)$, direct experience with nature is a prerequisite in determining an individual's conservation action, then the quality and quantity of experiences that urban residents have with the natural world has immense importance. In summary, the ecological impact of urbanisation may have big impacts on the ecological knowledge and environmental behaviours of urban residents. Thus it is important to understand the factors that may account for the variance in residents' ecological knowledge.

\subsection{Ecological knowledge}

There is no rigid definition of exactly what ecological knowledge is, and the definition has been widely contested in the literature. Ecological knowledge, in its simplest sense, would be knowledge about the natural world and its processes, the relationship of living beings with one another and with their environment (Berkes et al., 2000). Olsson and Folke (2001) define local ecological knowledge as being knowledge held by a specific group of people about their local ecosystems, concerning the relationships among organisms and also between organisms and the environment. This may be a mixture of scientific and practical knowledge. For most of human history, the main form of knowledge amongst people has been based on experience and testing and has been adapted to the local environment (Reyes-Garcia et. al., 2005), called folk or 
traditional ecological knowledge. However, other forms of ecological knowledge are not traditional, (i.e. not passed down over generations and not involving management and social institutions). Berkes et al. (2000) describe four levels of ecological knowledge, one aspect being the names of living components of the ecosystem. This will be the focus of my research, investigating knowledge about species, the ability to identify birds. This level of ecological knowledge can provide an indication of the participants' connectivity with the local environment (Pilgrim et. al., 2008).

Today, with increasing urbanisation, the local environment for much of the world's population will comprise urban areas. With trends showing reduced biodiversity and a reduction in native species richness in urban areas, two questions arise: (1) if urban residents are experiencing reduced biodiversity in urban areas, does this translate into reduced knowledge about the natural world?, and (2) with the dominance of common non-native species in cities, does this translate into reduced native species knowledge? As the proportion of people living in urban areas increases, it is important to know how urban environments influence residents' ecological knowledge. If urban residents are exposed to poor ecological conditions then people's baselines of ecological health are liable to diminish over time, referred to as intergenerational amnesia (see Pauly, 1995; Turner et al., 2004; Miller, 2005). This may have negative consequences for residents' ecological knowledge and appreciation of nature, and in turn the conservation of nature everywhere (Turner et al., 2004). An individuals' local environmental knowledge can vary depending on the degree of exposure to the natural world (Guest, 2002), which in turn can be affected by a variety of variables such as geographic residence, economic pursuits, recreational activities, and differential access to information (Johnson and Griffith, 1996). In this study I seek to examine how environmental knowledge varies according to geographic and socio- 
economic criteria, and to investigate whether certain predictors such as green space interaction and avian richness might predict levels of knowledge about birds.

There have been few studies that explicitly examine ecological knowledge of urban residents. Even so, the lack of ecological knowledge among urban residents has long been a concern (Schneider and Salk, 2002). These concerns seem justified, as comparisons between rural and urban residents show that rural residents are able to identify more local species than urban residents (Pilgrim et. al., 2007). In a study in Georgia, USA, McDaniel and Alley (2005) found that local environmental knowledge declines with increasing urbanisation.

In non-urban environments, the research investigating the link between socioeconomic variables and folk knowledge has produced mixed and unclear results (Reyes-Garcia et al., 2005). The factors affecting ecological knowledge can be different based upon social, cultural, and economic differences (Pilgrim et al., 2007). Gender, income, ethnicity, age, recreation activities, and nature experiences have all been shown to affect ecological knowledge. The influence of gender on ecological knowledge varies depending on the location and type of knowledge tested. For example, studies have found gender to be one of the most important demographic influences on attitudes towards wildlife, with a greater knowledge of wildlife amongst males (Kellert, 1976; Kellert and Barry, 1987). Gender differences in perceptions of nature are also well documented (see Martino, 2008). However, other studies show gender does not have a significant impact on environmental knowledge (McDaniel and Alley, 2005; Pilgrim et al., 2007), or environmental support (Gupte, 2002).

Studies of urban residents in the UK found that the knowledge of local species names was low, older people tend to be able to identify many more local species than 
younger people, and that the variance between experts and non-experts was large (Pilgrim et al., 2008). The length of time at the residential location was also found to be significant, with a longer length of time at the address correlated with a higher degree of knowledge. Amongst other socio-economic indicators, higher income levels have been linked to having a more active interest in nature, which correlated with a higher level of ecological knowledge (Kellert, 1976; Johnson and Griffith, 1996; Turpie, 2003). However, income had little or no impact in other studies (McDaniel and Alley, 2005; Pilgrim et al., 2007). Studies also show that ethnicity can be also a predictor of knowledge (Kellert, 1976; Johnson and Griffith, 1996).

Studies that have examined local ecological knowledge (e.g. Voeks and Leony, 2004; Quilan and Quilan, 2007) show that demographic variables such as age, gender, and ethnicity are significant in predicting people's level of ecological knowledge. There were negative relationships between knowledge and education, and with academic skills. However, some studies show that schooling can be positively associated with knowledge (Reyes-Garcia et al., 2005).

In urban areas, while studies show a higher education can be positively correlated with knowledge levels (Kellert, 1976; Kellert and Barry, 1987), more recent studies show that that formal education is not a strong predictor of knowledge (Guest, 2002; McDaniel and Alley, 2005; Pilgrim et al., 2007). It seems, in urban areas, that the most effective acquisition of ecological knowledge can lie outside the classroom, in outdoor experiences. While socio-economic variables can be important in the acquisition and social distribution of ecological knowledge (Guest, 2002), environmental knowledge seems to be distributed in a much different pattern than other types of knowledge (McDaniel and Alley, 2005). Rather than variables such as 
education and income, environmental knowledge seems more closely linked to an individuals' exposure to the natural environment (McDaniel and Alley, 2005).

A study in Georgia, USA (McDaniel and Alley, 2005), found that the key variable in the variance in urban ecological knowledge levels was active participation in outdoor recreation. Active bird-watchers had the highest environmental knowledge scores. Tarrant et al. (1997) also found bird-watchers to be significantly more knowledgeable and concerned about wildlife than others. The more time people spent outdoors in the natural world, the more knowledge they had about its characteristics, suggesting a potential for a strong negative cycle in the process of urbanisation (Tarrant et al., 1997). Numerous studies support the view that humans are becoming disconnected from nature, with a decline in nature-based recreation and National Park visits (Pergams and Zaradic, 2006; Pergams and Zaradic, 2008; Kareiva, 2008). Pergams and Zaradic (2006) show a correlation between this decline and an increase in sedentary activities involving electronic media. Similar trends exist in Japan and Spain, suggesting the trend of fewer visits to nature is widespread (Pergams and Zaradic, 2008). However, in the United States, while some forms of outdoor activities are declining (e.g. fishing, camping) other forms are growing (e.g. bird watching, outdoor photography) (Cordell et al., 2008). In Sweden, despite increasing urbanisation, residents visit parks outside the city about once a week in summer, similar to levels twenty years ago (Sandstrom et al., 2006). Therefore, urbanisation's impact on recreation may vary, and this has important implications for ecological knowledge. Residents' experiences with nature do not just happen locally, and urban residents may maintain contact with the natural world through travel and recreation outside urban centres. 
Interactions with nature are undoubtedly important for ecological knowledge. A United Kingdom study suggests that the frequency of individual visits to the countryside is the most important factor influencing ecological knowledge (Pilgrim et. al., 2007). There was a direct positive relationship between knowledge level and the frequency of visits outside urban areas. The study found that the individuals with the highest ecological knowledge levels acquired their knowledge from family, environment-based occupations, and hobbies (Pilgrim et. al., 2007), with the lowest acquiring their knowledge through television and schooling. This is of concern as 80 percent of children from industrialised regions rely on television and schooling to provide them with their ecological knowledge, even though it is the least efficient way of disseminating this knowledge (Pilgrim et al., 2007). However, with children spending more and more time indoors, natural connections may be getting lost. UK studies show the average time a child spends outdoors per day has drastically declined, reducing from 86 minutes in 1981 to 42 minutes in 1997 (Orr 2002, in Pilgrim et al., 2007).

There are conflicting results for the variables that are significant in predicting an individuals' ecological knowledge, suggesting that more research in this field needs to be undertaken. Significantly, more research needs to be conducted in urban areas, with most research on ecological knowledge focusing on traditional knowledge of non-urban residents. The role that the access and quality of green spaces have on shaping ecological knowledge has not been thoroughly tested. Additionally, all the previously cited research has thus been carried out overseas, with no studies that I could find having been undertaken locally. This study will help to provide a New Zealand prospective on this issue, and add to the existing international literature on this topic. 


\subsection{Conservation-related behaviour}

As well as impacting on knowledge, activities involving direct experiences with nature may also impact on environmental behaviours (Tarrant et al., 1997; Rogan et al., 2005). If environmental knowledge, attitudes, and behaviour are linked to exposure to the environment, then the lack of biodiversity and native species richness in urban environments may be fuelling a negative feedback cycle, with poorer and poorer ecological conditions as a result (e.g. Miller, 2005). Identifying possible characteristics of those involved in pro-environmental behaviour should be useful in understanding how urban ecosystems may be enhanced.

Environmental behaviour is a complex field for research. Numerous models of environmental behaviour exist, for example: The Elaboration Likelihood Model (Petty and Cacioppo, 1981), The Theory of Planned Behaviour Model (Ajzen, 1991), The Value-Action Gap Model (Blake, 1999), The Reasonable Person Model (Kaplan, 2000), The Value-Belief-Norm Model (Stern, 2000), and the Model of proenvironmental behaviour (Kollmuss and Agyeman, 2002). The models identify certain variables that seem to be prerequisites for pro-environmental behaviour. Conservationrelated behaviour can be influenced by demographic, external, and internal factors (Kollmuss and Agyeman, 2002). External factors include institutional factors (such as the provision of the necessary infrastructure), economic factors, and social or cultural factors (Kollmuss and Agyeman, 2002). Internal factors include the individuals' values and attitudes. According to the Value-Belief-Norm model (Stern, 2000), people need to value the environment for its own sake, and they need to know about environmental issues to understand the consequences of human actions. In studies on the factors that had shaped the values of environmentalists, childhood experiences in nature was the most important influence (Chawla, 1998, 1999). Amongst those who were active in 
environmental clubs later in life, at least 50 percent of those people identified childhood nature experiences as being significant (Chawla, 2007). Emotional connections also seem important in shaping beliefs and values towards the environment, and people seem more likely to conserve nature when they have these direct experiences (Chawla, 1998, 99). Direct experiences with nature with all five senses should be offered to promote emotional affinity towards and interest in the environment (Kals et al., 1999). Hungerford and Volk (1990) identify variables that predispose people to take an interest in the environment as a prerequisite for responsible environmental behaviour. An individuals' perception over whether they have control over the behaviour is also an important internal factor (Newhouse, 1991).

Other internal factors influencing conservation-based behaviours are environmental awareness and environmental knowledge. Chawla (2007) identifies three factors that frequently predict pro-environmental action or intention to take action: gender, socio-economic status, environmental attitudes and knowledge (see Chawla, 2007).

This study is linked to an ecological avian study conducted in Wellington in 2008 (Vinton, 2008). With access to these data, my focus is on behaviour directly related to urban bird ecology. For urban dwellers, two ways residents can participate in pro-environmental action and encourage bird life is by bird feeding and tree planting. Therefore, I will examine rates of bird feeding and the planting of trees that provide bird food and influence avian composition .These specific pro-environmental behaviours may be influenced by numerous factors.

For many urban residents, bird feeding and tree planting are ways to provide a connection with the natural world (Fuller et. al., 2008). Additionally, there are 
ecological benefits from both tree planting and bird feeding. Native birds can be encouraged to frequent gardens by selective plantings of vegetation, with higher native bird species abundances in gardens with native plants (Day, 1995). Bird feeding can also play an important role in the conservation of species (Cannon, 1999), as bird feeding is a long-term activity that can result in easily accessible, energy-dense sources of food for birds (Lepczyk et. al., 2004). An increase in feeder stations match closely the increase in bird numbers in gardens for numerous species (Chamberlain et al., 2005), which can be perceived as a positive or negative effect depending on the bird species which benefit (i.e. native or exotic). In turn, there is some debate as to whether urban bird feeding itself is actually desirable in terms of bird conservation (Parsons et al., 2006; Ishigame and Baxter, 2007).

However, much non peer-reviewed literature exists advocating the use of bird houses and promoting bird feeding amongst householders (Lepczyk et al., 2004), and it is a commonplace and popular activity in many parts of the world (e.g. Rollinson et al., 2003; Ishigame and Baxter, 2007). For example, between one-fifth and one-third of households in Europe, North America, and Australia provide supplementary food for wild birds (Rollinson et al., 2003; Lepczyk et al., 2004). Estimates in the UK suggest that between 48 percent (Davies et al., 2009), and 60 percent (DEFRA, 2002) of households with a garden feed wild birds. Bird feeding is a common feature in Australian urban areas, with a Brisbane study showing 37 percent of respondents regularly feeding wildlife and birds being the main recipients (Rollinson et al., 2003). An American study across urban residents found 44 percent of landowners provided bird houses, and 51 percent planted or maintained vegetation for birds (Lepczyk et al., 2004). 
Studies find there are certain attributes common to those participating in birdrelated behaviour. The accessibility of a garden and the average garden size are important variables in the spatial variation of wildlife gardening (predominantly bird feeding) (Gaston et. al., 2007). Women were more likely to feed birds and plant vegetation, and people more highly educated were less likely to feed birds (Lepczyk et al., 2004). Landowners who fed birds, provided bird houses, and planted or maintained vegetation were older than those who didn't (Lepczyk et al., 2004). In the UK, the prevalence of bird feeding across different neighbourhoods' decreases as socioeconomic deprivation increased, and increased with bird species richness and abundance (Fuller et. al., 2008). In Vancouver, Canada, people in the poorest neighbourhoods have lower levels of being involved in neighbourhood tree planting and community greening efforts than more well-off citizens (Melles, 2005). The poorer ecological conditions in lower socio-economic neighbourhoods may disassociate people from native diversity in the city, leading to lower support for natural diversity at regional or national levels. However, other studies have shown no link between the socio-economic status of householders and the participation by householders in activities to encourage wildlife (Garston et. al., 2007). Tree planting and bird feeding can have a huge influence, but no studies have examined the prevalence of these activities in New Zealand cities. I will fill this gap and also examine the many possible factors that may influence these important conservation-related behaviours.

In summary, the ecological impact of urbanisation may have big impacts on the ecological knowledge and environmental behaviours of urban residents. Thus it is important to understand the factors that may account for the variance in residents' ecological knowledge and behaviour. There are no studies that I could find examining New Zealand urban residents' knowledge about avian wildlife, nor about the 
prevalence of environmental behaviours such as bird feeding or tree planting. This study should help fill this gap in the literature, and help understand whether exposure to reduced biodiversity and reduced native species richness corresponds to a reduced knowledge about these species. This study will also examine other possible predictors for knowledge, such as socioeconomic factors and exposure to green spaces, and also examine whether these are predictors for bird feeding or tree planting. This study may also contribute to questions about urban planning, by examining how city design may positively affect residents' environmental knowledge and behaviours.

\subsection{Research Objectives}

1. To measure the ecological knowledge of Wellington urban residents. To investigate possible predictors of ecological knowledge.

2. To investigate the patterns of bird feeding behaviour amongst urban Wellington residents.

To investigate possible predictors of bird-related environmental behaviour.

3. To investigate Wellington urban residents knowledge of native/non-native species 


\section{Methodology}

\subsection{Case Study - Wellington, New Zealand}

Wellington is seen an ideal location to examine the knowledge and behaviours of urban residents. New Zealand is one of the most highly urbanised countries in the world, with 86 percent of the population living in urban areas (Statistics New Zealand, 2005). New Zealand transformed from having a predominantly rural population to an urbanised population, with just under 60 percent of the population living in a rural areas in New Zealand in 1881 (Statistics New Zealand, 2005; see Fig 2.1). The number of households in New Zealand has also increased substantially, contributing to urban expansion, due to the combination of population growth and the reduction in average household size (Liu et. al., 2003).

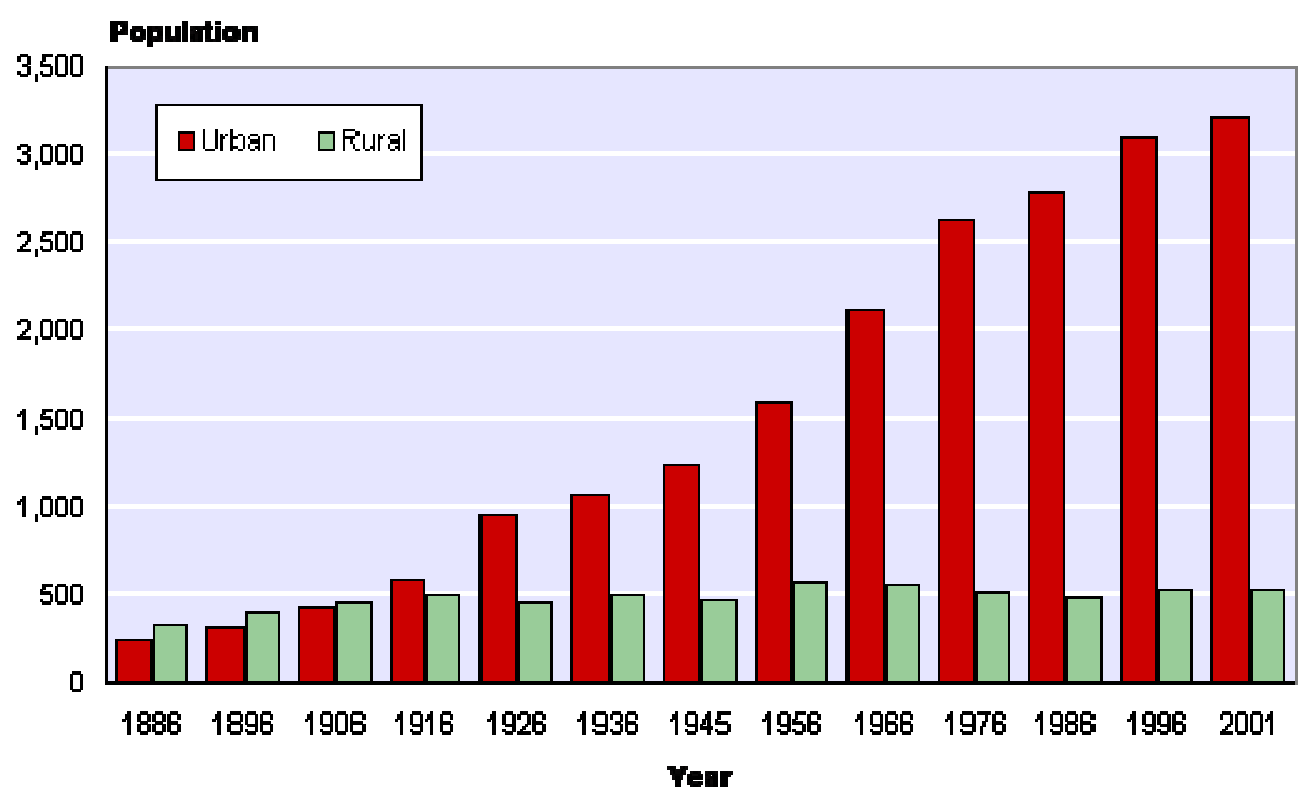

Figure 2.1 Population of New Zealanders in rural and urban areas, Statistics NZ (2005) 
Wellington is seen as an ideal location to investigate peoples' bird knowledge, residents' behaviour, and the effect of urbanisation. New Zealand has developed a unique bird fauna as a result of its unique location and geography, making it a special area for study. In Wellington, the creation in 1995 of the Karori Wildlife Sanctuary (comprising 225 ha of regenerating lowland forest protected by a predator-proof fence) has led to many rare native species being re-introduced. Additionally, council initiatives such as possum and other pest control measures have contributed to a resurgence of birdlife in urban Wellington, along with more native trees being planted in gardens (Department of Conservation, 2008). An increase in bird-related interest around Wellington may lead to an increase in knowledge and a general concern about wildlife (Tarrant et al., 1997). However, it is also important to note that Wellington may not be typical of urban areas globally or in New Zealand because of the abundance of green spaces here. Perhaps, Wellington could be seen as an 'ideal' location in that the level of ecological knowledge of the urban residents could be expected to be at the higher end of the knowledge spectrum if knowledge is correlated with access to nature (e.g. Miller, 2005).

The ecological impacts of urbanisation in New Zealand follow the general trends found globally, with declining species richness correlated with increasing urbanisation (van Heezik et al., 2008; Vinton, 2008). Wellington is an ideal location to test residents' knowledge of birds as it can be compared with recent ecological studies of Wellington's bird populations. In Wellington, the house sparrow, starling, blackbacked gull and feral pigeon comprise 60 percent of individual birds found in the city (Vinton, 2008). House sparrows and starlings were the most widespread and abundant species, both being exotic. Native forest birds such as the silvereye, fantail, tui, and 
grey warbler all show a descending abundance distribution from the less urbanised outer suburbs to the central commercial districts (Vinton 2008). These trends are mirrored in another New Zealand city, Dunedin (van Heezik et al., 2008). With the prevalence for exotic species in urban areas, it is hypothesised that urban residents might have a better knowledge of these species compared with native species. This may have implications for conservation attitudes and behaviours related to native and nonnative species throughout New Zealand.

\subsection{Site Location - Wellington}

I conducted all data collection in Wellington, New Zealand. Wellington is situated at the southern-most tip of the North Island, at a latitude of $41.25^{\circ} \mathrm{S}$ (shown below in Fig 2.3). Wellington is an ideal location to investigate my objectives as recent ecological avian studies have been carried out by Jennifer Vinton (Vinton, 2008) in Wellington City. Bird abundance data have been collected from locations all around the urban area (see Section 2.3), which can be compared with my research into residents' knowledge. Urban ecosystems are typically organised along gradients extending from the surrounding landscape to the town centre (Savard et. al., 2000), and the survey sites chosen encompass this range of habitat. I collected data via a self-administered mailbox questionnaire, and the 41 sites surveyed are all situated within a five-km radius of the

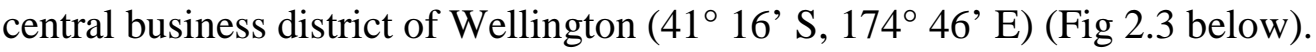

Wellington has a population density of 619 individuals per $\mathrm{km}^{2}$ (Statistics New Zealand, 2008), and is more densely populated than most other New Zealand cities. The high population density is largely due to the geography of the region, with a limited amount of flat or low slope building space between the harbour and the hill country that 
surrounds the city. The landscape of Wellington city is very diverse, with up to 500 square kilometres of regional parks and forests, and 102 park and recreation areas within the city (Wellington City Council, 2008). The map in Figure 1 below shows the areas of green space in the city. The central city itself is flat and largely devoid of large areas of green space, but the amount of green space increases with distance from the Central Business District, especially towards the west. The greenbelt areas are situated on hills that surround the central city.

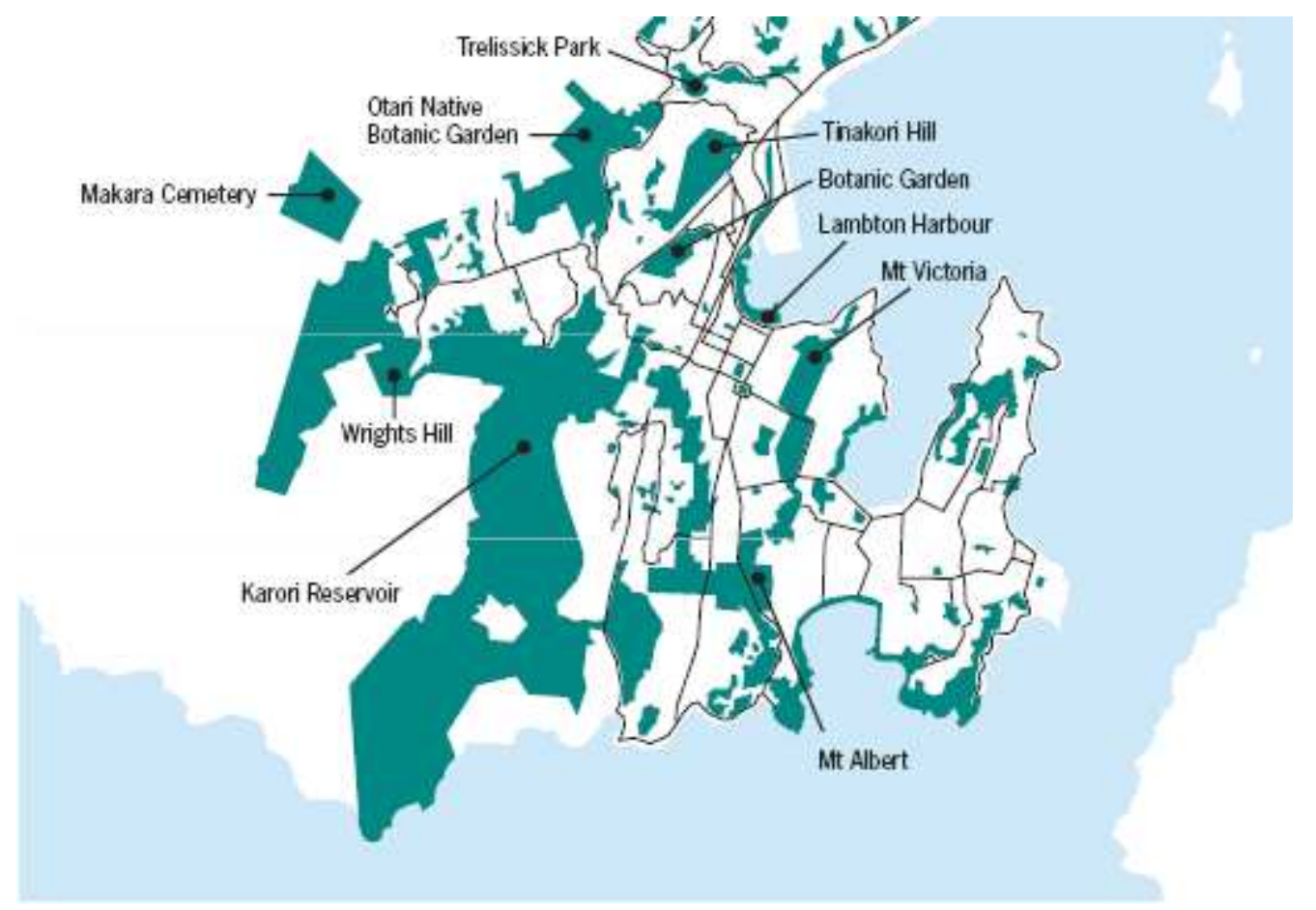

Figure 2.2 Map of Wellington showing the greenspaces managed by the Wellington City Council. Source: Wellington City Council, 1998

\subsubsection{Wellington Characteristics - Socio-economic variables}

The latest survey in 2006 found the population of Wellington City to be 188, 440 (Statistics New Zealand, 2008). Residents in the Wellington region and Wellington City tend to be highly educated, and have in general a higher percentage of higher formal education qualifications than the rest of the country (Statistics New Zealand, 
2008). Fewer residents in the Wellington Region have no formal qualification than New Zealanders in general (Statistics New Zealand, 2008). Wellington residents also have a higher median income $(\$ 28,000$ for people aged 15 years and older) than the rest of New Zealand $(\$ 24,400)$. There is also spatial variation of socio-economic variables within the suburbs of Wellington City. The transects where I gathered my data encompassed all of these areas, and are also shown below graphically in Fig 2.3. Wellington was a logistically convenient location for me to conduct this research, as I have lived in the city for eight years and been based at Victoria University of Wellington for the last three years.

\subsection{Site Location - Survey Design}

I collected data using a self-administered mailbox survey of Wellington residents in February and March 2008, closely following the locations used by Jennifer Vinton (2008). Research into bird ecology and abundance was conducted by Jennifer Vinton over a 12 month period in 2007. Vinton gathered data between March 2007 and March 2008 on all the bird species seen and heard along six transect lines, each originating in the central city and radiating out to the outer suburbs, with bird count locations located at approximately $400 \mathrm{~m}$ intervals along these transect lines. The striptransects were chosen by Jennifer to reflect the typical forms of development in the suburban-urban landscape of Wellington City. The transects radiate out from the central business district through higher to lower density residential suburbs and green spaces intermingled with built habitat. I used these same bird count locations to examine people's knowledge about birds, by surveying households surrounding each bird count location. In this way I got a complete cross-section of the city, with households 
surveyed in the central city to the outer suburbs, crossing different socio-economic and geographical zones. An advantage of matching my survey locations with Jennifer's bird-count points is that it enables me to compare residents' knowledge with Jennifer Vinton's data on bird diversity and abundance.

At each bird-count location I distributed surveys to all the households within a $100 \mathrm{~m}$ radius, to a maximum of 35 households. If there were no households within $100 \mathrm{~m}$ of a bird-count point, I disregarded this location from my survey, as I wanted to be able to accurately compare bird abundance with resident's knowledge. This occurred at a number of points within the $\mathrm{CBD}$, mainly near the waterfront. If more than 35 households were within this distance, the closest 35 households to Jennifer Vinton's bird-count location were surveyed. This number of households was selected as a large sample size was needed to examine the large number of variables I wanted to test, and because the response rate was difficult to predict in advance. Selecting 35 households at each location would gave a total of approximately 1000 households receiving the selfadministered questionnaire, for with some locations it was not possible to reach 35 households. Some locations included apartment buildings, and if this occurred, I took a random selection of apartments within the building. This was done using a random number generator, until the desired number of households from the area was achieved. Each individual apartment was included in the total number of households from which 35 was chosen, but the number of apartments chosen from each apartment complex was limited to five to ensure a building was not over-represented (However, in the situation where thirty-five houses couldn't be reached within the requisite $100 \mathrm{~m}$, then I surveyed more than five apartments from each block). The self-administered questionnaires were addressed to 'The Head of Household', and were hand-delivered to the household letterboxes. 
Overall, I surveyed households at 41 different locations in Wellington, along the six transect lines, as shown in Figure 2.3 below. The description of the six transect routes are shown below in Table 2.1.

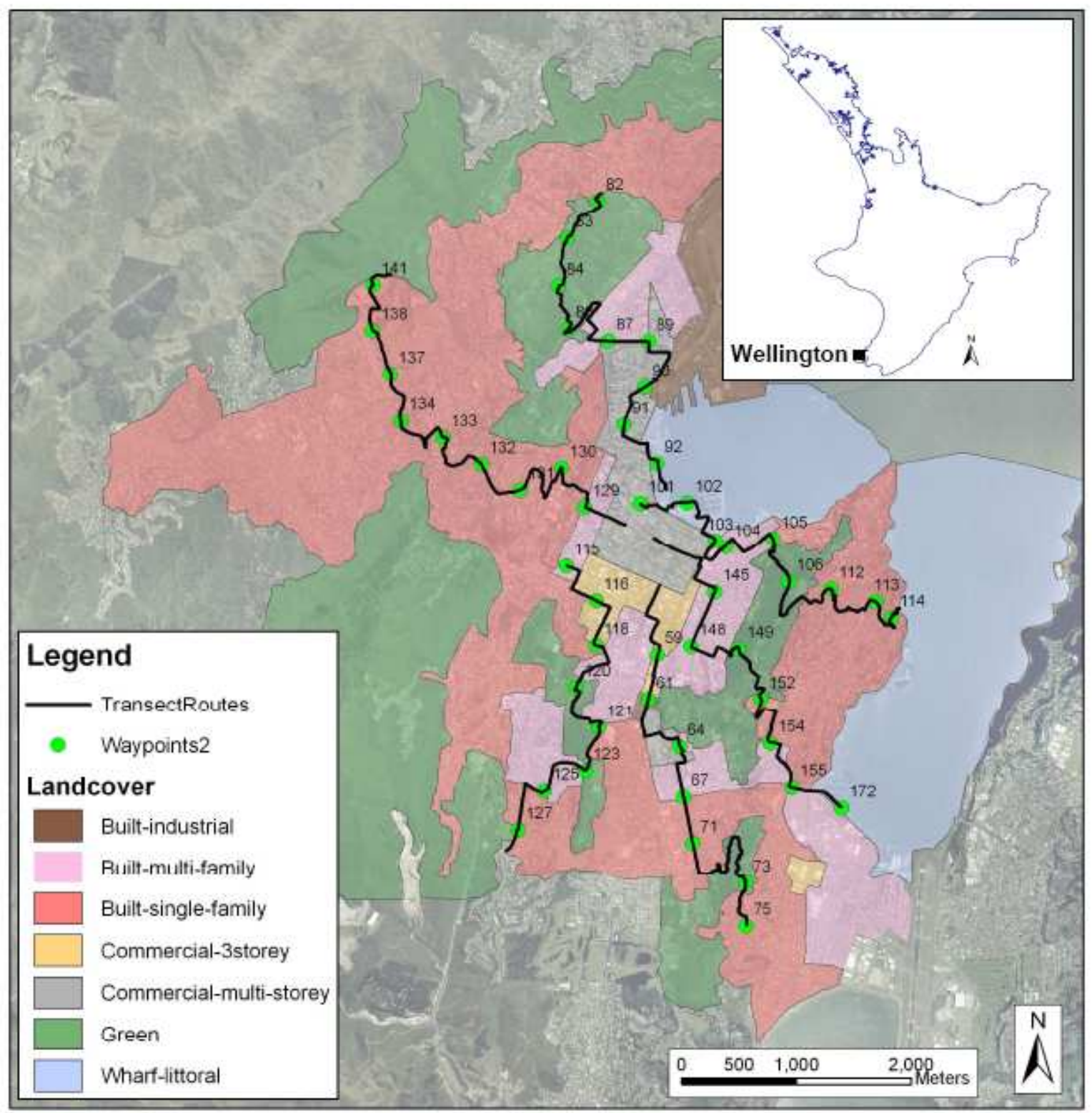

Figure 2.3 Aerial map of Wellington showing study area, landscape types, transect routes, and locations surveyed (numbered points) (Source: Vinton, 2008). Inset: Map of North Island, NZ, with Wellington identified (Source: Vinton, 2008) 
Table 2.1 Description of the six transect routes (A to F), along which the survey locations were spaced out. Source: Vinton 2008.

\begin{tabular}{|c|c|}
\hline $\begin{array}{l}\text { Sampling } \\
\text { route }\end{array}$ & Description of sampling route \\
\hline $\mathrm{A}$ & $\begin{array}{l}\text { Frank Kitts Park (Queens Wharf) - Lambton Quay = Hill Street } \\
\text { Tinakori Road = Grant Road = Town Belt = Weld Street } \\
\text { (Wadestown). }\end{array}$ \\
\hline B & $\begin{array}{l}\text { Kio Road (Evans Bay Parade) }=\text { Ariki Road = Alexandra Road } \\
\text { Town Belt }=\text { Mt. Victoria }=\text { Kent Terrace }=\text { Cable Street }=\text { Wakefield } \\
\text { Street (Wellington). }\end{array}$ \\
\hline $\mathrm{C}$ & 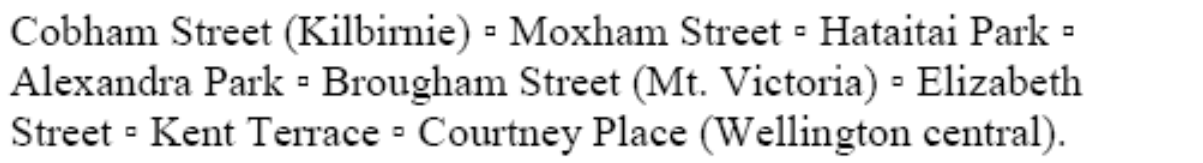 \\
\hline D & $\begin{array}{l}\text { Sutherland Road (Melrose) = Truby King Park and Town Belt a } \\
\text { Daniel Street (Newtown) - Wellington Hospital = Ridderford Street } \\
\text { " Adelaide Road = Basin Reserve " Tory Street (Wellington } \\
\text { central). }\end{array}$ \\
\hline $\mathrm{E}$ & $\begin{array}{l}\text { Wentworth Street (Mornington) - Mills Road - Whaui Street a } \\
\text { Prince of Wales Park (Town Belt) - Rolleston Street - Hopper } \\
\text { Street - Webb Street a Abel Smith Street (Te Aro). }\end{array}$ \\
\hline $\mathrm{F}$ & $\begin{array}{l}\text { Karori Cemetery " Chaytor Street - Northland Road - Upland Road } \\
\text { " Kelburn Parade - Victoria, University of Wellington campus a } \\
\text { The Terrace - Dixon Street (Wellington central). }\end{array}$ \\
\hline
\end{tabular}

\subsection{Survey Design}

Although low response rates and non-response bias are concerns in conducting mail surveys (Dillman, 2000), by employing certain measures some very high mail 
questionnaire response rates have been achieved in other studies (Kanuk and Berenson, 1975), and mail surveys can have a number of advantages (Bernard 2002). One advantage is that the cost in terms of time and money is much reduced compared with face-to-face interviews, allowing for a larger sample size. Having a larger sample size is important in this study as there are a large number of variables that I wish to examine. By utilising a self-administered mailbox questionnaire over 1000 households in the Wellington region received the questionnaire. Additionally, there is no concern about interviewer bias as all respondents receive the same questions (Bernard, 2002). I employed Dillman's Total Design method (Dillman, 2000) to increase the response rate. The full self-administered questionnaire with the final formatting (i.e., in the form which the respondents received it in the mail) can be seen in Appendix 1. The steps in the Dillman Method that I employed are listed below:

1. Formatting: The construction of the pages of the questionnaire accorded to standard conventions. Studies show that the general appearance, the number of pages, and type of introduction all affect the response rates (Bernard, 2002).

2. Question order: The first question was directly related to the topic of my study, non-threatening, and easy to answer. Studies have shown that once someone starts a questionnaire they are more likely to finish it (Bernard, 2002). I placed the general socio-economic and demographic questions at the end of the questionnaire, because once respondents filled out the questionnaire up to that point they are more likely to complete it (Bernard, 2002).

3. Length: I limited the questionnaire to eleven pages, as beyond that length response rates can drop (Dillman, 2000). I achieved this by using A4 size paper folded in half to create a booklet, using three sheets of paper. The booklet format made the questionnaire easy to distribute, user-friendly, in an easy-to- 
read format, with an easily followed non-ambiguous progression from question to question.

4. Contact and follow-up reminder: Each household received a preliminary letter explaining the survey and informing the respondent that a self-administered questionnaire would be coming along soon. This introductory letter was sent out one week before the questionnaire. Additionally, one week after the questionnaire I sent a thank-you/reminder letter to all households, thanking the respondents if they had sent back the questionnaire and reminding them to return it if they had not. Examples of the preliminary and post letters are in Appendix 2. These two measures (pre and post letters) have both been shown to improve response rates significantly (Dillman, 2000).

5. The cover letter: I enclosed a one page cover letter (Appendix 3) with the questionnaire, explaining how I selected the respondent, who should fill in the questionnaire, who was carrying out the research, and why it was important for the respondent to send back the questionnaire. I personally signed each cover letter. The cover letter makes the questionnaire seem more personal to the recipients, and helps increase the response rate (Dillman, 2000).

6. Packaging: I packaged the questionnaire, cover letter, and pre-paid reply envelope in another envelope for mailing to the respondent. This envelope had the Victoria University of Wellington logo on the back. I personally signed each cover letter. The addition of the Victoria University logo was to help maximise the response rate, as people have been shown to be more receptive and likely to participate in the survey if it is conducted by an independent research facility, rather than by a commercial or marketing organisation (Dillman, 2000). 
All of these measures have been shown to increase the response rates in selfadministered mail surveys (Dillman, 2000). The pre-letter, surveys, and thank you/reminder letters were hand delivered over a three week period in February 2008.

The questionnaire was pre-tested by approximately 30 people in early February 2008 for independent feedback on the content, layout, and length of the questionnaire. A number of minor alterations and improvements were made following the feedback given, mostly concerning question clarity. Based on the results from piloting the questionnaire, I estimated that the survey was estimated would take respondents an average of 10-15 minutes to complete. I hand-delivered the survey to each household and addressed each to the 'Head of Household', allowing the household to self-select the respondent. The potential for response bias must thus be acknowledged.

\subsection{Survey Questions}

The self-administered mailbox questionnaire consisted of 30 questions (see Appendix 1).

\subsubsection{The Model}

As reviewed in the introduction, the literature shows that the level of ecological knowledge can reflect certain characteristics of an individual. Respondents' demographics, frequency of outdoor activities, and group membership all have been shown to be predictors of ecological knowledge levels. The amount of nature interaction has also been shown to be a predictor of knowledge, which I also test here 
by examining the landscape type and amount of green space on the respondents' property. A full review is covered in the introduction.

I hypothesise that the level of ecological knowledge of an urban resident reflects characteristics of the respondents' demographics (age of respondent, gender, level of formal education, income), outdoor activities (frequency of visitation to local parks, regional parks, accessibility of green spaces, frequency of participation in outdoor recreation activities), being an active member of a social group (sports club, community group, hobby group), and characteristics of the property and neighbourhood in which the household is located (landscape type at the location of the respondents' household, level of green space on the respondents' property), and bird abundance. I express the level of ecological knowledge, $\mathrm{Y}$, of an urban resident as:

$\mathrm{Y}=\mathrm{a}+\mathrm{bX}+\mathrm{cZ}+\mathrm{dN}+\mathrm{eV}+\mathrm{U}$

where, $Y=$ the level of ecological knowledge of the respondent, a=intercept, $\mathrm{X}=$ =vector of demographic characteristics of the respondent, $\mathrm{Z}=$ group membership, $\mathrm{N}=$ property and neighbourhood characteristics, $\mathrm{V}=$ bird abundance at the location of the respondents' household, $\mathrm{U}=$ unexplained variance or random error. a, b, c, d, and e are the coefficients I estimate with the regression model .

I use the same model to hypothesise that the level of bird-related behaviour (bird feeding, tree planting) reflects the same characteristics. So, in this case, Y=bird related activity, and a, b, c, d, and e are the coefficients I estimate with the regression model. Additionally, I also test the respondents' ecological knowledge level as a predictor variable. 
Because of concerns with survey length and corresponding response rates, I have limited the number of possible explanatory variables tested. I chose those variables that had the most promise in the literature and were also easy to measure in a written selfadministered questionnaire.

\subsubsection{Data on Ecological Knowledge (dependent variables)}

Four questions measured levels of ecological knowledge, addressing Research Question 1.1. First, respondents were asked to produce a free list (Bernard, 2002) of all the bird species they could think of within five minutes (Question Two). This question was designed to establish which bird species were most salient to respondents, as well as a means of gathering a measure of ecological knowledge. The rest of the page was left blank to provide space to allow the respondents to list all the species they were able, so as to not limit or guide the number of species listed. Within the question I state that the respondents should not use any references or talk to others to help answer the question. Many of the bird names listed by the respondents did not coincide with species-level classifications. For example, "gull" was commonly noted, instead of specifying a particular gull species. However, I only analysed the number of bird names noted by the respondent. Therefore, if a respondent listed "gull", I tallied this as one species, but if another respondent listed "black-backed gull, black-billed gull”, I tallied this as two species. This question also gathered information on knowledge about native and exotic bird species (Research Question Three), and the depth of the knowledge as measured by the recognisability of the species identified. Respondents were asked to put a tick beside those birds that are native to New Zealand. In ambiguous cases, such as if the respondent listed "pigeon", which could be considered native or non-native, 
these responses were left out of the native bird knowledge analysis. Ambiguous cases were rare however (10 cases).

Secondly, following from the preceding question, I asked respondents to list the bird species they had commonly seen or heard in their local neighbourhood within the last year (Question Three). A blank space provided to list all the species they were able, so as to not limit or guide their number of species listed. In the resulting analysis, the total number of bird species named was used, as well as the percentage of native New Zealand birds correctly identified with a tick next to their name.

The third question measuring levels of ecological knowledge asked respondents to identify bird species from photographs (Question 13). Eight black-and-white pictures of bird species were provided (through piloting of the questionnaire, I found that the colour of the photographs did not make a notable difference in the ability of respondents to answer these questions). The bird species shown were a mixture of native, exotic, common and rare species. All the species shown are found in the Wellington region. In the resulting analysis, the proportion of birds correctly identified was used.

The species shown in the photographs were: tui (Prosthemadera novaeseelandiae), kereru (Hemiphaga novaeseelandia), silvereye (Zosterops lateralis), house sparrow (Passer domesticus), European starling (Sturmus vulgaris), fantail (Rhipidura fulginosa), red-billed gull (Larus novaehollandiae), and kaka (Nestor meridionalis). The acceptable, or correct, answers for each species were as follows: tui; kereru, wood pigeon; silvereye, wax-eye, white-eye, tauhou; house sparrow, sparrow; 
European starling, starling; fantail, piwakawaka; red-billed gull, seagull, gull, tarapunga; and kaka.

A fourth question asked respondents to self-rate their own knowledge of bird species in their neighbourhood (Question 1). The first question in a questionnaire is important, as research shows that once people start a questionnaire they are likely to finish it (Bernard, 2002), and so this question was designed to be directly related to the topic of my study, non-threatening, and easy to answer.

\subsubsection{Data on Ecological Behaviour (dependent variables)}

Four questions measured aspects of bird-related behaviour, addressing Research Question 2.1. First, I asked respondents whether they had planted any trees or plants on their current property to encourage bird-life (Question 18). The respondents could answer by ticking one of three boxes: No; No, but would do if they had the opportunity; and Yes. This allowed my analysis to account for the situation where respondents had a lack of garden space or planting opportunities. However, in the regression model, the answers were condensed into yes or no, with only those who had planted vegetation for the benefit of birds being classified as yes. This was because of uncertainties in the relationship between intention and actual behaviour.

The second behaviour question asked respondents whether they place food outside for birds on their property (Question 19). A follow-up question elicited more information regarding what food was given, how the food was delivered, and whether any particular bird species were targeted. I also asked whether there were any other 
steps the respondent took to encourage bird activity (Question 21), including possible answers of: keeping pets indoors; placing a bell on cat; minimising pesticide/herbicide use; maintaining nest boxes; maintaining bird baths; and other.

\subsubsection{Data on socioeconomic variables (independent variables)}

I collected a series of socioeconomic variables, most of which have been shown by previous studies to influence ecological knowledge, or have been hypothesised to influence ecological knowledge (see introduction for details). The independent variables included in the analysis were age (Question 24), income level (Question 30), educational qualifications (Question 29), and participation in outdoor recreation activities (Questions 10, 11). I modelled the outdoor recreation options respondents chose from previous surveys (E.g. Maffi, 2001), as well as from the common 'other' responses in my initial pilot of the survey. The multi-choice options given in Questions 25 and 30 for ethnicity and income were modelled on those in the New Zealand Census (2006), as well as the National Health and Wellbeing survey (Statistics NZ, 2008).

Questions 24 and 29 on age and on the level of education obtained were also modelled from the latest New Zealand Census (2006).

An individual's local environmental knowledge can vary according to the degree of exposure to the natural world (Guest, 2002); and the degree of environmental exposure can be affected by a variety of variables. Maffi (2001) has shown that these variables can include the geographic location of the place of residence, as well as 
economic pursuits, and recreational activities. To investigate other possible predictors of ecological knowledge and behaviour, questions were asked about the frequency of visits to local and regional parks (Questions 6 and 8), and ease of access to local green spaces (Question 5). Respondents were asked whether they belong to a sports club, hobby, or community group (Question 12). Questions regarding the description of the outside area and level of green space on the property were also included (Question 15, 17), to investigate the potential for bird-related behaviour such as tree planting or birdfeeding. Bird abundance was also included as an independent variable. This was to examine whether higher abundances of birdlife in the neighbourhood would correspond to differing levels of avian knowledge. If respondents were exposed to greater numbers of birdlife, it was hypothesised that respondents may have an increased knowledge about birds. The bird abundance information was measured using Vinton's (2008) data collected on the actual bird abundances at each questionnaire location, using the average number of bird species identified at each location over a year long observational period.

I characterised the geographic type of each survey location following Vinton's (2008) characterisations. I split the survey locations (see Fig. 2.3) into five different geographic types: households adjoining green space, residential single-family detached, residential multi-family attached, commercial 1-3 story, and commercial multi-story (Table 2.2). The geographic types can be loosely characterised by a gradient from the outer suburbs to the central business district. The numbers of survey locations within each landscape type were: adjoining green (7 locations), residential single-family detached (17 locations), residential multi-family attached (9 locations), commercial 1-3 story (5 locations), and commercial multi-story (3 locations). There was a lack of 
households to survey at a number of the CBD bird-count locations, hence the bias with the higher numbers of locations outside the CBD.

Table 2.2 Definitions of the landscape types used to describe the land cover surrounding each survey location. Landscapes were classified by the degree to which ground cover consisted of vegetation or human-made structures. Source: Vinton, 2008.

\begin{tabular}{|c|c|}
\hline Landscape Type & Description of landscape \\
\hline 1. Adjoining Green & $\begin{array}{l}\text { Adjoining un-built open reserve land } \\
\text { comprised mainly of trees that were a mix of } \\
\text { exotic and native species. }\end{array}$ \\
\hline 2. Residential single-family detached & $\begin{array}{l}\text { Single or double storied individual dwellings } \\
\text { with large plots and gardens }\end{array}$ \\
\hline 3. Residential multi-family attached & $\begin{array}{l}\text { Multi-story (more than two) apartments with } \\
\text { small or no gardens and few or no tree-lines } \\
\text { streets. }\end{array}$ \\
\hline 4. Commercial 1-3 story & $\begin{array}{l}\text { Predominantly commercial, and falls outside } \\
\text { the central business district. }\end{array}$ \\
\hline 5. Commercial multi-story & $\begin{array}{l}\text { Surroundings include buildings of more than } \\
\text { three stories in the central business district. }\end{array}$ \\
\hline
\end{tabular}

\subsubsection{Analysis}

I ran linear multiple regressions to test for the effects of the explanatory socioeconomic variables described above on the dependant variables for ecological knowledge. Binary logistic regressions were run for the dependant variables for birdrelated behaviour, due to the categorical yes/no options for bird feeding and tree planting. The analyses were undertaken independently for each measure of ecological knowledge and each measure of bird-related behaviour. Because the dependant 
variables for ecological knowledge were not distributed normally, natural log transformations were used to correct both the freelisting measure of knowledge and the number of birds seen / heard in the neighbourhood. The number of birds seen or heard in the neighbourhood was also weighted against the actual species richness at each location. This was achieved by dividing the number of species seen or heard by the species richness indicator for that location (gathered from Vinton, 2008). For the photoidentification measure of knowledge, I calculated the proportion of bird species correctly identified from the photos (i.e. the ratio correctly identified was either $1 / 8$, $2 / 8,3 / 8,4 / 8,5 / 8,6 / 8,7 / 8,8 / 8)$, and computed the arcsine of the proportion of birds correctly identified. This was used in the binary logistic regression model. Before I ran all regressions, I tested for multi-collinearity between the explanatory variables. All independent variables were left in the regression as multi-collinearity was found to be non-significant, with no adjustments needed in the analysis. A backward stepwise selection process was used to determine which explanatory variables were employed in each regression. A backward stepwise method is preferable to the forward method, because of suppressor effects (Field, 2005).

For the analysis of native versus non-native bird knowledge, I compared the mean number of native birds free listed against the mean number of exotic birds free listed. The Wilcoxon test was used to compare significance between the means as the data were discrete, non-banded, and not adequately normally distributed. The Wilcoxon test was also used to compare significance between the number of native and exotic birds seen / heard in the neighbourhood. 


\section{Results and Analysis}

\subsection{Urban Wildlife and Ecological Knowledge Survey - Response Rates}

I sent questionnaires to 1052 Wellington households. The final response rate was $43 \%$ (453 returned). The response rate was higher than expected for a mail survey of this type, with mail survey's typically having a low response rate (Dillman, 2000). The responses covered a wide range of socio-economic and geographical areas throughout Wellington City. The response rates varied across the different locations I surveyed (see Table 3.1). The highest response rate from a single location was 68 percent returned, the lowest 20 percent returned. The highest response rates came from the regions furthest from the Central Business District, and the least from the people living in residential multi-family attached residences (Table 3.1).

Table 3.1 Geographic variation of the response rates

\begin{tabular}{|l|l|l|l|l|l|}
\hline & $\begin{array}{l}\text { Household } \\
\text { Adjoining Green } \\
\text { Space }\end{array}$ & $\begin{array}{l}\text { Residential } \\
\text { single-family } \\
\text { detached }\end{array}$ & $\begin{array}{l}\text { Residential } \\
\text { multi- } \\
\text { family } \\
\text { attached }\end{array}$ & $\begin{array}{l}\text { Commercial } \\
\mathbf{1 - 3} \text { story }\end{array}$ & $\begin{array}{l}\text { Commercial } \\
\text { multi-story }\end{array}$ \\
\hline $\begin{array}{l}\text { Questionnaires } \\
\text { sent / } \\
\text { Questionnaires } \\
\text { returned }\end{array}$ & $121 / 214$ & $193 / 443$ & $81 / 260$ & $37 / 105$ & $21 / 57$ \\
\hline $\begin{array}{l}\text { Percentage } \\
\text { returned }\end{array}$ & 57 & 44 & 31 & 35 & 37 \\
\hline
\end{tabular}




\subsection{Ecological knowledge}

When asked to self-rate their own bird knowledge (Fig 3.1), respondents generally saw themselves as possessing low levels of ecological knowledge, with the majority (63 percent) rating their knowledge as either poor or fair. Less than two percent categorised themselves as having an excellent knowledge base, and 22 percent noted a good level of knowledge.

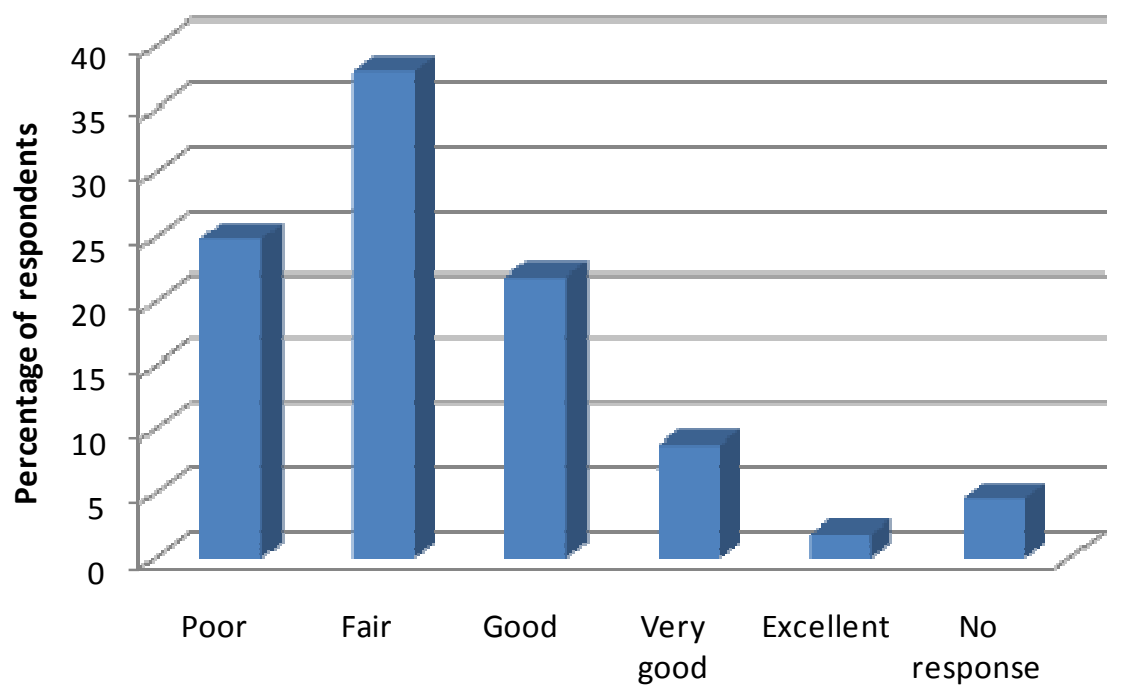

Self-rated bird knowledge

Figure 3.1 The self-rated level of ecological knowledge of the respondents 
The respondents' self-rating of bird knowledge provided an accurate measure of their actual knowledge (Fig 3.2 and 3.3). For example, respondents' that rated their knowledge as good or excellent could name significantly more birds than those who rated their knowledge as poor $(\mathrm{F}(\mathrm{ANOVA})=8.18, \mathrm{p}<0.005)$, and this trend was consistent across all ratings. Similarly, the higher that respondents rated their knowledge, the higher the number of birds they named as being commonly seen or heard in their neighbourhood $(\mathrm{F}($ Welsh $)=49.338, \mathrm{p}<0.005)$.

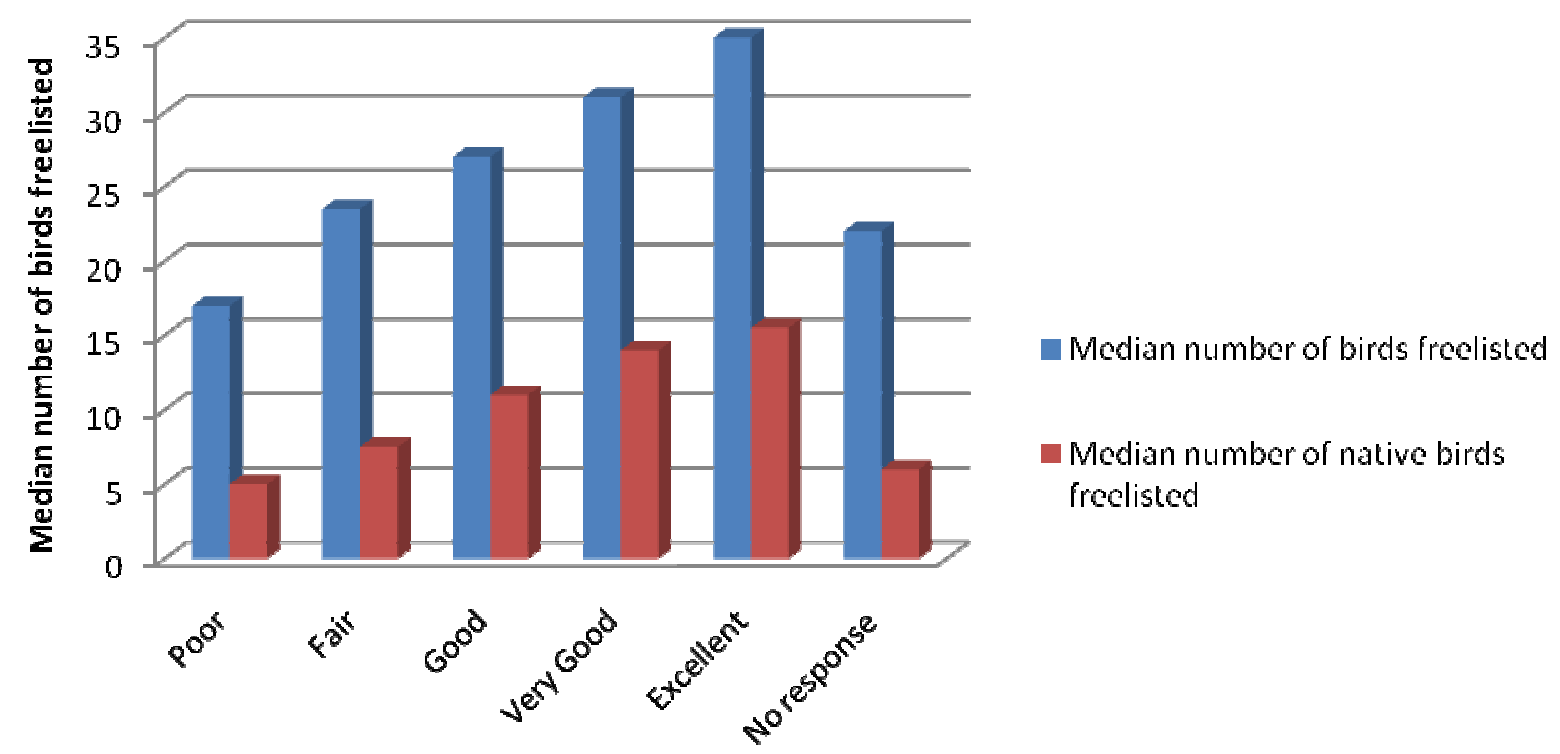

How the respondents self-rated their own bird knowledge

Figure 3.2 Comparison between the respondents' self-rated level of ecological knowledge and their actual knowledge, measured by the number of birds free listed. 


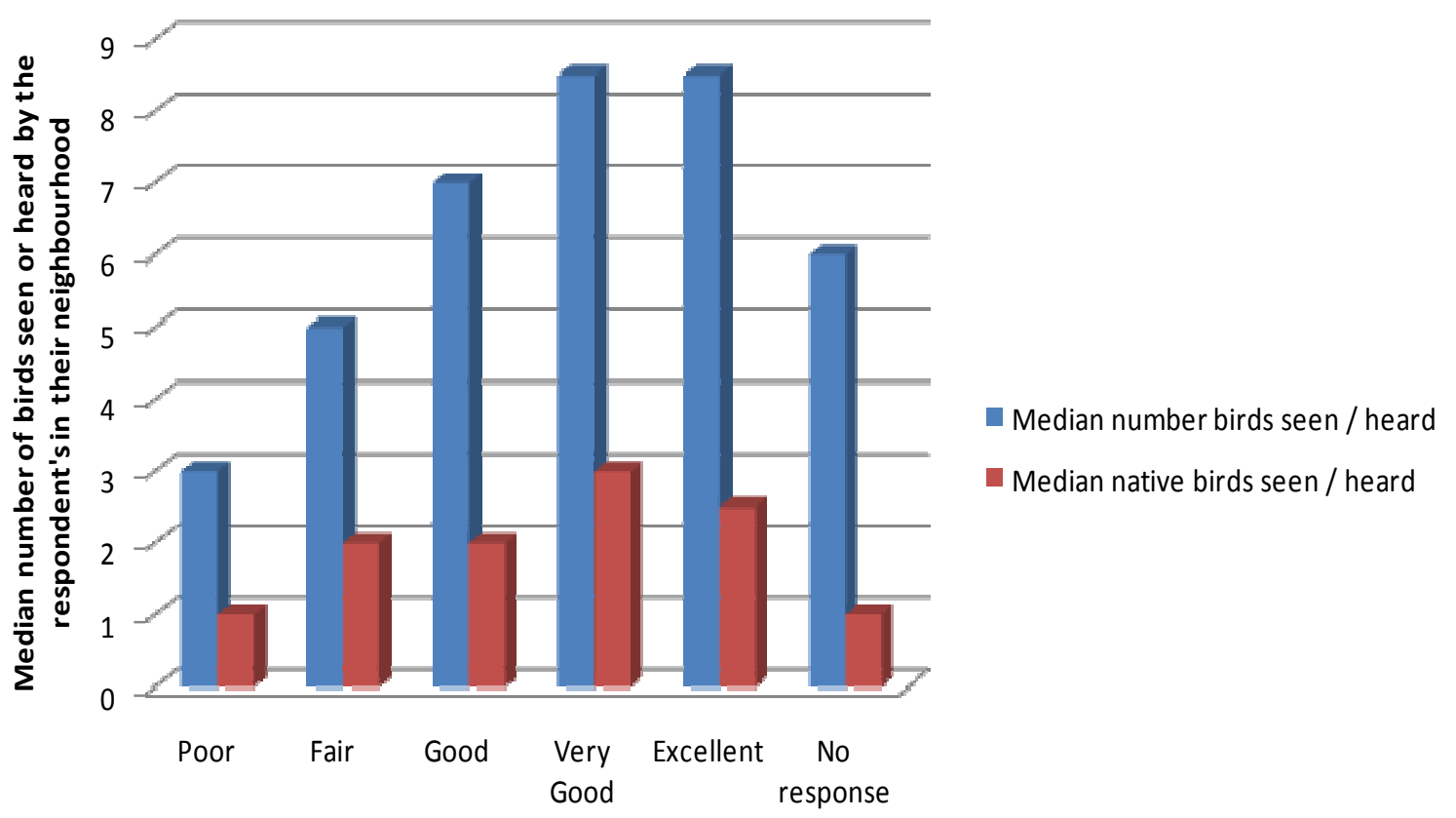

How the respondents self-rated their own bird knowledge

\section{Figure 3.3 The number of birds respondents had seen or heard in the} neighbourhood measured against their perceived level of knowledge

Ecological knowledge about birds was gathered using three different questions:

number of bird species respondents could name, number of bird species commonly seen / heard in the neighbourhood, and identifying bird species from photographs. The number of bird species respondents could name in five minutes ranged from 0 to 109 species $($ median $=23$ species, mode $=16$, Fig. 3.4). A value of zero (no answer provided) may indicate either a lack of knowledge about birds or that the respondent simply skipped the question. 


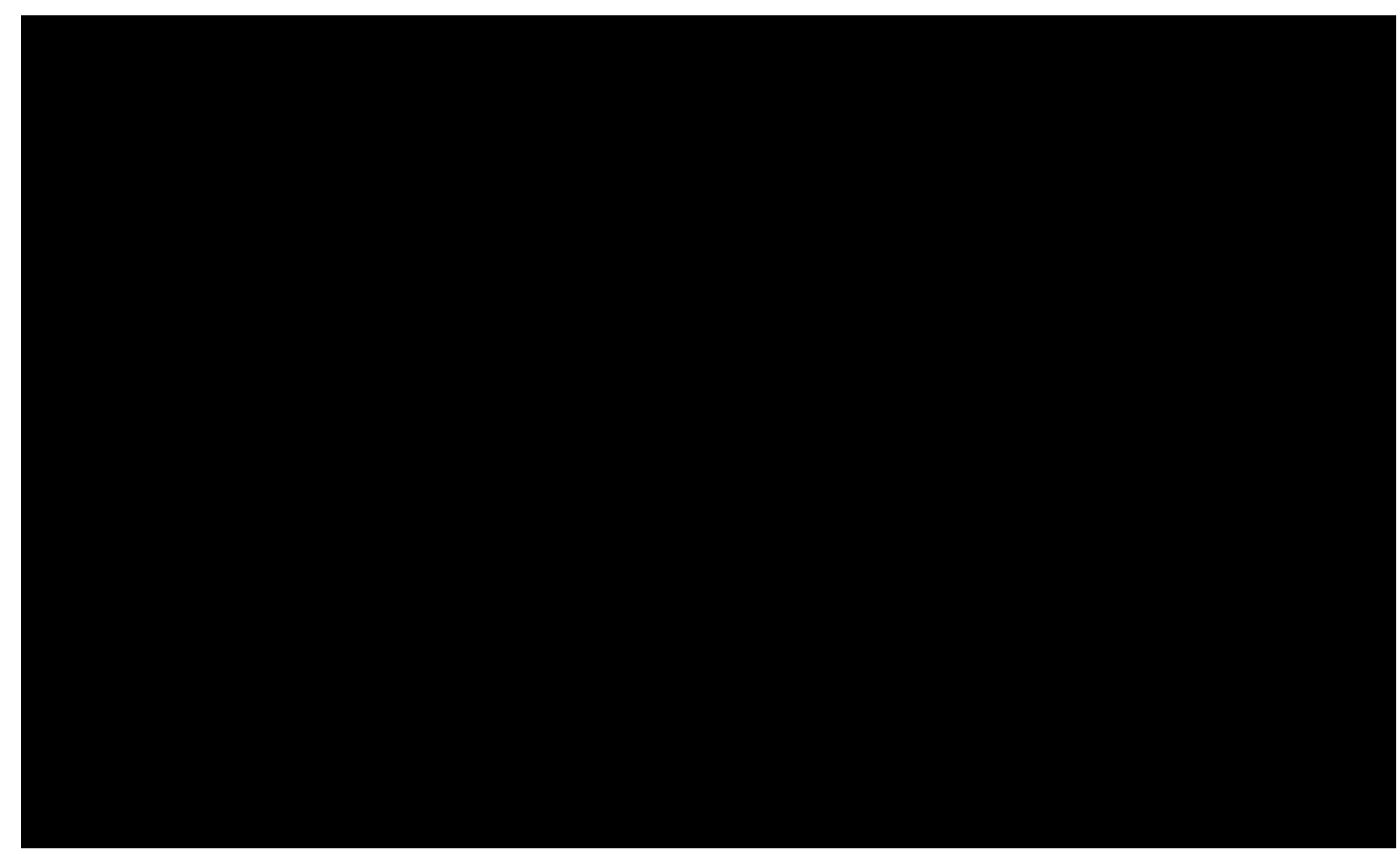

Figure 3.4 Number of bird species freelisted in five minutes

Respondents saw or heard between 0 (no answer) and 24 birds in their neighbourhoods over the last year (median $=5$, mode $=3$, Fig. 3.5) Again the distribution shows a tail at the higher end, with only a few people noting many birds that were commonly seen or heard in the neighbourhood. 


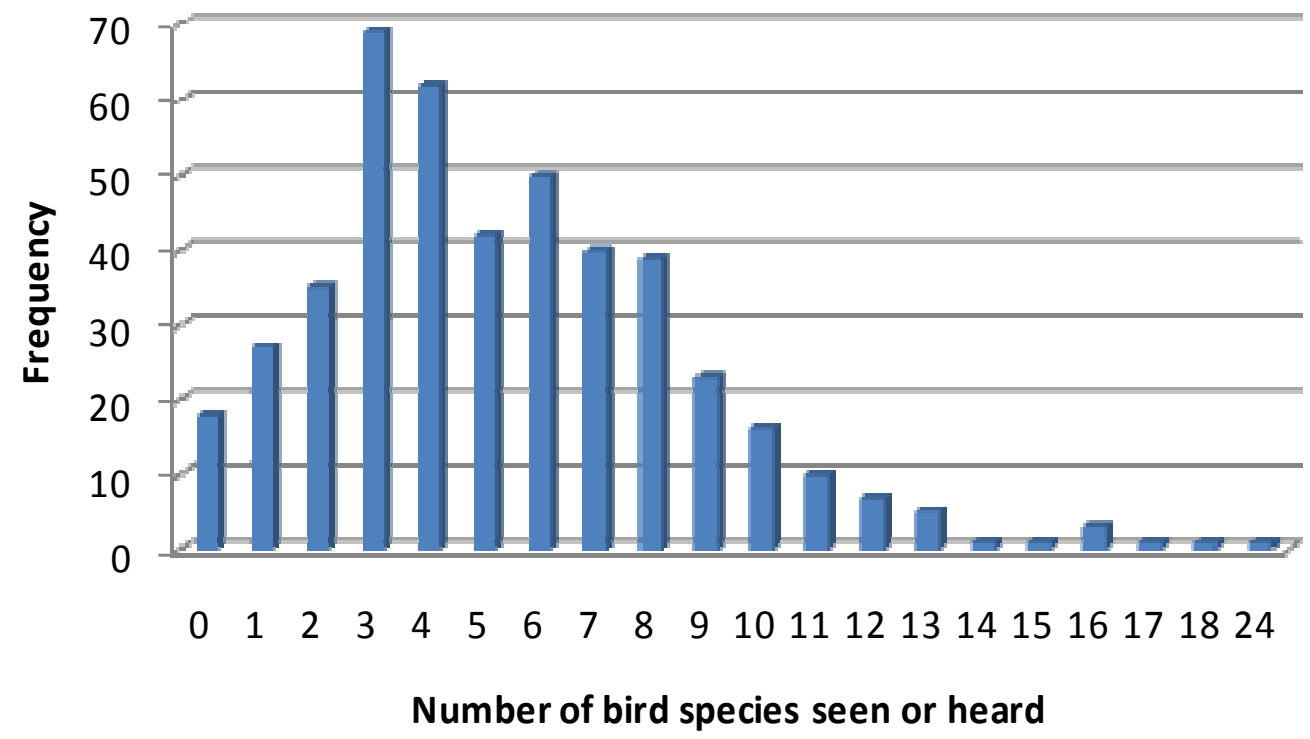

Figure 3.5 Number of bird species respondents had seen or heard in their neighbourhood within the past year

Answers to the bird identification questions ranged from no correct answers (which includes those who chose not to respond) to all eight birds correctly identified (median $=6$ correct answers, Fig. 3.6) Over half the respondents $(50.3 \%)$ answered at least six of the eight questions correctly, while 30.2 percent of respondents could only name four or fewer of the questions correctly. Only 8.6 percent of respondents could answer all eight questions correctly. 


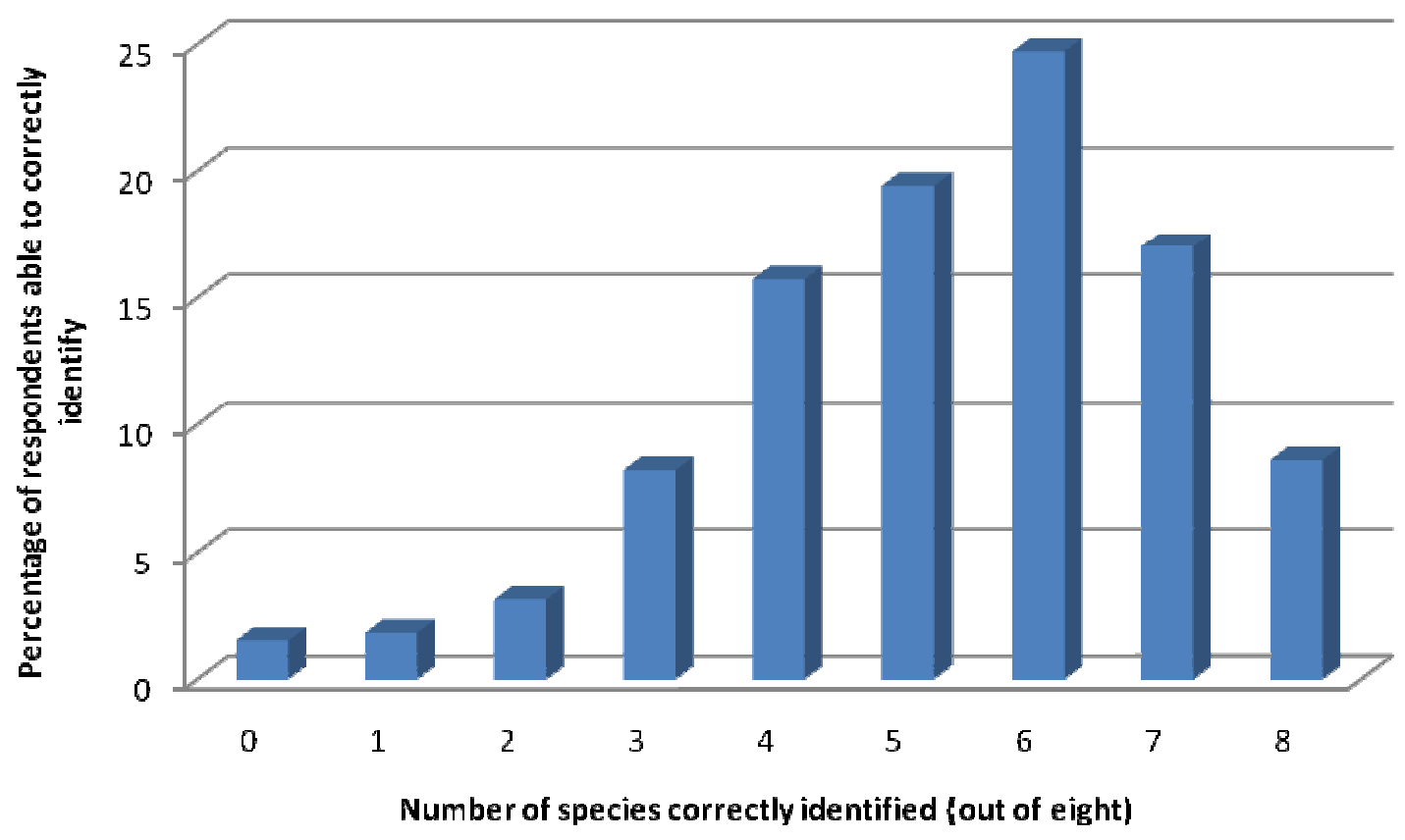

Figure 3.6 Number of birds the respondents correctly identified from photographs

The patterns in which questions were answered incorrectly are shown in Fig 3.7 below. Kaka identification had the highest percentage of respondents answering incorrectly (76.4 percent unable to identify correctly), whilst 96.9 percent of respondents could identify the fantail correctly. The Kaka was frequently mistaken for a Kea, a closely related species, and it might have been the case that a higher definition picture may have reduced the error rate. After the kaka, the hardest to identify were the starling (37.1 percent identified correctly), and kereru (49.9 percent identified correctly). 


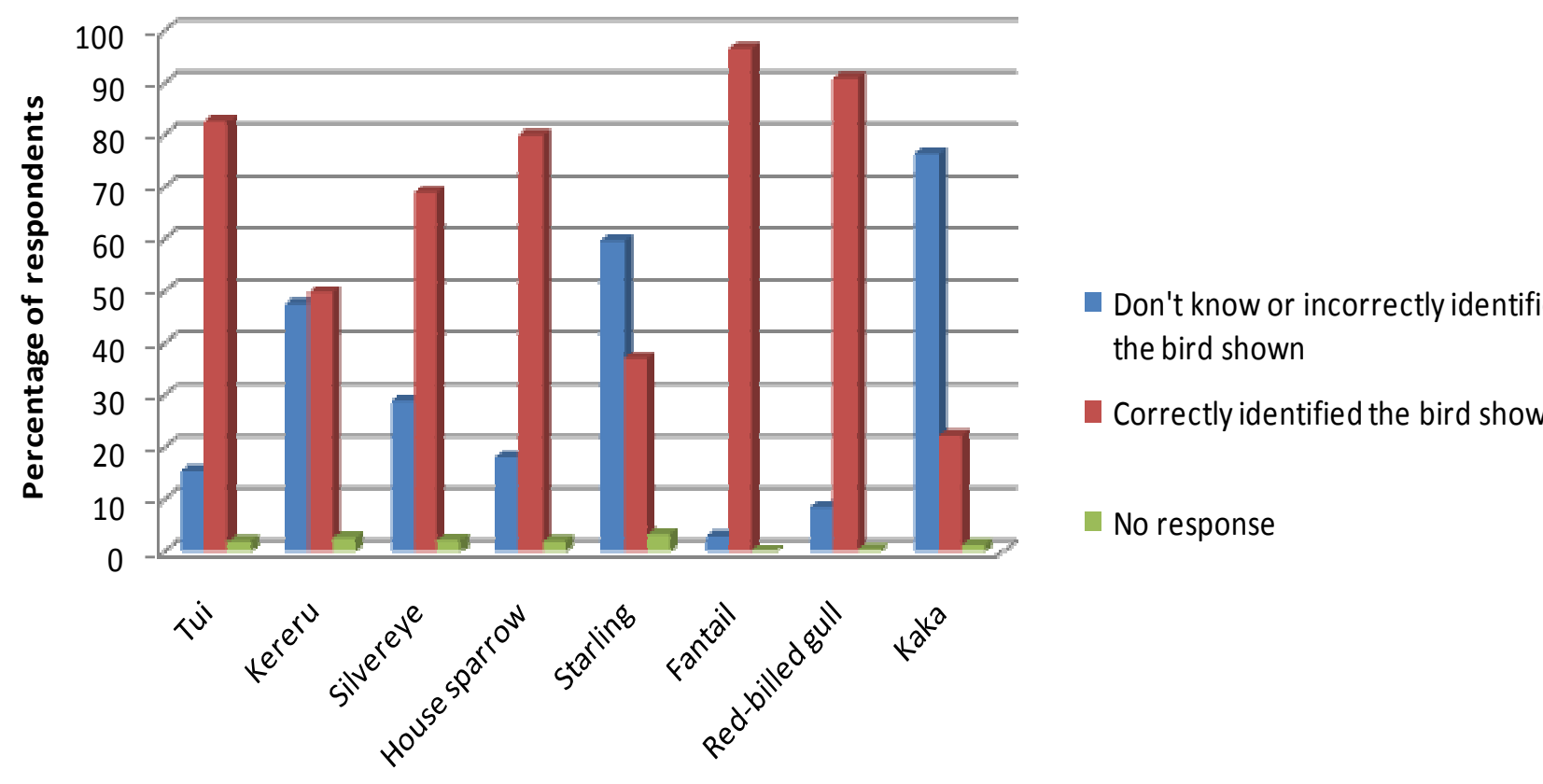

Bird shown in photograph

Figure 3.7 How the respondents answered questions concerning bird identification from photographs

Respondents' levels of ecological knowledge were consistent across all three measures (Table 3.2). If a respondent performed well in one measure they were likely to perform well in the others, although the relationship was not particularly strong $\left(\mathrm{R}^{2}<0.5\right)$. The number of bird species freelisted was significantly correlated with the knowledge of neighbourhood birds, $r=.44$, as well as with the proportion of birds correctly identified from photographs, $\mathrm{r}=.50$; the knowledge of neighbourhood birds was also significantly correlated with the proportion of birds correctly identified from photographs, $\mathrm{r}=.46($ all $\mathrm{ps}<0.005)$. 
Table 3.2 Comparison of respondents' knowledge level between different measures of ecological knowledge

\begin{tabular}{|l|l|l|l|l|}
\hline & $\begin{array}{l}\text { Spearman's } \\
\text { Coefficient }\end{array}$ & $\mathbf{R}^{\mathbf{2}}$ & Significance & N. \\
\hline $\begin{array}{l}\text { Species freelisted vs } \\
\text { Neighbourhood species knowledge }\end{array}$ & .440 & .19 & .000 & 429 \\
\hline $\begin{array}{l}\text { Species freelisted vs Photo } \\
\text { identification }\end{array}$ & .495 & .25 & .000 & 442 \\
\hline $\begin{array}{l}\text { Neighbourhood species vs Photo } \\
\text { identification }\end{array}$ & .455 & .21 & .000 & 434 \\
\hline
\end{tabular}

Note: All comparisons analysed using Spearman's correlations. Data normalised by: The species freelisted and neighbourhood species were transformed using natural logarithms. The proportion of correct birds identified from photographs transformed using arcsine values.

\subsection{Respondent Socio-Demographics}

The survey included socio-demographic questions to address Research Question 1.2 (Investigating possible predictors of ecological knowledge) and Research Question 2.2 (Investigating possible predictors of ecological behaviour). The socio-demographic variables also gave an insight into the characteristics of the survey respondents, and how the respondents compared with the population of Wellington City. 
Table 3.3 Comparison table of the composition of survey residents with the averages for Wellington City population

\begin{tabular}{|c|c|c|c|}
\hline & & $\begin{array}{l}\text { Wellington } \\
\text { residents }\end{array}$ & $\begin{array}{l}\text { Survey } \\
\text { respondents }\end{array}$ \\
\hline Age & $\begin{array}{l}15-25 \\
26-35 \\
36-50 \\
51-70 \\
70+ \\
\text { Mean }\end{array}$ & $\begin{array}{l}17.7 \\
18.1 \\
23.8 \\
16.9 \\
5.8\end{array}$ & $\begin{array}{l}10.7 \\
20.7 \\
31.4 \\
30.7 \\
6.5\end{array}$ \\
\hline Gender & $\begin{array}{l}\text { Male } \\
\text { Female }\end{array}$ & $\begin{array}{l}48.4 \\
51.6\end{array}$ & $\begin{array}{l}40.3 \\
59.7\end{array}$ \\
\hline Ethnicity & $\begin{array}{l}\text { NZ European } \\
\text { Maori } \\
\text { Other }\end{array}$ & $\begin{array}{l}70.1 \\
7.7 \\
22.2\end{array}$ & $\begin{array}{l}84.5 \\
3.8 \\
11.7\end{array}$ \\
\hline $\begin{array}{l}\text { Educational } \\
\text { Qualifications }\end{array}$ & $\begin{array}{l}\text { No formal } \\
\text { School Qual. } \\
\text { Post-school Qual. }\end{array}$ & $\begin{array}{l}11.2 \\
33.3 \\
55.5\end{array}$ & $\begin{array}{l}2.9 \\
17.3 \\
79.8\end{array}$ \\
\hline
\end{tabular}

Note: The statistics regarding the characteristics of Wellington residents sourced from the New Zealand Census 2006, from Statistics New Zealand

The survey respondents were self-selected, and the greater response rate from females is mirrored by the general Wellington population trends. The proportion of female respondents is greater in this survey however (Table 3.10). There was an age bias in the respondents, with fewer respondents from the lowest age bracket, 15-25 (17.7 percent for Wellington, 10.7 percent for survey respondents), and a higher proportion of older residents aged over 50 years old (22.7 percent for Wellington, 37.2 
percent for the survey respondents). The appeal to the 'Head of Household' to complete the questionnaire may have provided an age bias to the results.

An overwhelming majority of the respondents were New Zealand European (85\%), and only 3.8 percent self-identified as Maori. Because of the low sampling of other ethnicities, ethnicity was excluded from further analyses. In the Wellington region, 70.1 percent of people belong to the European ethnic group (67.6 percent for the whole country), and 7.7 percent of people belong to the Maori ethnic group (14.6 percent for all of New Zealand). The high response rates from New Zealand Europeans in my survey may represent a bias in the results. With the questionnaire being exclusively in English, there may also have been a language barrier restricting some respondents.

In order to investigate possible predictors of ecological knowledge (Research Question 1), the patterns and predictors of ecological behaviour (Research Question 2), and to determine whether ecological knowledge and behaviour can be correlated with certain demographic attributes, I included questions regarding the length of time lived in New Zealand, highest educational qualification, and the personal income of the respondents.

The survey respondents were highly educated, with nearly 80 percent having a post-school qualification, compared with 56 percent for Wellington residents. Only 2.9 percent of respondents had no formal qualifications, compared with 11.2 percent for the population of Wellington City (Statistics New Zealand, 2006). 
Participants were also asked about their level of participation in outdoor recreational activities (Fig 3.8 below), and whether they belonged to a sport, hobby, or community group. For each category, the percentage of respondents belonging to each group is very similar, with roughly two-thirds of respondents belonging to sports $(64.7$ percent), hobby (68.4 percent), and community groups (66.7 percent). Arts groups were the most numerous (25 percent). A sizable percentage of the respondents (11 percent) belonged to the Karori Wildlife Sanctuary, and a further 13 percent belonged to other environmental groups.

The vast majority of respondents visit a local park or reserve each year (93 percent) and over one-third visit a local park or reserve once a week or more (35 percent, see Fig. 3.8). However, respondents visited parks or reserves outside Wellington less frequently: 22 percent never do so, and just over five percent do so more than once a month, compared with over 50 percent who visit local parks or reserves on a monthly basis. Nearly half of respondents (42 percent) participate in some form of outdoor recreation activity once a week or more, and only 11 percent never participate (Fig 3.8).

Respondents were also asked about the ease or difficulty they perceived in accessing local green spaces in their neighbourhood, and almost all respondents (95.3 percent) perceived local green spaces to be easy or very easy to access (Fig. 3.9). 


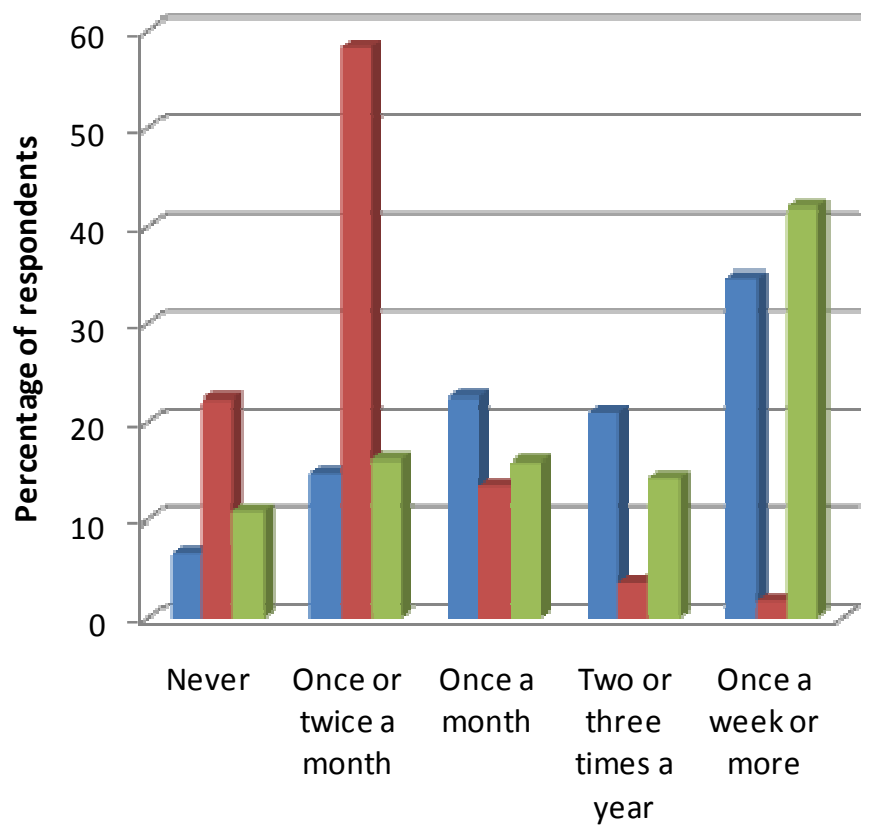

Frequency of participation
Frequency of visit to local park or reserve

Frequency of visit to regional park or reserve

Frequency of participation in outdoor recreation activities

Figure 3.8 Frequency of visits to parks and participation in outdoor recreation activities

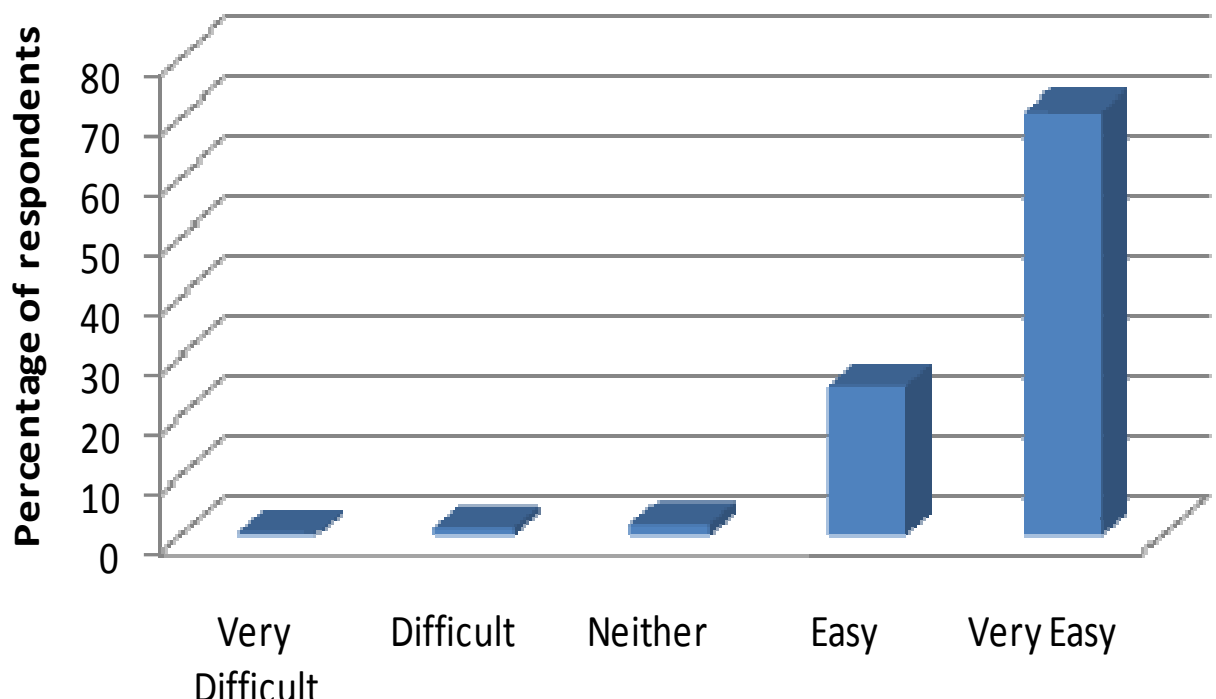

Ease or difficulty of access to local green spaces

Figure 3.9 The accessibility of local green spaces, as perceived by the respondents 


\subsection{Ecological Knowledge Analysis}

I ran a bivariate correlation analysis of all the dependent and independent variables to establish any general trends (Appendix 1). Across all three measures of knowledge, the level of green space on the property $(\mathrm{r}=.211, .108, .126)$, frequency of visits to regional parks $(\mathrm{r}=.110, .214, .187)$, and membership in a community group $(\mathrm{r}=.114, .137, .127)$ were all positively correlated with increased knowledge. Additionally, level of education $(\mathrm{r}=.180, .122)$, frequency of visit to local parks $(\mathrm{r}=.125$, $.151)$, and living in a less urbanised location ( $\mathrm{r}=-.111,-.112)$, were all positively correlated with increased knowledge in the photo identification and general freelisting knowledge measures. Age was positively correlated ( $\mathrm{r}=.346)$ with neighbourhood bird knowledge.

To establish whether there were any confounding variables, I ran partial correlations of all the variables significantly correlated with knowledge, whilst controlling for other independent variables. The correlations that changed after controlling for other variables are shown below in Table 3.4. Geographic location was not significantly correlated with knowledge after controlling for green space. Regional and local park visits were still correlated with knowledge after controlling for income and education levels. For two of the measures of knowledge, education was still positively correlated after controlling for local and regional park visits, and income. 
Table 3.4 Partial correlations of the variables correlated with knowledge, controlling for other correlated independent variables

\begin{tabular}{|c|c|c|c|c|}
\hline Knowledge variable & $\begin{array}{l}\text { Independent } \\
\text { variable }\end{array}$ & $\begin{array}{l}\text { Correlation } \\
\text { coefficient }\end{array}$ & Significant? & $\begin{array}{l}\text { Controlling } \\
\text { for: }\end{array}$ \\
\hline $\begin{array}{ll}\text { - } & \text { Freelisting } \\
\text { - } & \text { Neighbourhood } \\
\text { - } & \text { Photo ID }\end{array}$ & $\begin{array}{l}\text { Geographic } \\
\text { location }\end{array}$ & $\begin{array}{l}-.037 \\
.029 \\
-.075\end{array}$ & $\begin{array}{ll}\text { - } & \text { No } \\
\text { - } & \text { No } \\
\text { - } & \text { No }\end{array}$ & Green space \\
\hline $\begin{array}{ll}\text { - } & \text { Freelisting } \\
\text { - } & \text { Neighbourhood } \\
\text { - } & \text { Photo ID }\end{array}$ & $\begin{array}{l}\text { Geographic } \\
\text { location }\end{array}$ & $\begin{array}{l}-.081 \\
-.061 \\
-.112\end{array}$ & $\begin{array}{ll}\text { - } & \mathrm{No} \\
\text { - } & \mathrm{Yes} \\
\text { - } & \mathrm{No}\end{array}$ & $\begin{array}{l}\text { Income, } \\
\text { education }\end{array}$ \\
\hline $\begin{array}{ll}\text { - } & \text { Freelisting } \\
\text { - } & \text { Neighbourhood } \\
\text { - } & \text { Photo ID }\end{array}$ & $\begin{array}{l}\text { Regional park } \\
\text { visits }\end{array}$ & $\begin{array}{l}.172 \\
.107 \\
.155\end{array}$ & $\begin{array}{lc}\text { - } & \text { Yes } \\
\text { - } & \text { Yes } \\
\text { - } & \text { Yes }\end{array}$ & $\begin{array}{l}\text { Income, } \\
\text { education }\end{array}$ \\
\hline $\begin{array}{ll}\text { - } & \text { Freelisting } \\
\text { - } & \text { Neighbourhood } \\
\text { - } & \text { Photo ID }\end{array}$ & $\begin{array}{l}\text { Local park } \\
\text { visits }\end{array}$ & $\begin{array}{l}.101 \\
.109 \\
.129\end{array}$ & $\begin{array}{lc}\text { - } & \text { Yes } \\
\text { - } & \text { Yes } \\
\text { - } & \text { Yes }\end{array}$ & $\begin{array}{l}\text { Income, } \\
\text { education }\end{array}$ \\
\hline $\begin{array}{ll}\text { - } & \text { Freelisting } \\
\text { - } & \text { Neighbourhood } \\
\text { - } & \text { Photo ID }\end{array}$ & Education & $\begin{array}{l}.160 \\
-.031 \\
.138\end{array}$ & $\begin{array}{ll}\text { - } & \text { Yes } \\
\text { - } & \text { Yes } \\
\text { - } & \text { No }\end{array}$ & $\begin{array}{l}\text { Local park, } \\
\text { regional park } \\
\text { visits, } \\
\text { Income }\end{array}$ \\
\hline $\begin{array}{ll}\text { - } & \text { Freelisting } \\
\text { - } & \text { Neighbourhood } \\
\text { - } & \text { Photo ID }\end{array}$ & $\begin{array}{l}\text { Community } \\
\text { Group }\end{array}$ & $\begin{array}{l}.075 \\
.102 \\
.118\end{array}$ & $\begin{array}{ll}\text { - } & \text { No } \\
\text { - } & \text { Yes } \\
\text { - } & \text { Yes }\end{array}$ & Green space \\
\hline
\end{tabular}

I then examined possible predictors of ecological knowledge by running a linear multiple regression model for each of the dependent variables (number of birds free 
listed, knowledge of neighbourhood birds, and bird identification from photographs). The independent variables included in each model were chosen by a backwards stepwise method. I weighted the neighbourhood bird knowledge variable to account for the difference in bird diversity at each location. The weighting was done by dividing the number of birds the respondent identified by the bird diversity score for the residents' location, using the bird diversity data (Vinton, 2008). To deal with issues of normality, the natural log was taken of the general and neighbourhood species knowledge scores, and the arcsine of the proportion of correctly identified birds from photographs was used. This normalised the dependant variables. Multi-colinearity was tested for but no alterations needed to be made.

In general, respondents with higher levels of education, who frequented local parks and regional parks, and who lived further from the central business district in less-urbanised locations, had higher levels of ecological knowledge (Table 3.5). A lower score for the geographic location represents a less urbanised landscape type, and generally a location further from the Central Business District. Other variables were significant predictors of individual models. Respondents having a higher level of green space on the property freelisted significantly more bird species. Members of a community group and older respondents had a higher level of knowledge about neighbourhood bird species. Community group members also had a higher level of knowledge concerning bird identification from photographs.

The model predicts that an increase of one category of educational qualifications will correspond with a 0.14 increase in ecological knowledge about birds freelisted, and a 0.13 increase in bird identification. An increase of one category of 
geographic area will correspond to a 0.27 increase in ecological knowledge about neighbourhood bird species, and a 0.12 increase in bird identification. The model also predicts that an increase of one level of regional park visits will correspond with a 0.13 increase in both knowledge about neighbourhood birds and birds freelisted. An increase in frequency of one category of local park visits will correspond with a 0.11 increase in knowledge concerning freelisted birds, a 0.14 increase in neighbourhood bird knowledge, and a 0.08 increase in bird identification.

Although the models were significant (Table 3.6), they only explained a relatively small amount of the variance in two of the measures of ecological knowledge (8.7 percent of the variance in the number of bird species freelisted, and 7.4 percent of the variance in bird identification from photographs, and 16.5 percent on the variance in the neighbourhood bird knowledge; Table 3.5). This suggests that other factors not included in the model are determining most of the variance in the level of ecological knowledge amongst residents.

Table 3.5 Socio-economic and other predictors of ecological knowledge: results from stepwise linear regression

\begin{tabular}{|c|c|c|c|c|c|c|}
\hline $\begin{array}{l}\text { Dependent } \\
\text { variable }\end{array}$ & $\begin{array}{l}\mathbf{R}^{2} \\
\text { Adjuste } \\
\text { d }\end{array}$ & $\begin{array}{l}\text { Independent } \\
\text { variables }\end{array}$ & $\begin{array}{l}\text { Coefficien } \\
t\end{array}$ & $\begin{array}{l}\text { Standar } \\
\text { d Error }\end{array}$ & $\begin{array}{l}\text { Standardis } \\
\text { ed } \\
\text { Coefficient }\end{array}$ & $\begin{array}{l}\text { Significanc } \\
\mathbf{e}\end{array}$ \\
\hline
\end{tabular}




\begin{tabular}{|c|c|c|c|c|c|c|}
\hline \multirow{7}{*}{$\begin{array}{l}\text { Ecological } \\
\text { knowledge } \\
\text { - general }\end{array}$} & \multirow[t]{7}{*}{0.087} & Gender & -0.091 & 0.068 & -0.072 & 0.179 \\
\hline & & Education & 0.093 & 0.035 & 0.143 & 0.008 \\
\hline & & Green space & 0.097 & 0.039 & 0.132 & 0.014 \\
\hline & & Local park visits & 0.058 & 0.028 & 0.114 & 0.040 \\
\hline & & Regional Park visits & 0.105 & 0.044 & 0.132 & 0.019 \\
\hline & & Community group & 0.109 & 0.078 & 0.076 & 0.159 \\
\hline & & (Constant) & 2.112 & 0.219 & & 0.000 \\
\hline \multirow{8}{*}{$\begin{array}{l}\text { Ecological } \\
\text { knowledge } \\
\text { - local } \\
\text { birds }\end{array}$} & \multirow{8}{*}{0.165} & Age & 0.248 & 0.035 & 0.376 & 0.000 \\
\hline & & Green space & 0.094 & 0.044 & 0.110 & 0.033 \\
\hline & & Local park visits & 0.076 & 0.032 & 0.133 & 0.016 \\
\hline & & Regional Park visits & 0.084 & 0.049 & 0.091 & 0.088 \\
\hline & & Green space access & -0.128 & 0.071 & -0.096 & 0.075 \\
\hline & & Hobby Group & -0.147 & 0.091 & -0.086 & 0.107 \\
\hline & & Community group & 0.131 & 0.085 & 0.080 & 0.123 \\
\hline & & (Constant) & -0.679 & 0.360 & & 0.060 \\
\hline \multirow{7}{*}{$\begin{array}{l}\text { Ecological } \\
\text { knowledge } \\
\text { - birds } \\
\text { identified } \\
\text { from photo }\end{array}$} & \multirow{7}{*}{0.074} & Education & 0.046 & 0.019 & 0.129 & 0.018 \\
\hline & & Local park visits & 0.023 & 0.016 & 0.083 & 0.135 \\
\hline & & Regional park visits & 0.044 & 0.025 & 0.099 & 0.076 \\
\hline & & Geographic area & -0.037 & 0.017 & -0.119 & 0.026 \\
\hline & & Hobby group & 0.069 & 0.045 & 0.083 & 0.123 \\
\hline & & Community group & 0.077 & 0.043 & 0.097 & 0.072 \\
\hline & & (Constant) & 0.395 & 0.113 & & 0.001 \\
\hline
\end{tabular}


Note:

a) For the first two models of ecological knowledge, the dependent variables were transformed using natural logs. The knowledge about neighbourhood birds variable was weighted based on the diversity of birds at the location, by dividing the number of species noted by the number of species present, before taking the natural log. This made these variables fit a normal distribution. For the birds identified from photographs, this dependent variable was transformed by taking the arcsine of the proportion of birds correctly identified, making this categorical variable fit a normal distribution.

b) The variables to be included in the regression model were established by using a backward regression model.

Table 3.6 Significance of the regression model, ANOVA summary

\begin{tabular}{|lllllll|}
\hline $\begin{array}{l}\text { Dependent } \\
\text { variable }\end{array}$ & $\begin{array}{l}\text { Sum of } \\
\text { Squares }\end{array}$ & Df & $\begin{array}{l}\text { Mean } \\
\text { Square }\end{array}$ & F & Significance \\
\hline $\begin{array}{l}\text { General bird } \\
\text { knowledge }\end{array}$ & 12.888 & 6 & 2.148 & 6.192 & 0.000 \\
$\begin{array}{l}\text { Neighbourhood } \\
\text { bird knowledge }\end{array}$ & 29.251 & 6 & 4.217 & 10.222 & 0.000 \\
$\begin{array}{l}\text { Birds correctly } \\
\text { identified }\end{array}$ & 3.523 & 6 & & & \\
\end{tabular}

As a comparison between the level of ecological knowledge concerning native

birds and knowledge concerning exotic birds amongst the respondents, I ran the multiple regression models again, but for knowledge of exclusively native and then 
exotic birds in turn (Table 3.7). The photo identification measure was not analysed for native and exotic differences because of the low number of exotic birds examined (two).

Table 3.7 Socioeconomic and other predictors of ecological knowledge: results from linear regression of native and exotic bird knowledge

\begin{tabular}{|c|c|c|c|c|c|c|}
\hline $\begin{array}{l}\text { Dependent } \\
\text { variable }\end{array}$ & $\begin{array}{l}\mathbf{R}^{2} \\
\text { Adjuste }\end{array}$ & $\begin{array}{l}\text { Independent } \\
\text { variables }\end{array}$ & $\begin{array}{l}\text { Coefficien } \\
\mathbf{t}\end{array}$ & $\begin{array}{l}\text { Standar } \\
\text { d Error }\end{array}$ & $\begin{array}{l}\text { Standardis } \\
\text { ed } \\
\text { Coefficient }\end{array}$ & $\begin{array}{l}\text { Significanc } \\
\text { e }\end{array}$ \\
\hline \multirow{8}{*}{$\begin{array}{l}\text { Ecological } \\
\text { knowledge } \\
\text { - native } \\
\text { birds } \\
\text { freelisted }\end{array}$} & \multirow[t]{8}{*}{0.089} & Age & -0.085 & 0.052 & -0.088 & 0.102 \\
\hline & & Education & 0.161 & 0.060 & 0.146 & 0.008 \\
\hline & & Outdoor Rec & -0.092 & 0.043 & -0.125 & 0.032 \\
\hline & & Local park visits & 0.148 & 0.050 & 0.171 & 0.003 \\
\hline & & Regional Park & 0.180 & 0.077 & 0.134 & 0.020 \\
\hline & & & -0.088 & 0.050 & -0.093 & 0.082 \\
\hline & & Geographic area & 0.140 & 0.130 & 0.058 & 0.279 \\
\hline & & $\begin{array}{l}\text { Community Gp } \\
\text { (Constant) }\end{array}$ & 1.107 & 0.377 & & 0.004 \\
\hline \multirow{4}{*}{$\begin{array}{l}\text { Ecological } \\
\text { knowledge } \\
\text { - exotic } \\
\text { birds } \\
\text { freelisted }\end{array}$} & \multirow[t]{4}{*}{0.039} & & 0.087 & 0.039 & 0.121 & 0.026 \\
\hline & & Outdoor Rec & 0.080 & 0.026 & 0.167 & 0.002 \\
\hline & & Greenspace & 0.087 & 0.044 & 0.105 & 0.052 \\
\hline & & Constant & 1.699 & 0.211 & & 0.000 \\
\hline
\end{tabular}




\begin{tabular}{|c|c|c|c|c|c|c|}
\hline \multirow{3}{*}{$\begin{array}{l}\text { Ecological } \\
\text { knowledge } \\
\text { - native } \\
\text { birds seen } \\
\text { / heard }\end{array}$} & \multirow{3}{*}{0.141} & Gender & -0.100 & 0.084 & -0.067 & 0.238 \\
\hline & & Education & 0.141 & 0.045 & 0.178 & 0.002 \\
\hline & & Outdoor Rec & -0.052 & 0.032 & -0.103 & 0.099 \\
\hline & & Local park visits & 0.102 & 0.038 & 0.171 & 0.007 \\
\hline & & Regional park & 0.156 & 0.057 & 0.168 & 0.006 \\
\hline & & Green access & -0.214 & 0.083 & -0.156 & 0.011 \\
\hline & & Geographic area & -0.121 & 0.037 & -0.186 & 0.001 \\
\hline & & Hobby group & 0.210 & 0.105 & 0.114 & 0.047 \\
\hline & & Community group & 0.103 & 0.098 & 0.061 & 0.293 \\
\hline & & (Constant) & 2.347 & 0.479 & & 0.000 \\
\hline $\begin{array}{l}\text { Ecological } \\
\text { knowledge }\end{array}$ & 0.136 & Age & 1.050 & 0.17 & 0.347 & 0.000 \\
\hline $\begin{array}{l}\text { - exotic } \\
\text { birds seen }\end{array}$ & & Income & -0.031 & 0.012 & -0.137 & 0.017 \\
\hline / heard & & Geographic area & -0.081 & 0.028 & -0.154 & 0.004 \\
\hline & & Regional park & 0.099 & 0.042 & 0.128 & 0.018 \\
\hline & & Hobby group & -0.136 & 0.079 & -0.096 & 0.088 \\
\hline & & Constant & 1.048 & 0.168 & & 0.000 \\
\hline
\end{tabular}

Note:

a) A backward stepwise method was used to select the variables to be included in the regression model.

b) The geographic area represents the landscape type at the survey location. An increase in number of the geographic type reflects an increasingly urbanised landscape.

c) For both models, the dependent variables were transformed using natural logs. 
Table 3.8 Significance of the regression model, ANOVA summary

\begin{tabular}{|c|c|c|c|c|c|}
\hline $\begin{array}{l}\text { Dependent } \\
\text { variable }\end{array}$ & $\begin{array}{l}\text { Sum of } \\
\text { Squares }\end{array}$ & Df & $\begin{array}{l}\text { Mean } \\
\text { Square }\end{array}$ & $\mathbf{F}$ & Significance \\
\hline $\begin{array}{l}\text { Native birds } \\
\text { freelisted }\end{array}$ & 38.218 & 7 & 5.460 & 5.546 & 0.000 \\
\hline $\begin{array}{l}\text { Exotic birds } \\
\text { freelisted }\end{array}$ & 7.129 & 3 & 2.376 & 5.467 & 0.001 \\
\hline $\begin{array}{l}\text { Native birds } \\
\text { seen or heard }\end{array}$ & 24.278 & 9 & 2.698 & 5.979 & 0.000 \\
\hline $\begin{array}{l}\text { Exotic birds } \\
\text { seen or heard }\end{array}$ & 15.698 & 5 & 3.140 & 10.664 & 0.000 \\
\hline
\end{tabular}

In general, the results remain the same, for both native and exotic species knowledge models. Respondents with higher levels of education, who more frequently visited local parks and regional parks, and who lived in a less urbanised location, had higher levels of ecological knowledge (Table 3.7). Other variables were significant predictors of individual models. Participation in outdoor recreation activities and property greenspace levels were predictors for higher levels of exotic species knowledge in the bird freelisting model, while being a member of a hobby group and having a reduced access to greenspace correlated with a higher level of neighbourhood 
native bird knowledge. Age was a positive predictor for exotic neighbourhood bird knowledge, but not for native species knowledge.

The model predicts that an increase of one category of educational qualifications will correspond with a 0.15 increase in ecological knowledge about native birds freelisted, and a 0.18 increase in native neighbourhood bird knowledge. An increase in frequency of one category of local park visits will correspond with a 0.17 increase in both knowledge concerning freelisted native birds and native neighbourhood birds. Although the models were significant (Table 3.8), they again only explained a relatively small amount of the variance in ecological knowledge (between 3.9 and 14.1 percent of the variance in the models; Table 3.7).

\subsection{Bird Feeding and Tree Planting}

To examine the patterns of behaviour related to encouraging birdlife on the property, I asked respondents about feeding birds on their property, and whether they had planted trees to encourage bird life. Forty-two percent of respondents put food out for birds (Fig 3.10) and 37\% had planted trees on their property to encourage birdlife (Figure 3.11). Only one-third of respondents had not planted trees for this purpose and stated they wouldn't even if there was the space and opportunity to do so. Twenty-two percent of people said they would have planted trees if they were given the opportunity to do so. 


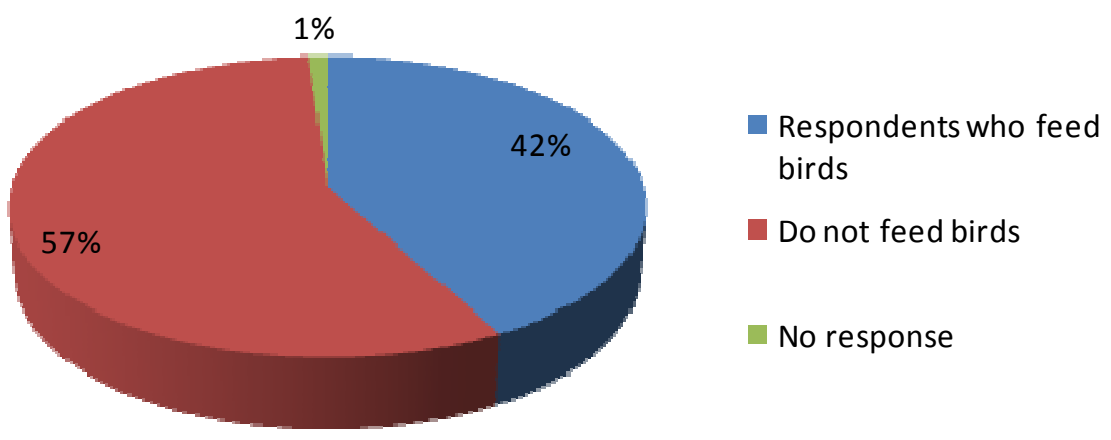

Figure 3.10 Percentage of respondents feeding birds on their property

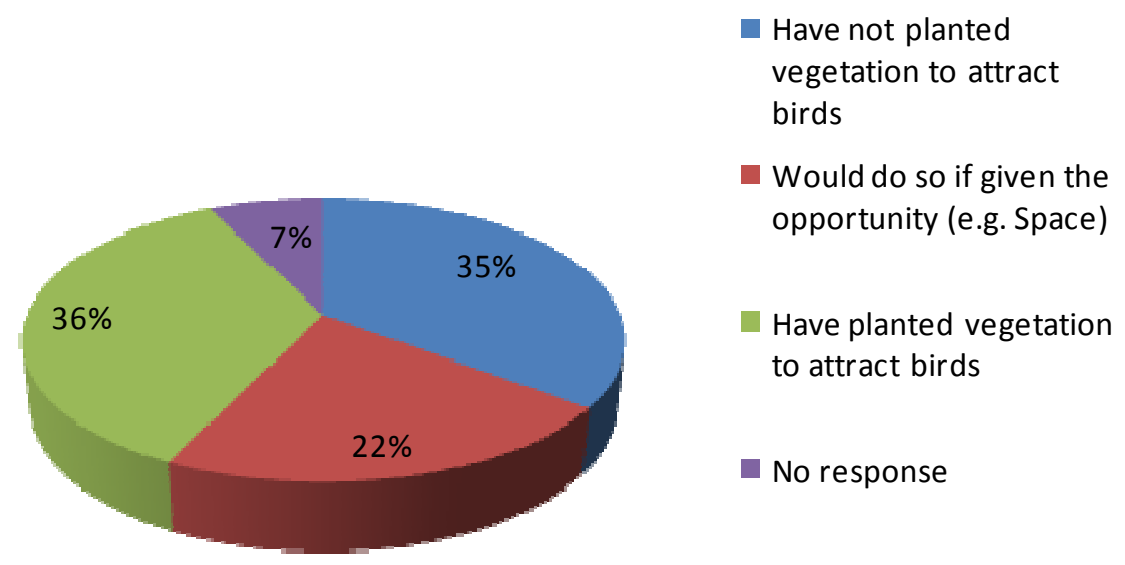

Figure 3.11 Percentage of respondents planting trees on their property

Amongst those who fed birds, only $10 \%$ were specifically targeting native bird species. In addition, less than one-third of respondents (31.2\%) fed birds from a feeding 
structure on their property. The structures used included feeders hanging in a tree, with the next favoured method a raised platform on the lawn. Comparing respondents who participated in bird feeding and tree planting against those who did not, I found differences in the socio-demographic factors of the respondents involved in each activity. Specifically, the respondents who fed birds were older and had lived for a longer length of time at their present address than those who did not feed birds (Table 3.9). Respondents who had planted trees for the benefit of birdlife were older, more likely to be female, and had lived on the property for a longer length of time than those who did not plant trees (Table 3.9). There were no significant education and income differences between those who participated in the activities and those who did not. 
Table 3.9 Comparison of respondents participating in bird feeding and tree planting versus nonparticipants based on sociodemographic factors.

\begin{tabular}{|c|c|c|c|c|c|}
\hline Activity & Factor & Participant & Nonparticipant & $\begin{array}{l}\text { Statistic } \\
\text { - see note }\end{array}$ & p-value \\
\hline $\begin{array}{l}\text { Bird } \\
\text { Feeding }\end{array}$ & $\begin{array}{l}\text { Age } \\
\text { Gender } \\
\text { Education } \\
\text { Income } \\
\text { Length at } \\
\text { address }\end{array}$ & $\begin{array}{l}3.24 \\
62.4 \\
3.91 \\
7.67 \\
12.19\end{array}$ & $\begin{array}{l}2.86 \\
57.8 \\
4.04 \\
7.75 \\
7.884\end{array}$ & $\begin{array}{l}-3.466 \\
0.946 \\
-1.645 \\
-0.229 \\
-5.109\end{array}$ & $\begin{array}{l}0.001 \\
0.331 \\
0.100 \\
0.819 \\
0.000\end{array}$ \\
\hline $\begin{array}{l}\text { Tree } \\
\text { Planting }\end{array}$ & $\begin{array}{l}\text { Age } \\
\text { Gender } \\
\text { Education } \\
\text { Income } \\
\text { Length at } \\
\text { address }\end{array}$ & $\begin{array}{l}3.43 \\
65.8 \\
4.08 \\
7.94 \\
14.56\end{array}$ & $\begin{array}{l}2.76 \\
57.3 \\
3.96 \\
7.58 \\
6.65\end{array}$ & $\begin{array}{l}-6.291 \\
2.808 \\
-1.022 \\
-1.330 \\
-8.025\end{array}$ & $\begin{array}{l}0.000 \\
0.094 \\
0.307 \\
0.183 \\
0.000\end{array}$ \\
\hline
\end{tabular}

Note: For Age, Education, Income, and Length of time at address, values are means and presented with a t-value for the statistic. For Gender, values represent the percentage female, and presented with a $\chi^{2}$ value for the statistic. 


\subsection{Bird-Related Behaviour Analysis}

I ran a bivariate correlation analysis of the dependent and independent variables to establish any general trends (Appendix 1). Increased bird knowledge, age, level of green space on the property, and geographic location were all positively correlated with tree planting and bird feeding. Being a member of a sports club, community group, and frequency of visits to local green spaces were all positively correlated with tree planting. Access to green spaces and the level of green space on the property were also positively correlated with bird feeding. Neighbourhood bird species richness and increasing urbanisation was negatively correlated with bird feeding.

To establish whether there were any confounding variables, I ran partial correlations of the variables significantly correlated with tree planting and bird feeding, whilst controlling for other independent variables (Table 3.10). Age was still significantly positively correlated with tree planting and bird feeding after controlling for income and hobby group membership. Green space on the property was still positively correlated with tree planting and bird feeding after controlling for geographic location and public green space access. Controlling for green space, public green space access, and bird diversity, the geographic location was still significantly correlated with bird feeding and tree planting. 
Table 3.10 Partial correlations of the variables correlated with knowledge, controlling for other correlated independent variables

\begin{tabular}{|c|c|c|c|c|}
\hline $\begin{array}{l}\text { Behaviour } \\
\text { variable }\end{array}$ & $\begin{array}{l}\text { Independent } \\
\text { variable }\end{array}$ & $\begin{array}{l}\text { Correlation } \\
\text { coefficient }\end{array}$ & Significant? & Controlling for: \\
\hline $\begin{array}{ll}- & \text { Bird } \\
& \text { feeding } \\
\text { - } & \text { Tree } \\
& \text { planting } \\
\end{array}$ & Age & $\begin{array}{r}.180 \\
-.057\end{array}$ & $\begin{array}{ll}\text { - } & \text { Yes } \\
\text { - } & \text { No }\end{array}$ & $\begin{array}{l}\text { Income, hobby } \\
\text { group }\end{array}$ \\
\hline $\begin{array}{ll}- & \text { Bird } \\
& \text { feeding } \\
\text { - } & \text { Tree } \\
& \text { planting } \\
\end{array}$ & $\begin{array}{l}\text { Green space } \\
\text { on property }\end{array}$ & $\begin{aligned} & .141 \\
& .104\end{aligned}$ & $\begin{array}{ll}\text { - } & \text { Yes } \\
\text { - } & \text { Yes }\end{array}$ & $\begin{array}{l}\text { Geographic } \\
\text { location, green } \\
\text { space access }\end{array}$ \\
\hline $\begin{array}{ll} & \text { Bird } \\
\text { feeding } \\
\text { - } & \text { Tree } \\
& \text { planting }\end{array}$ & $\begin{array}{l}\text { Geographic } \\
\text { location }\end{array}$ & $\begin{array}{r}-.114 \\
-.098\end{array}$ & $\begin{array}{ll}\text { - } & \text { Yes } \\
\text { - } & \text { Yes }\end{array}$ & $\begin{array}{l}\text { Green space, } \\
\text { access to green } \\
\text { space, Bird } \\
\text { Diversity }\end{array}$ \\
\hline
\end{tabular}

I also ran a stepwise logistic regression analysis to identify the significant predictors of tree planting and bird feeding. There were no issues with multicolinearity, with the relationships between knowledge and the independent variables being relatively weak. For bird feeding, the strongest predictors were a higher knowledge of neighbourhood birds, having a higher level of green space on the property, and a greater accessibility to green spaces (Table 3.11). Other significant predictors of bird feeding were an increase in age and a reduced level of education. The strongest predictor of tree planting was knowledge of neighbourhood birds, followed by age, the level of bird diversity in the neighbourhood, the amount of green space on the property, and education levels, all having a positive relationship. Other predictors of 
planting trees for the purpose of encouraging birdlife were being male and not being a member of a sports group.

The model predicts that as the level of knowledge about neighbourhood birds increases by one standard deviation, the level of bird feeding increases by 1.603 standard deviations, and the level of tree planting increases by 3.161 standard deviations. An increase in age by one standard deviation relates to an increase in tree planting of 1.957 standard deviations.

Similar to the ecological knowledge results, the models were significant (Table 3.12), but only explained a small amount of the variance in the respondents feeding birds or tree planting (10 percent of the variance for bird feeding, and 24 percent of the variance in tree planting; Table 3.12). 
Table 3.11 Socioeconomic and other predictors of ecological behaviour: results from stepwise logistic regression

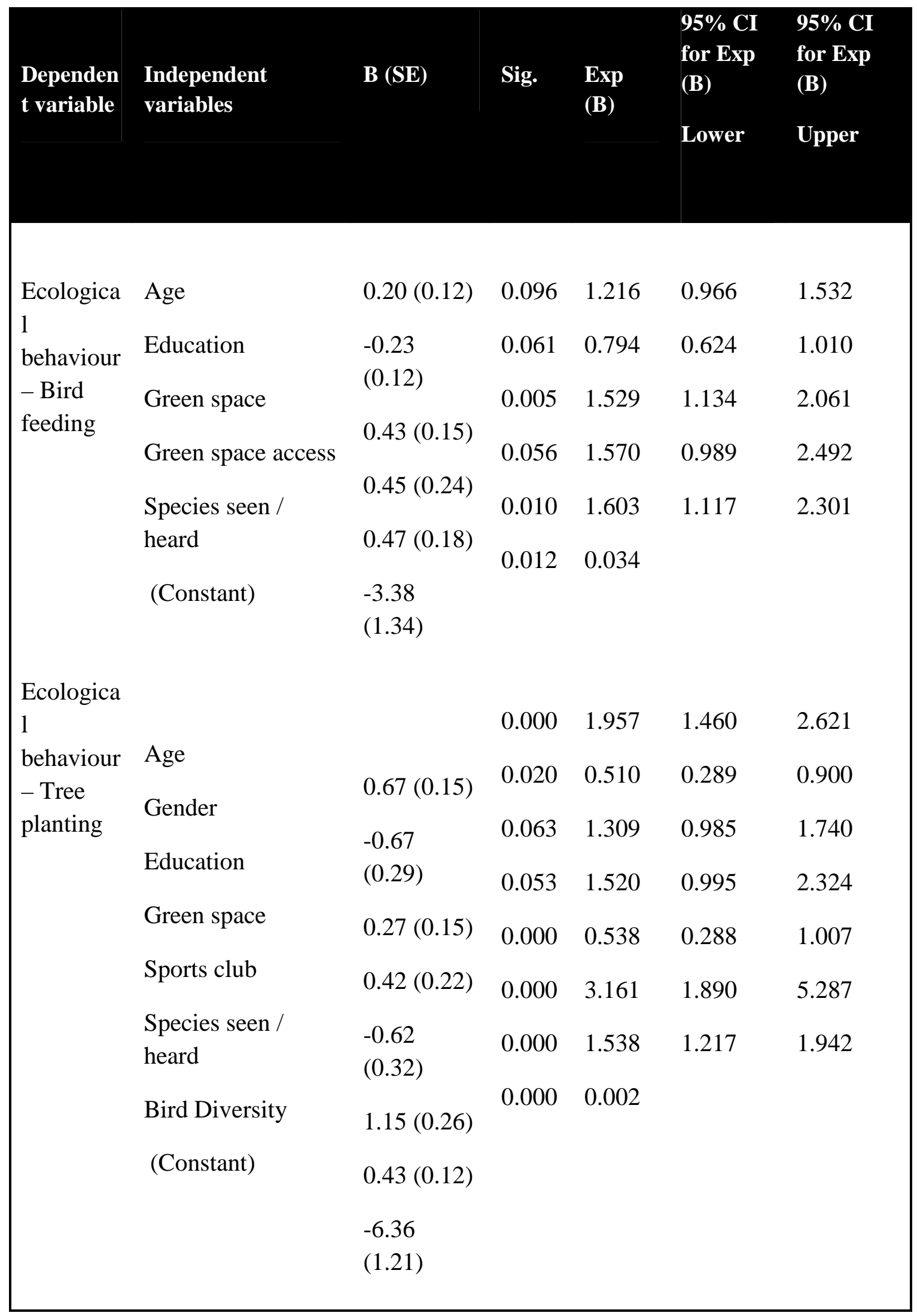


Note:

a) A backward stepwise method was used to select the variables to be included in the regression model.

b) The geographic area represents the landscape type at the survey location. An increase in number of the geographic type reflects an increasingly urbanised landscape.

c) A positive correlation for gender signifies a positive relationship with female respondents.

Table 3.12 Significance of the ecological behaviour regression models

\begin{tabular}{|lllll|}
$\begin{array}{l}\text { Dependent } \\
\text { Variable }\end{array}$ & Chi-square & Significance & $\begin{array}{l}\text { Cox and } \\
\text { Snell } \mathbf{R}^{\mathbf{2}}\end{array}$ & $\begin{array}{l}\text { Nagelkerke } \\
\mathbf{R}^{\mathbf{2}}\end{array}$ \\
\hline $\begin{array}{l}\text { Bird } \\
\text { Feeding }\end{array}$ & 34.460 & 0.000 & 0.097 & 0.130 \\
& & & & \\
$\begin{array}{l}\text { Tree } \\
\text { Planting }\end{array}$ & 85.835 & 0.000 & 0.240 & 0.325 \\
& & & & \\
\hline
\end{tabular}

3.7. Exotic and Native species

The survey asked the respondents to name all the bird species they could within five minutes, and to mark the species they recognised as native to New Zealand. The distribution of the number of species named was not normally distributed, so I have 
used median values and non-parametric statistics for comparisons. To establish whether there was a significant difference between the number of native and exotic species named, I used the Wilcoxon test as the data were discrete, non-banded, and not normally distributed. The respondents named significantly more exotic species (median=13) than native species (median=8; Wilcoxon test, $\mathrm{z}=9.3, \mathrm{p}<0.001$ ). There was a larger range of exotic species listed (range $=0$ to 62), than native species (range $=0$ to 47). The percentage of native birds listed by the respondents was $37 \%$, compared to $45 \%$ of exotic species listed (8\% of species named remained unlabeled as exotic or native). The median number of total species named was 23 , with a range from 0 to 109 .

The participants were then asked about the birds they saw and/or heard in their neighbourhood. Respondents noted that they saw and/or heard more exotic species (median=3) than native (median=1; Wilcoxon test, $\mathrm{z}=11.3, \mathrm{p}<0.001)$ species in their neighbourhoods. Overall, the median number of species seen and/or heard in the neighbourhood was five, (range $=0$ to 24 ). There was also a larger range of native species given ( 0 to 15$)$, than exotic species (range $=0$ to 13 ). Therefore, as with the freelisting of all the birds, the birds that respondents noted they saw and/or heard in their neighbourhood were more commonly exotic than native. The percentage of birds seen or heard in the neighbourhood that were identified as native was 32 percent, with 37 percent of the birds seen or heard in the neighbourhood being identified as exotic.

There was no significant difference between the percentage of native species correctly identified and the percentage of native and exotic species combined that respondents could identify. In the identification of bird species from photographs, 
respondents were able to correctly identify on average 68.6 percent (Std Dev=22.06) of native species, compared with a 66.06 percent $(\operatorname{Std} \mathrm{Dev}=21.86)$ of native and exotic species correctly identified.

The bivariate correlation analysis showed native neighbourhood bird knowledge was positively correlated with the amount of green space on the property, and being a member of a community group (Appendix 1). Native neighbourhood bird knowledge was negatively correlated with geographic location (also see Table 3.7). The geographic location was ranked on an increasingly urbanised scale, so respondents living in less urbanised locations had higher native species knowledge. Native species richness over the survey locations also decreases with increasing urbanisation (Vinton, 2008). Respondents name more native species in neighbourhoods with more native bird species present. However, whilst overall species diversity showed a negative correlation with geographic location, this was not a significant predictor of neighbourhood species knowledge. 


\section{Discussions and Conclusions}

\subsection{Ecological knowledge}

Although many studies have looked at traditional ecological knowledge, few explicitly examined ecological knowledge of urban residents. With the world's population becoming more and more urbanized, the study of urban residents is an important one. An individuals' level of ecological knowledge, as well as an interest and affinity for nature, can be a powerful predictor in pro-environmental behaviour (Kals et al., 1999), so it is important to know what factors might influence, or be predictors of, of ecological knowledge.

This study examined the levels of bird knowledge of Wellington residents. With few urban ecological studies in the literature, it is difficult to compare the depth of residents' bird knowledge with other studies. There is a need for more studies both in terms of the same methods in different locations, as well as longitudinal studies. It seems likely, however, that those having an interest in birds would spend more time on the free listing question, increasing the gap between those with higher and lesser knowledge. Most respondents (63 percent) selfrated their knowledge of birds as poor or fair. In relative terms, this self-assessment showed to be an accurate measure, with those assessing their knowledge to be greater showing greater scores for all measures of knowledge. With more and more people living in urban areas, support for conservation measures outside urban locations will likely need to come from urban residents (Miller, 2006; Dunn et al., 2006). Finding this support may be difficult without residents being knowledgeable about ecological issues. However, in terms of general bird knowledge in Wellington, I found that knowledge varied widely between respondents, with a few respondents' having an extensive knowledge. Given the variance in total knowledge held by different respondents, knowing what variables might predict different levels of knowledge is important. 


\subsection{Predictors of Ecological knowledge}

I utilized a self-administered mail survey of Wellington residents to examine possible relationships between ecological knowledge and various socio-economic and other indicators. Across the three measures of knowledge, residents with higher levels of education, who more frequently visited parks inside and outside Wellington, who had higher levels of green space on the property, and who lived in the least urbanised areas (generally further form the Central Business District), had higher levels of ecological knowledge. These variables were much more important for ecological knowledge levels than avian richness, which was not a key predictor. The variables of gender, hobby and sports groups, income, perceived access to greenspace, and participation in outdoor recreation activities were not significant predictors. Age and community group membership were each predictors in only one measure of knowledge. For the specific knowledge about neighbourhood birds, older residents tended to have higher levels of knowledge.

Geographic location - The geographic location of the residents' home showed significance in predicting knowledge levels, with those residents living further from industrial and commercial districts showing greater levels of knowledge than those living in a more central and urbanised location. This supports the study of MacDaniel and Alley (2005). Those respondents whose residence adjoined green spaces had the highest levels of knowledge. However, accessibility to greenspaces was not correlated with knowledge, and it cannot be assumed that those living near green spaces have a higher knowledge because of the effect of the green spaces. It may also be that those with a higher appreciation for nature, and who are possibly more knowledgeable about the natural world, simply prefer to live in these locations. My results do not seek to prove causation, but to simply identify predictors of knowledge. I analysed the factors that correlated with location, and identified the amount of residential green space as being strongly correlated. When I controlled for the amount of private green space, the geographic location was no longer significantly correlated with ecological knowledge. This 
suggests the level of green space on the property was a strong factor in the characteristics of the location in terms of residents' knowledge.

Park visits - Additionally to the amount of greenspace on the property, I found that individuals who more frequently visit parks, both locally and regionally, had higher levels of ecological knowledge. This supports the idea that an increased interaction with the natural world has a positive effect on knowledge levels (e.g. Miller, 2005; Pilgrim, 2007). The psychological importance of urban green spaces for the well-being of urban residents is welldocumented (e.g. Pretty et al., 2005; Tzoulas et al., 2007; Maas et al., 2009), and my study supports the idea that urban green spaces can have a positive effect on ecological knowledge levels as well. Yet given the general trends of fewer visits to parks and reserves (e.g. Pergams and Zaradic, 2008; Kareiva, 2008) and of residents spending more and more time indoors (Orr, 2002), then the ecological knowledge of urban residents seems likely to decrease as well. The 'extinction of experience', as people become disconnected with nature, has long been a concern regarding urban residents (Schneider and Salk, 2002). It needs to be stressed that my results do not prove causation, and it may be that those who have a greater ecological knowledge simply visit parks and reserves more frequently. However, since the frequency of visits to urban green spaces is positively correlated with ecological knowledge, then good urban planning in encouraging urban residents to regularly frequent urban green spaces is likely to have importance.

Outdoor Recreation - As others have noted (e.g. Tarrant et al.,1997; MacDaniel and Alley, 2005), the type of outdoor interaction seems important. In my study, most respondents (90 percent) participated in some form of outdoor recreation, but the frequency of participation in outdoor recreation activities was not a significant predictor of ecological knowledge, nor significantly correlated. The frequency of visits to green spaces was a significant predictor of knowledge however. 
Greenspace assessiblilty - Characteristics such as the amount, accessibility, and quality of urban green spaces have all been shown to affect the way in which knowledge is acquired (Herzele and Wiedemann, 2003). However, my study found perceived accessibility to green space was not a predictor for knowledge, and this may be explained by the fact that the vast majority of respondents (95 percent) found green spaces easy or very easy to access. Studies show that accessibility is important, with most people unwilling to walk more than $400 \mathrm{~m}$ from home to reach a green space (Burgess et al., 1988), and in Wellington accessibility does not appear to be a barrier for residents. As my results show, 35 percent of respondents visit local parks at least once a week. In other cities where access to green spaces is more limited, a stronger link might be found between perceived accessibility, frequency of visits, and knowledge, but in Wellington accessibility does not appear to be an issue.

Education - Various studies in the literature support my findings of a positive relationship between ecological knowledge and a higher level of education (e.g. Kellert, 1976; Kellert and Barry, 1987; Reyes-Garcia, 2005). It should be noted that my survey respondents were generally more highly educated than the Wellington population as a whole, which is a possible source of bias in the results. Other studies have found only a weak relationship (MacDaniel and Alley, 2005), or a negative relationship between higher levels of education and ecological knowledge (e.g. Guest, 2002; Voeks and Leony, 2004; Quilan and Quilan, 2007). The wide range in results likely reflects the different roles of education among the various studies shown to date. For example, various studies have concluded that exposure to government-run education systems has led to a loss of traditional ecological knowledge in different indigenous communities (e.g. Voeks and Leony, 2004; Quilan and Quilan, 2007). Similarly, Pilgrim et al (2007) found that in an urban non-traditional setting in the UK, individuals with the lowest levels of ecological knowledge tended to acquire what knowledge they had from television and school. My results showed that the relationship between education and ecological knowledge is unlikely to be spurious. Education was positively correlated with income and frequency of visits to parks and reserves, yet the positive relationship between 
education and knowledge still held when controlling for these other variables. It is possible though that education instead correlates with other variables that I have not tested for, such as travel. The survey respondents were also more educated than the general Wellington population, so there may be a possible bias here.

Age - Age was a significant predictor of knowledge levels about the birds seen or heard in the neighbourhood, with older residents having a higher level of knowledge than younger residents. Age was still significantly correlated with neighbourhood bird knowledge after controlling for the other variables correlated with age (income and belonging to a hobby group). Other studies, particularly those focused on traditional ecological knowledge in nonurban communities (Voeks and Leony, 2004; Quilan and Quilan, 2007), also found that older residents have a greater ecological knowledge. In an urban UK study, Pilgrim et al. (2008) found older people were able to identify more species than younger people. The loss of knowledge between the age groups may be because ecological knowledge is acquired continually through life, but may also represent a loss of knowledge between generations. If the latter is the case, this is of concern. One reason for the loss of traditional ecological knowledge is the loss of transmission and change in livelihoods (e.g. Voeks and Leony, 2004; Quilan and Quilan, 2007). This may contrast with the ecological knowledge that I have examined, in that the knowledge is not always passed on from one generation to the next. Therefore, the effect of age on TEK and on other forms of ecological knowledge may differ. Since age was not a significant predictor for the other measures of knowledge I studied (general freelisting of species and photograph identification), it seems possible that the positive association with knowledge about the neighbourhood bird species reflects experiential knowledge. This correlation still holds when I control for residence time, and shows a linear relationship so seems unlikely to be influenced by retirement factors. It should be noted that there is a possible bias in my results, with the survey respondents being older than the general Wellington population. 
Gender - Gender has often been shown to be an influential factor in predicting knowledge levels (e.g. Voeks and Leony, 2004; Quilan and Quilan, 2007), as well as perceptions of nature (Kellert and Barry, 1987; Martino, 2008). However, like many previous other studies (Guest, 2002; Gupte, 2002; MacDaniel and Alley, 2005; Pilgrim et al., 2007) I found gender was not a significant variable in predicting ecological knowledge of urban residents. It may be that gender has a more significant role in ecological knowledge variation amongst traditional societies, or concerning traditional ecological knowledge, rather than generalised knowledge in an urban setting.

Income - Income was another non-significant predictor of knowledge, lending support to other studies of urban residents such as MacDaniel and Alley (2005) and Pilgrim et al. (2007). The general trend seems to be that nature experiences have a larger effect on knowledge levels than various socio-economic characteristics. Although hobby and sports club membership were not significant predictors of general bird knowledge, participation in community groups was significant. Previous studies show that individuals with the highest knowledge scores acquired the knowledge from word-of-mouth associations, such as family or interest groups (Pilgrim et al., 2007), and this may help explain why being a community group member was significant in predicting knowledge. However, amongst the hobby group members, almost one quarter of those that specified the groups they were affiliated with, were part of environmentally focused groups. If knowledge is correlated with interest (Turpie, 2003), then this might have been expected to be a predictor. A possible reason for the lack of relationship that I found may be that my analysis only examined whether they were part of a group, which was too general. Analysing those respondents that were part of an environmental group may have showed a significant relationship. However, my data were not robust enough to analyse this, as most respondents chose not to specify which group(s) they belonged. 
Species richness - The quality of the greenspace, as measured in terms of bird diversity and richness, differed among landscape types across Wellington. Species richness was highest in green landscapes ( $S=15.9)$, and lowest in commercial districts ( $S=6.7)$ (Vinton, 2008). Using this local avian richness data, the neighbourhood bird diversity was analysed against the unweighted knowledge scores of respondents from those neighbourhoods. It was hypothesized that the decreased flora and fauna diversity that residents are exposed to across an urbanisation gradient might correlate with lower knowledge scores. However, regression and correlation analyses showed that bird diversity was not significantly correlated with ecological knowledge, and that bird diversity was not consistently found as a significant predictor of knowledge levels. Therefore, although greenspace seems to be an important predictor for ecological knowledge, direct access to a greater richness of birds is not. Possible explanations for this may be that the time spent outdoors is more significant than having high avian richness in the neighbourhood. If people are not outdoors and experiencing wildlife firsthand, increased neighbourhood species diversity may have little impact on knowledge. Additionally, it may also be that visiting greenspaces increases an individuals' interest in the natural world, which in turn makes them more interested in ecological issues, and consequently more ecologically knowledgeable (e.g. Turpie, 2003). If this is the case, then the decreased species diversity in urban areas may not have such an adverse effect on residents' knowledge as hypothesised, as long as there are opportunities for natural interactions (e.g. Miller, 2005).

These results support the literature advocating the importance of green spaces (e.g. Bonaiuto et. al., 1999; Frumkin, 2001; Chiesura, 2004; Yli-Pelkonen and Niemela, 2005; Maas et. al., 2009). Research has shown the benefits of green spaces to be wide-ranging for urban residents, in terms of health and general well-being (e.g. de Vries et al., 2003; Pretty et al., 2005; Maas et. al., 2009), as well as providing social benefits such as space for human interactions (Kim and Kaplan, 2004). My findings show that living closer to greenspaces and visiting these spaces more frequently are predictors of higher levels of ecological knowledge amongst residents. Ecological knowledge is important in many ways, and especially for 
conservation efforts. People are unlikely to support conservation movements without knowledge about the ecological issues involved (Miller, 2005), and knowledge can be an important factor in pro-environmental behaviour (Hungerford and Volk, 1990; Kals et al., 1999). Therefore, my results lend further support to efforts aimed at increasing residents' visits to urban green spaces (e.g. Burgess et al., 1998; Cranz and Bolard, 2004).

\subsection{Native and exotic bird knowledge}

The second research objective was to investigate the level of knowledge amongst Wellington residents about native and exotic bird species, and whether there were significant differences in knowledge levels between the two groups. If urban dwellers do not have knowledge of and regard for native species it will be harder to convince them of the need for conversation measures to protect these species (McKinney, 2002). My study found that respondents named more exotic than native bird species both in terms of neighbourhood birds and when free listing species, and could correctly identify more exotic than native species by photograph. Two of the three most commonly incorrectly identified birds were native birds. Analysing further the residents' general knowledge of native species (as measured by freelisting), the greater knowledge of non-native species was true across different sectors of the Wellington population. Irrespective of the respondents' age, education level, or income group, more exotic species were named than native species. This trend held true across the different geographic locations, and households with differing levels of green space. The lower levels of knowledge about native species may have worrying implications for native conservation efforts (Miller, 2005).

According to the actual bird richness data for Wellington City, exotic birds were more common than native species, with sparrows, starlings, black-backed gulls, and feral pigeons being the most common species (Vinton, 2008). The native bird species all showed a descending abundance distribution with increasing urbanisation. The participants' knowledge 
levels concerning native birds followed this same pattern, with residents having a higher knowledge of native birds in less urbanised locations further from Wellington's commercial districts. Similarly in a Dunedin study, overall species richness did not differ much between most urban habitats in Dunedin, but the number and abundance of native species did differ (Heezik et al., 2008). The neighbourhood bird abundance and richness can be influenced by the neighbourhood socio-economic status, and native and non-native species are not equally distributed throughout the urban area (Melles, 2005; Loss et al. 2009). Native species were more common on the outer edges of the urban area, and exotic species more common in the central city. Therefore, it may be that non-native species are better known because they are generally more common in the urban area. Native birds survive in bush remnants and green spaces, but residents are likely to see more exotic birds on the streets and central city area. However, the effect of location on native knowledge was not confined to species richness, as the pattern of higher levels of knowledge of non-native species still held after I controlled for species richness. A reason why species richness was not found to be a predictor for knowledge of neighbourhood native species may be due to the way the species richness was measured. I used a measure of overall species richness, which included both exotic and native species, and the overall richness measure may have masked trends in native species richness. However, overall species richness and native species richness both generally decline with increasing urbanisation (Vinton, 2008).

Investigating the patterns in native and exotic species knowledge, I hypothesise that knowledge may be learned differently depending on the species. The multiple regression analysis showed that for general bird knowledge (as measured by freelisting), the amount of green space on the property was a significant predictor for exotic species knowledge, but not native knowledge. Comparing neighbourhood bird knowledge, age was only significant for exotic species knowledge, while education was significant for native species knowledge. The knowledge of many native bird species may be less likely to come from direct experience with the species but rather through education, books, family, or the media. For example, most New 
Zealanders would be able to name a kiwi, but few would have actually seen one in the wild. Respondents might be able to name more exotic birds through having seen them on or around their property (influenced by the level of green space). Hobby group membership, being a predictor of higher native species knowledge but lower exotic species knowledge, supports the idea that native bird knowledge may be acquired through social interactions (Pilgrim, 2007).

Therefore, different types of knowledge can have different predictors. The different types of knowledge are strongly correlated with each other, but they appear to be affected by different types of variables. Thus, if we hope to impact ecological knowledge we may need to decide which type of knowledge to impact, and therefore target different predictors. However, because the models explained relatively little of the variation, other factors that I haven't tested for seem important.

\subsection{Unexplained Variance}

Whilst the regression models were shown to be significant in analyzing the variables, much of the variance could not be explained (77-93\% of the variance remained unaccounted for in the models). This result should not be entirely unexpected, as knowledge accumulation has been shown to be a complex process, with the contributing factors not well understood (MacDaniel and Alley, 2005). Several variables I did not include in the multiple regression models may be impacting knowledge levels. For example, Pilgrim et al (2007) found that individuals with the highest degree of ecological knowledge acquired it from family and environmental occupations (Pilgrim et al, 2007). Family situations may also be important in terms of the childhood experiences of individuals. Studies show that direct experience with nature as a child is an important factor in knowledge and pro-environmental behaviour later in life (Chawla, 1998; 99).

In addition, the definition of greenspace I used may limit the predictive power of this variable. For example, Yli-Pelkonen and Niemela (2005) divide urban natural areas into three 
categories: 1) 'relict' nature, remnants of original nature, 2) 'man-made' nature such as parks, gardens, restored nature, and 3) 'spontaneous' nature, such as flora and fauna in highly urbanised sites. Simply walking around town may bring residents into contact with examples of 'spontaneous' nature without the need for time in parks or formally designated green spaces. Therefore, time spent outdoors may also account for part of the unexplained variance, outside and above the formal parks and outdoor recreation opportunities that I examined. In terms of park and green space visits, there is also an issue of discrepancy between apparent connection and having a real depth of contact (Pyle, 2003). An urban dweller may have a greater intimacy with the living world by walking through an overgrown, abandoned site, rather than driving to a park and having lunch while sitting in the car, for example.

Therefore, this study found certain socio-economic factors were significant as predictors of ecological knowledge, but other factors had little effect. However, private and public green space interactions were positive predictors across all measures. Identifying how knowledge can be enhanced holds importance for behaviour as well. Knowledge is often a critical factor determining behaviour (Kals et al., 1999). It is of interest then to examine the characteristics of those feeding birds and planting trees for the benefit of birds, and any trends amongst participants.

\subsection{Bird Feeding and Tree Planting}

I examined the characteristics of those Wellington residents who were feeding birds and planting trees for the benefit of birdlife. A large proportion of residents were feeding birds on their property (42 percent), with almost a third of these using a purpose-built feeder. Of those feeding birds, ten percent were specifically targeting native birds with their feeding. I also found that many residents had planted trees to attract birdlife (36 percent), with a further 22 percent willing to do so if they had the opportunity. Studies in North America, Australia, and 
the United Kingdom have found similar results, with 20-60 percent of urban residents feeding wildlife (DEFRA, 2002, Rollinson et al., 2003; Lepczyk et al., 2004, Ishigame and Baxter, 2007, Davies et al., 2009), and around 50 percent of urban residents had planted or maintained vegetation for the benefit of birds in an American study (Lepczyk et al., 2004). However, differences between the methods in all of these studies make direct comparisons difficult.

With bird feeding and tree planting having been shown to be able to influence the composition of avian communities in urban environments (e.g. Fuller et al., 2008; Loss et al., 2009), understanding which residents are participating in these activities is of interest.

Residents who fed birds and planted trees were both older and had lived for a longer length of time at their current address than those who did not. Women were also more likely than men to have planted trees to attract birds. These results support the findings of Lepczyk et al. (2004), who also concluded that gender and age are significant predictors of tree planting. However, unlike Lepczyk et al (2004), I found no significant difference between those planting trees and feeding birds in terms of education and income levels. Similarly to ecological knowledge, the amount of green space on the property was positively correlated with tree planting and bird feeding.

I ran a logistic regression model to examine the characteristics of those participating in activities encouraging birdlife to their garden. My results showed that the level of greenspace on the property was a positive predictor for residents' bird feeding behaviour. This result supports the literature, that key variables in the distribution of bird feeding are access to a garden and the garden size due to logistical or infrastructural barriers presented by a lack of outdoor space in which to attract wildlife (e.g. Gaston et al., 2007). I also found that accessibility to greenspace was a predictor for feeding. The significance of greenspace accessibility may be that this is impacting on knowledge, awareness, and attitudes, which in turn may influence behaviour (Kals et al., 1999). The analysis showed that knowledge of neighbourhood birds was indeed a positive predictor for bird feeding. This is not unexpected as models show knowledge can be a key pre-requisite of behaviour (e.g. Hungerford and Volk, 
1990; Ajzen, 1991). However, the other two measures of knowledge that I examined were not predictors of bird feeding. Another factor that may have contributed to the low predictive power of my models is the debate over the value of wildlife feeding. For example, studies in Australia (e.g. Ishigame and Baxter, 2007) have shown that the most common reason for feeding birds was concern for the birds' welfare, indicating that non-feeders are not necessarily detached from wildlife and are instead actively not participating. In New Zealand, the Department of Conservation recommends planting native trees and plants as a means of encouraging bird life to residents' gardens, and does not specifically support providing supplementary food (DOC, 2009). Therefore, this may help account for the lack of association between the other two measures of knowledge and feeding.

Higher neighbourhood bird richness was negatively correlated with bird feeding. Other studies have shown that bird feeding declines across different neighbourhoods as socioeconomic deprivation increases, but increases with avian species richness and abundance (Parsons et al., 2006; Fuller et al., 2008). Further, providing food for birds increases the diversity and number of individuals visiting an individual garden and can impact the status of urban bird populations (Daniels and Kirkpatrick, 2006; Parsons et al., 2006; Fuller et al., 2008). A possible explanation for my finding could be that a significant reason for feeding might be to encourage birds to the property (Ishigame and Baxter, 2007), and so if bird diversity is already high, there is a reduced need to provide supplementary food to encourage birdlife. With debate concerning whether providing supplementary food is ecologically beneficial to birds or not, residents in areas with high bird populations might refrain from feeding. Additionally, I only examined bird species richness, and it may have been that while bird richness was low in some areas, the bird abundance was high.

Alternatively to bird feeding, another way to encourage birds to residents' properties which is actively encouraged, is tree planting (DOC, 2009). I found women, older residents, those with higher educational qualifications, and those having a higher knowledge about neighbourhood birds were more likely to plant trees to attract birds. There have been mixed 
reviews in the literature investigating the participation of householders in wildlife-encouraging activities. Some studies showed an individual's socio-economic status had little effect on this behaviour (Gaston et al., 2007), while other studies showed that there are some socio-economic variables that can have influence (such as age and gender), while others (such as education) do not (Lepczyk et al., 2004). In my study, it is possible that a higher level of education represented a higher awareness of the benefits tree planting could have on bird abundance and diversity, and reflected in higher rates of tree planting. Respondents with a greater knowledge about the neighbourhood bird species (both native and exotic) were also more likely to plant trees. A possible reason given is that respondents with a greater knowledge of bird species may have a greater appreciation for birds, and may seek to encourage more species to the property through tree planting. Planting vegetation can influence and increase bird richness and abundance, both native and exotic, depending on the tree species planted (Heezik et al., 2008). However, it should be noted that I do not seek to prove causation. Studies suggest that activity which reduces an individual's perceived separation between self and nature will then lend itself to an increase in the individual's biospheric concern (Schultz 2000), biospheric environmental concerns being based on a value for all living things. Thus, any environmental education activity such as a trip to the park, or a walk through a green space, should lead to the individual having a feeling of greater inclusiveness and interconnectedness (Shultz 2000), and so encourage pro-environmental behaviour.

Similarly to the ecological knowledge analysis, little of the variance in bird feeding (9.9 percent) could be explained by the independent variables I examined. The model had more success in predicting tree planting behaviour ( 25 percent of the variance). This reflects the complexity in predicting behaviour. Knowledge and attitudes may be prerequisites for behaviour (e.g. Hungerford and Volk, 1990; Stern, 2000), but the predictors for action are hard to identify.

With the drivers of pro-environmental behaviour being so complex, there are likely to be many variables that I did not examine which may correspond to some of the unexplained 
variance. Kollmuss and Agyeman (2002) identify demographic factors, external factors (e.g. institutional, economic, social, and cultural) and internal factors (e.g. motivation, proenvironmental knowledge, awareness, values, attitudes, emotion, responsibilities and priorities) as all having influence on pro-environmental behaviour. Residents that feed birds are likely to be doing so for a variety of reasons, such as the pleasure it gives the participants, the link with the natural world, or for environmental reasons (Rollinson et al., 2003; Miller, 2005; Ishigame and Baxter, 2007; Jones and Reynolds, 2008).

So while demographic factors and ecological knowledge can influence behaviour, there are many other factors also having influence. However, I have identified certain factors which have been shown to be predictors of ecological knowledge and behaviour, and focused urban planning could help enhance levels of knowledge and behaviour.

\subsection{Urban planning considerations}

The key variables that predict ecological knowledge and behaviour were frequency of visits to greenspaces, the amount of greenspace on the property, and the level of education. From an urban planning perspective, the focus should be on increasing visits to greenspaces, given their importance in ecological knowledge levels. A variety of options are available to increase interactions between people and the natural world, including the creation of more green areas and corridors, improving access (Neuvonen, 2007), and encouraging people to participate in activities such as bird feeding (Davies et. al., 2009). However, accessibility does not appear to be limiting residents' visits to greenspaces in Wellington, with most residents perceiving they have easy access to greenspaces. Therefore, people seem to be choosing to visit or not visit depending on other variables. 
The type of greenspace available may be an important variable in encouraging residents to visit. Greenspaces that have multiple uses (e.g. for walkers, sports participants, picnickers) tend to be visited by residents more frequently (Giles-Corti et al., 2005). A need also exists for a variety of greenspaces at different functional levels, ranging from small parks that residents may connect with strongly on a daily basis, through to large greenspaces that may be visited less frequently (van Herzele and Wiedemann, 2003). An issue in urban planning is that authorities tend to accord higher 'green values' to conventional parks and playing fields, rather than to high-biomass sites which would not have the status of formal open spaces (e.g., derelict and temporarily vacant sites; Nicol and Blake, 2000). People visit parks for a variety of reasons, but the main reasons often given for visiting natural areas are to rest, relax, and to be close to nature (Chiesura, 2004). Reducing the traffic or traffic speeds (and noise) on streets surrounding greenspaces may make the space more attractive to visit (Gidlof-Gunnarsson and Ohrstrom, 2007), and in turn increase the frequency of visits by residents.

Increasing the attractiveness of greenspaces can extend to the area surrounding the greenspace as well. While residents may have easily accessible greenspaces nearby, they may not be pleasant to access. The presence of large, attractive greenspaces nearby has been shown to increase walking amongst residents (Giles-Corti et al., 2005). Additionally, making the streetscape more attractive for walking may encourage people to walk to a nearby park. In the Netherlands, for example, residents who commuted by foot or cycle tended to participate in other outdoor activities more frequently (Neuvonen et al., 2007). The streetscape can be enhanced for walking by reducing or slowing down traffic, providing pathways offset from the road, and by the planting of streetscape vegetation. The planting of streetscape vegetation is can also influence avian diversity (e.g. White et al., 2005). Planting native vegetation within streetscapes can promote native species by providing advantageous habitat and enhancing remnant vegetation in parks by diffusing the park edge (White et al., 2005). The planting of 
native trees rather than exotics on streets would also be an effective way urban planners could enhance the quality of the urban habitat.

The quality of natural interaction urban residents experience needs consideration, with this study finding higher levels of exotic species knowledge amongst urban residents. Although greenspace interactions were positive predictors for native species knowledge, knowledge of native species knowledge was still relatively low. Exotic species knowledge was higher across all sections of the population. The higher proportion of exotic bird species residents were able to name, and identify, may have worrying implications for native conservation measures. If urban residents are disconnected and unfamiliar with native flora and fauna, then it may be difficult to persuade them to promote native species conservation (McKinney, 2002; Turner et al., 2004, Miller, 2005). This could result in disaffection and apathy, which in turn could produce even more degenerative environments, fuelling a negative feedback cycle (Miller, 2005).

To help increase residents' knowledge of native species, urban measures to encourage native species should be promoted. There is a large potential for native tree planting in the Wellington region. A recent study of residents in the Greater Wellington region found that over 50 percent of residents were willing to volunteer their own labour to plant native trees and shrubs on public lands (Kaval et al., 2007). However, only a small proportion of these people are active participants in the number of organisations that already organise such schemes (Kaval et al., 2007). The challenge then is to connect the large number of people who say they are willing to plant trees with organisations that actually plant. Well-publicised council-led schemes could potentially reach more people. Additionally, a survey found that Wellington urban residents were willing-to-pay an average of $\$ 189$ /annually for Biodiversity Enhancement Schemes, on public and private lands (Kaval et al., 2007). There is a possibility then of funding 
these schemes through annual rates. The Wellington City Council already has a scheme to give out free plants for residents to plant on reserves and road-reserves once a year (Wellington City Council, 2009), but this scheme could be extended to include plants for private gardens.

As well as public green spaces, private gardens were also a significant factor in predicting higher levels of ecological knowledge and behaviour. Private greenspaces may be a major factor in the effect of residential location on knowledge, as location was no longer a predictor for knowledge after controlling for the amount of greenspace on the property. Greenspace was also a key predictor of knowledge. Private domestic gardens often constitute the single largest green space in many cities (van Heezik et al., 2008), but garden sizes are currently declining in New Zealand and elsewhere (Liu et al., 2003). Cities around the world are implementing 'compaction' as a strategy, to both mitigate urban sprawl and satisfy development needs. Compaction advocates new residential development should take place on land within the city limits, but unfortunately this is often at the expense of green spaces (Yokohari et. al., 2000). There are methods to have urban greenspaces with compaction however, such as the development of rooftop gardens (Takahashi, 2008).

Gardens vary greatly in terms of the vegetation and composition (Garston et al., 2005; Mathieu et al., 2007). From an urban planning perspective, one measure to enhance urban ecosystems, and encourage native fauna, could be to encourage native tree plantings in private gardens. I found 36\% of respondents had planted trees for encouraging birdlife in Wellington, and a further 22 percent would be willing if they had the space to do so. Urban areas can support high levels of species diversity (Head and Muir, 2006), so the potential is there for urban residents to interact with nature in a meaningful way with thoughtful urban planning, with positive benefits for knowledge and conservation. A focus on encouraging private greenspace management would be a way to immediately impact interaction rates. Planting 
could be encouraged by providing cheap native trees, subsidised by the council, for planting in gardens.

Residents can also interact with nature through bird feeding, and my study shows bird feeding is prevalent across Wellington. This can have consequences for conservation, as the provision of supplementary food for birds by urban residents can also impact urban bird populations (Fuller et al., 2008). Feeding birds in urban areas is often discouraged because it may attract exotic 'pest' birds that can displace native species (Parsons et al., 2006). However, with urban residents becoming more disconnected with nature (e.g. Miller, 2005), perhaps certain types of feeding can be encouraged that focus on native species. Or perhaps, as Dunn et al. (2006) propose, we may need to reconsider how we portray non-native species. If bird feeding helps connect residents with the natural world, it may have positive benefits for interest and knowledge levels in ecological issues, which can in turn help provide support for conservation measures outside urban areas. Given the high percentage of Wellington residents feeding birds, more research is needed on the ecological impacts of bird feeding and on mechanisms which can ensure any impacts are positive.

\subsection{Research Suggestions}

There is a need for more research on urban social ecology, with few studies examining urban ecological knowledge. A comparative study with another New Zealand city comprising lower levels of urban greenspace than Wellington would be useful. Longitudinal studies would also provide more detailed information on predictors of ecological knowledge, and understanding whether knowledge is being lost through generational change. 
An additional variable that could be added to the models I used would be investigating the possible effect that residents' mode of transport has on ecological knowledge levels. Residents' who commute around town by walking or cycling have been shown to more frequently visit greenspaces in a study from the Netherlands (Neuvonen et al., 2007). Walking itself may also lead to more interaction with the natural world, due to the abundance of vegetation often growing alongside roads. Another variable worth adding to the models would be the location of an individuals' childhood residence. Nature interactions while growing up have been shown to have a large influence on environmental behaviours later in life (e.g. Chawla, 1999).

An interesting area for study would be to investigate the effect that 'spontaneous' urban nature has upon urban residents, such as overgrown vegetation in abandoned lots, or by the roadside, areas that councils would normally deem 'waste land'. Comparing the effect of the spontaneous vegetation against the other two types of vegetation would also be of interest. Urban green spaces in the forms of parks and reserves are often landscaped and lacking the 'wild' aspects of the natural world that urban residents may well be becoming neglected from, and the effects on knowledge and attitudes towards the natural world upon interaction with these different 'types' of nature would be an interesting study.

Future studies investigating how native and exotic knowledge is obtained is important, given the lack of native knowledge exhibited in this study. As well, research needs to be done investigating the links between knowledge and behaviour, looking at why some residents participate in pro-environmental behaviour while others do not. For example, investigating the motivations and barriers towards tree planting would be useful. 


\subsection{Conclusion - Urbanisation, Ecological Knowledge, and Behaviour}

Despite substantial biodiversity overall in cities worldwide, most urban residents are concentrated in neighbourhoods of reduced biodiversity, and live in biological poverty (Turner et al., 2004). Native species show an often severe decline with increasing urbanisation, with natives replaced with non-native species, and urban environments often have more in common with other cities than with adjacent natural ecosystems (McKinney, 2002). This leads to the 'extinction of experience', a cycle of impoverishment initiated by the homogenisation and reduction of local flora and fauna, which is then followed by disaffection and apathy (Miller, 2005). This in turn leads to even more impoverished environments and isolation from nature. Knowledge is positively associated with attitude towards the importance of ecological knowledge (Pilgrim, 2006), so knowledge loss leads to a greater disconnection from nature, and a reduced time spent outdoors, fuelling a disconnection cycle. With knowledge being a prerequisite for pro-environmental behaviour (REF), there is the potential for further negative ecological effects.

This study found that time spent outdoors in green spaces, parks, and reserves had a positive effect on ecological knowledge levels, providing support that experiences with the natural world, and urban green spaces, are important. Higher frequencies of visiting parks and reserves locally and regionally were both correlated with higher knowledge scores for individuals. The residential location was also an important variable, with knowledge decreasing with increasing urbanisation. The key change is the decrease in amount of garden space and the quality of greenspace (as measured by species richness). Education was generally positively 
correlated with knowledge, except on identifying common neighbourhood birds, suggesting nature experience is a more important variable. The effect of residential location on knowledge levels was linked in part to the level of greenspace on the property. Property greenspace levels were strongly positively linked with ecological knowledge and behaviour.

Responsible behaviour toward the environment is closely related to people's direct experiences with nature, stressing their importance (Chawla, 2007). This study also found that the frequency of visits to local and regional parks was a positive predictor of tree planting and bird feeding. A small minority of those feeding birds were targeting native species (ten percent), but with mixed evidence as to the ecological benefits of bird feeding this should not necessarily be seen as a lack of concern or preference for exotic species. The abundance of bird feeders shows the potential to influence urban flora however. Of concern was the lack of knowledge concerning native bird species, with exotic species more widely known and identifiable by residents. With exotic bird richness and abundance increasing across an increasing urbanisation gradient, this may reflect the urban nature residents are exposed too, and gives support to measures aimed at increasing native species richness and abundance in urban areas.

These findings are important and stress the importance that greenspaces can have on ecological knowledge and behaviour. Efforts need to be focused on increasing residents' frequency of visits to greenspaces, and providing measures to help encourage activities that enhance the urban environment, such as tree planting. 


\section{References}

Adams, L. W. (2005). Urban wildlife ecology and conservation: A brief history of the discipline. Urban Ecosystems, 8, 149-156.

Ajzen, I. (1991). The Theory of Planned Behaviour. Organizational Behaviour and Human Decision Processes 50, 179-211.

Atkinson, I. A. E., and Cameron, E. K., 1993. Human influence on the terrestrial biota and biotic communities of New Zealand. Trends in Ecology and Evolution 8(12), 447-451.

Balmford, A., Clegg, L., Coulson, T., and Taylor, J. (2002). Why conservationists should heed Pokemon. Science, 295, 2367.

Beedell, J. D. C., and Rehman, T. (1999). Explaining farmers' conservation behaviour: Why do farmers behave the way they do? Journal of Environmental Management, 57, 165-176.

van den Berg, A. E., Hartig, T., and Staats, H. (2007). Preference for nature in urbanised societies: Stress, restoration, and the pusuit of sustainability. Journal of Social Sciences, 63(1), 79-96.

Berling-Wolff, S., and Wu, J. (2004). Modelling urban landscape dynamics: A case study in Phoenix, USA. Urban Ecosystems, 7, 215-240.

Berkes, F., Colding, J., and Folke, C. (2000). Rediscovery of traditional ecological knowledge as adaptive management. Ecological Applications 10(5), 1251-1262.

Bernard, H. R. 2002. Research methods in anthropology: Qualitative and quantitative approaches. Alta Mira Press, Walnut Creek, CA, USA.

Blair, R. B. (1996). Land Use and Avian Species Diversity Along an Urban Gradient. Ecological Applications, 6(2), 506-519.

Blake, J. (1999). Overcoming the 'value-action gap' in environmental policy: tensions between national policy and local experience. Local Environment 4(3), 257-278.

Bonaiuto, M., Aiello, A., Perugini, M., Bonnes, M., and Ercolani, A. (1999). Multidimensional perception of residential environment quality and neighbourhood attachment in the urban environment. Journal of Environmental Psychology, 19, 331-352.

Bonnes, M., Uzzell, D., Carrus, G., and Kelay, T. (2007). Inhabitants' and Experts' Assessments of Environmental Quality for Urban Sustainability. Journal of Social Issues, 63(1), 59-78. 
Borgstrom, S. T., Elmqvist, T., Angelstam, P., and Alfsen-Norodom, C. (2006). Scale Mismatches in Management of Urban Landscapes. Ecology and Society, 11(2), 16.

Brennan, M., and Hoek, J. (1992). The Behaviour of Respondents, Nonrespondents, and Refusers Across Mail Surveys. The Public Opinion Quarterly, 56(4), 530-535.

Brooks, J. J., Warren, R. J., Nelms, M. G., and Tarrant, M. A. (1999). Visitor attitudes toward and knowledge of restored bobcats on Cumberland Island National Seashore, Georgia. Wildlife Society Bulletin, 27(4), 1089-1097.

Burgess, J., Harrison, C. M., and Limb, M. (1988). People, parks and the urban green: a study of popular meanings and values for open spaces in the city. Urban Studies, 25(6), 455-473.

Cadenasso, M. L., and Pickett, T. A. (2008). Urban principles for ecological landscape design and management: Scientific fundamentals. Cities and the Environment, 1(2), article 4, 16pp.

Cannon, A. (1999). The significance of private gardens for bird conservation. Bird Conservation International, 9, 287-297.

Casperson, O. H., Konijnendijk, C. C., and Olafsson, A. S. (2006). Green space planning and land use: An assessment of urban regional and green structure planning in Greater Copenhagen. Danish Journal of Geography, 106(2), 7-20.

Chace, J. F., and Walsh, J. J. (2006). Urban effects on native avifauna: a review. Landscape and Urban Planning, 74, 46-69.

Chamberlain, D. E., Vickery, J. A., Glue, D. E., Robinson, R. A., Conway, G. J., Woodburn, R. J. W., and Cannon, A. R. (2005). Annual and seasonal trends in the use of garden feeders by birds in winter. Ibis, 147, 563-575.

Chawla, L. (1998). Significant life experiences revisited: a review of research on sources of environmental sensitivity. The Journal of Environmental Education 29, 11-21.

Chawla, L. (1999). Life paths into effective environmental action. The Journal of Environmental Education 31, 15-26.

Chawla, L., and Cushing, D. F. (2007). Education for strategic environmental behaviour. Environmental Education Research, 13(4), 437-452.

Chiesura, A. (2004). The role of urban parks for the sustainable city. Landscape and Urban Planning, $68,129-138$.

Cincotta, R. P., Wisnewski, J., and Engelman, R. (2000). Human population in the biodiversity hotspots. Nature 404, 990-992.

Collins, J. P., Kinzig, A., Grimm, N. B., and Fagan, W. F. (2000). A new urban ecology. American Scientist, 88(5), 416-426.

Connor, E. F., Hafernik, J., Levy, J., Moore, V. L., and Rickman, J., K. (2002). Insect conservation in an urban biodiversity hotspot: The San Francisco Bay Area. Journal of Insect Conservation, 6, 247-259.

Cordell, H. K., Betz, C. J., and Green, G. T. (2008). Nature-based Outdoor Recreation Trends and Wilderness. International Journal of Wilderness, 14(2), 7-13. 
Cranz, G., and Boland, M. (2004). Defining the Sustainable Park: A Fifth Model for Urban Parks. Landscape Journal, 23(2), 102-120.

Daniels, G. D., and Kirkpatrick, J.B. (2006). Does variation in garden characteristics influence the conservation of birds in suburbia? Biological Conservation, 133, 326-335.

Daniere, A. G., and Takahashi, L. M. (1999). Environmental Behaviour in Bangkok, Thailand: A Portrait of Attitudes, Values, and Behaviour. Economic Development and Cultural Change, 47, 525-557.

Davies, Z. G., Fuller, R. A., Loram, A., Irvine, K. N., Sims, V., and Gaston, K. J. (2009). A national scale inventory of resource provision for biodiversity within domestic gardens. Biological Conservation, 142, 761-771.

Day, T. D. (1995). Bird species composition and abundance in relation to native plants in urban gardens, Hamilton, New Zealand. Notornis, 42, 175-186.

DeLeeuw, E. D. (1992). Data Quality in Mail, Telephone and Face-to-Face Surveys. T.T. Publikaties, Amsterdam, pp177.

Dillman, D. A. (2000). Mail and internet surveys: the tailored design method $2^{\text {nd }}$ ed. Brisbane: John Wiley \& Sons Inc.

DOC (2008). Wellingtonians meet their wild locals. Media release, Department of Conservation website, accessed 10/03/09 from: http://www.doc.govt.nz/about-doc/news/mediareleases/2008/wellingtonians-meet-their-wild-locals/

DOC (2009). Attracting birds. Department of Conservation website, accessed 15/07/09 from: http://www.doc.govt.nz/conservation/native-animals/birds/attracting-birds-to-yourgarden/attracting-birds/

DEFRA (2002). Working with the grain of nature. DEFRA Publications, London in Fuller, R. A., Warren, P. H., Armsworth, P. R., Barbosa, O., and Gaston, K. J. (2008). Garden bird feeding predicts the structure of urban avian assemblages. Diversity and Distributions, 14, 131-137.

Di Giulio, M., Holderegger, R., and Tobias, S. (2009). Effects of habitat and landscape fragmentation on humans and biodiversity in densely populated landscapes. Journal of Environmental Management, 90, 2959-2968.

Dunlap, R. E., Van Liere, K. D., Mertig, A. G., and Jones, R. E. (2000). Measuring Endorsement of the New Ecological Paradigm: A revised NEP Scale. Journal of Social Issues, 56(3), 425-442.

Dunn, R. D., Gavin, M. C., Sanchez, M. C., and Solomon, J. N. (2006). The Pigeon Paradox: Dependence of Global Conservation on Urban Nature. Conservation Biology, 20(6), 18141816.

Eisler, A. D., Eisler, H., and Yoshida, M. (2003). Perception of human ecology: cross-cultural and gender comparisons. Journal of Environmental Psychology, 23(1), 89-101.

Ernstson, H., Sörlin, S., and Elmqvist, T. (2008). Social movements and ecosystem services-the role of social network structure in protecting and managing urban green areas in Stockholm. Ecology and Society, 13(2), 39. 
Field, A. (2005). Discovering statistics using SPSS. Second Edition. London: SAGE Publications Ltd.

Fransson, N., and Gorling, T. (1999). Environmental Concern: Conceptual Definitions, Measurement Methods, and Research Findings. Journal of Environmental Psychology, 19, 369-382.

Freeman, C., and Buck, O. (2003). Development of an urban methodology for urban areas in New Zealand. Landscape and Urban Planning, 63(3), 161-173.

Frumkin, H. (2001). Beyond Toxicity: Human health and the natural environment. American Journal of Preventative Medicine, 20(3), 234-240.

Fuller, R. A., Warren, P. H., Armsworth, P. R., Barbosa, O., and Gaston, K. J. (2008). Garden bird feeding predicts the structure of urban avian assemblages. Diversity and Distributions, 14, 131137.

Gaston, K. J., Warren, P. H., Thompson, K., and Smith, R. M. (2005). Urban domestic gardens (IV): the extent of the resource and its associated features. Biodiversity Conservation, 14(14), 33273349 .

Gaston, K. J., Fuller, R. A., Loram, A., MacDonald, C., Power, S., and Dempsey, N. (2007). Urban domestic gardens (XI): variation in urban wildlife gardening in the United Kingdom. Biodiversity Conservation, 16, 3227-3238.

Gavin, M. C., and Anderson, G. J. (2007). Socioeconomic predictors of forest use values in the Peruvian Amazon: A potential tool for biodiversity conservation. Ecological Economics, 60, 752-762.

Gidlof-Gunnarsson, A., and Ohrstrom, E. (2007). Noise and well-being in urban residential environments: The potential role of perceived availability to nearby green areas. Landscape and Urban Planning, 83, 115-126.

Gilchrist, G., Mallory, M., and Merkel, F. (2005). Can local ecological knowledge contribute to wildlife management? Case studies of migratory birds. Ecology and Society, 10(1), 20.

Giles-Corti, B., Broomhall, M. H., Knuiman, M., Collins, C., Douglas, K., Ng, K., Lange, A., and Donovan, R. J. (2005). Increasing walking: How important is distance to, attractiveness, and size of public open space? American Journal of Preventive Medicine, 28(2S2), 169-176.

Giles-Corti, B., and Donovan, R. J. (2002). The relative influence of individual, social and physical environment determinants of physical activity. Social Science and Medicine, 54, 1793-1812.

Godoy, R., Brokaw, N., Wilkie, D., Colon, D., Palermo, A., Lye, S., and Wei, S. (1998). Of Trade and Cognition: Markets and the Loss of Folk Knowledge among the Tawahka Indians of the Honduran Rain Forest. Journal of Anthropological Research, 54(2), 219-234.

Grahn, P., and Stigsdotter, U. A. (2003). Landscape planning and stress. Urban Forestry and Urban Greening, 2, 1-18.

Grimm, N. B., Grove, J. M., Pickett, S. T., and Redman, C. L. (2000). Integrated approaches to longterm studies of urban ecological systems. Bioscience, 50(7), 571-585.

Grimm, N. B., and Redman, C. L. (2004). Approaches to the study of urban ecosystems: The case of Central Arizona-Phoenix. Urban ecosystems, 7, 199-213.

Grimm, N. B., Stanley, H. F., Golubiewski, N. E., Redman, C. L., Wu, J., Bai, X., and Briggs, J. M. 
(2008). Global change and the Ecology of Cities. Science, 319, 756-760.

Grose, M. J. (2009). Changing relationships in public open space and private open space in suburbs in south-western Australia. Landscape and Urban Planning, 92, 53-63.

Grove, J. M., and Burch, W. R. (1997). A social ecology approach and applications of urban ecosystem and landscape analyses: A case study of Baltimore, Maryland. Urban Ecosystems, 1, 259-275.

Guest, G. (2002). Market integration and the distribution of ecological knowledge within an Ecuadorian Fishing community. Journal of Ecological Anthropology 6, 38-49.

Gupte, M. (2002). Gender, Feminist Consciousness, and the Environment. Women and Politics, 24(1), 47-62.

Head, L., and Muir, P. (2006). Suburban life and the boundaries of nature: resilience and rupture in Australian backyard gardens. Transactions of the Institute of British Geographers, 31(4), 505524.

Hillsdon, M., Panter, J., Foster, C., and Jones, A. (2006). The relationship between access and quality of urban green space with population physical activity. Public Health, 120, 1127-1132.

Hope, D., Gries, C., Zhu, W., Fagan, W. F., Redman, C. L., Grimm, N. B., Nelson, A. L., Martin, C., and Kinzig, A. (2003). Socioeconomics Drive Urban Plant Diversity. Proceedings of the National Academy of Sciences of the United States of America, 100(15), 8788-8792.

Hostetler, M. (1999). Scale, birds, and human decisions: a potential for integrative research in urban ecosystems. Landscape and Urban Planning, 45, 15-19.

Hostetler, M., and Knowles-Yanez, K. (2003). Land use, scale, and bird distributions in the Phoenix metropolitan area. Landscape and Urban Planning, 62, 55-68.

Hox, J. J., and DeLeeuw, E. D. (1994). A comparison of non-response in mail, telephone, and face-toface surveys: Applying multilevel modelling to meta-analysis. Quality and Quantity, 28(4), 329-344.

Hungerford, H. and Volk, T. (1990). Changing learner behaviour through environmental education, Journal of Environmental Education, 21(3), 8-21.

Ishigame, G., and Baxter, G. (2007). Practice and attitudes of suburban and rural dwellers to feeding wild birds in Southeast Queensland, Australia. Ornithological Science, 6, 11-19.

Iverson, L. R., and Cook, E. A. (2000). Urban forest cover of the Chicago region and its relation to household density and income. Urban Ecosystems, 4, 105-124.

Jim, C. J. (2004). Green-space preservation and allocation for sustainable greening of compact cities. Cities, 21(4), 311-320.

Johnson, J. C., and Griffith, D. C. (1996). Pollution, food safety, and the distribution of knowledge. Human Ecology 24(1), 87-107.

Jones, D. N., and Reynolds, S. J. (2008). Feeding birds in our towns and cities: a global research opportunity. Journal of Avian Biology 39(3), 265-271.

Kals, E., Schumacher, D., and Montada, L. (1999). Emotional affinity toward nature as a motivational 
basis to protect nature. Environment and Behaviour, 31, 178-202.

Kanuk, L., and Berenson, C. (1975). Mail Surveys and Response Rates: A Literature Review. Journal of Marketing Research, 12(4), 440-453.

Kaplan, R. (2001). The nature of the view from home: Psychological Benefits. Environment and Behaviour, 33(4), 507-542.

Kaplan, S. (2000). Human nature and environmentally responsible behaviour. Journal of Social Issues 56(3), 491-508.

Kareiva, P. (2008). Ominous trends in nature recreation. PNAS, 105(8), 2757-2758.

Kaval, P., Yao, R., Parminter, T. (2007). The value of native biodiversity enhancement in New Zealand: a case study of the Greater Wellington Area. Department of Economics Working Paper, University of Waikato, Hamilton, New Zeland

Kellert, S. R. (1976). Perceptions of animals in American society. Transactions of the North American Wildlife and Natural Resources Conference, 41, 533-545

Kellert, S. R., and Berry, J. K. (1987). Attitudes, Knowledge, and Behaviours toward Wildlife as Affected by Gender. Wildlife Society Bulletin, 15(3), 363-371.

Kim, J., and Kaplan, R. (2004). Physical and psychological factors in sense of community. New Urbanist Kentlands and Nearby Orchard Village. Environmental Behaviour, 36, 313-340.

Kollmuss, A., and Agyeman, J. (2002). Mind the gap: why do people act environmentally and what are the barriers to pro-environmental behaviour? Environmental Education Research, 8(3), 239260 .

Kuo, F. E., Bacaicoa, M., and Sullivan, W. C. (1998). Transforming inner-city landscapes: trees, sense of safety, and preference. Environment and Behaviour, 30(1), 28-59.

Kyle, G. T., Mowen, A. J., and Tarrant, M. (2004). Linking place preferences with place meaning: An examination of the relationship between place motivation and place attachment. Journal of Environmental Psychology, 24, 439-454.

Lee, M. E., and Miller, R. (2003). Managing Elk in the Wildland-Urban Interface: Attitudes of Flagstaff, Arizona Residents. Wildlife Society Bulletin, 31(1), 185-191.

Lepczyk, C. A., Mertig, A. G., and Liu, J. (2004). Assessing landowner activities related to birds across rural-to-urban landscapes. Environmental Management 33(1), 110-125.

Lindhagen, A., and Hörnsten, L. (2000). Forest recreation in 1977 and 1997 in Sweden: changes in public preferences and behaviour. Forestry 73(2), 143-153.

Liu, J., Daily, G. C., Ehrich, P. R., and Luck, G. W. (2003). Effects of household dynamics on resource consumption and biodiversity. Nature, 421, 530-533.

Loss, S. R., Ruiz, M. O., and Brawn, J. D. (2009). Relationships between avian diversity, neighbourhood age, income, and environmental characteristics of an urban landscape. Biological Conservation 142, 2578-2585. 
Luck, M., and Wu, J. (2002). A gradient analysis of urban landscape pattern: a case study from the Phoenix metropolitan region, Arizona, USA. Landscape Ecology, 17, 327-339.

Maas, J., Verheij, R. A., Groenewegen, P. P., de Vries, S., and Spreeuwenberg, P. (2009). Green space, urbanity, and health: how strong is the relation? Journal of Epidemiol Community Health, 60, 587-592.

Maffi, L. (2001). On Biocultural Diversity: linking language, knowledge, and the environment, Smitsonian Institute, Washington, DC.

Martin, C. A., Warren, P. S., and Kinzig, A. P. (2004). Neighbourhood socioeconomic status is a useful predictor of perennial landscape vegetation in residential neighbourhoods and embedded small parks of Phoenix, AZ. Landscape and Urban Planning 69, 355-368.

Martino, D. (2008). Gender and Urban Perceptions of Nature and Protected Areas in Banados del Este Biosphere Reserve. Environmental management, 41, 654-662.

Marzluff, J. M., and Ewing, K. (2001). Restoration of Fragmented Landscapes for the Conservation of Birds: A General Framework and Specific Recommendations for Urbanizing Landscapes. Restoration Ecology, 9, 280-292.

Mathieu, R., Freeman, C., and Aryal, J. (2007). Mapping private gardens in urban areas using objectorientated techniques and very high-resolution satellite imagery. Landscape and Urban Planning, 81(3), 179-192.

McDaniel, J., and Alley, K. D. (2005). Connecting local environmental knowledge and land use practices: A human ecosystem approach to urbanization in West Georgia. Urban Ecosystems, 8, 23-38.

McDonnell, M. J., and Hahs, A. K. (2008). The use of gradient analysis studies in advancing our understanding of the ecology of urbanizing landscapes: current status and future directions. Landscape Ecology, 23, 1143-1155.

McFarlane, B. L., and Boxall, P. C. (2003). The role of social psychological and social structural variables in environmental activism: an example of the forest sector. Journal of Environmental Psychology, 23, 79-87.

McFarlane, B., and Garland, R. (1994). A Comparison of Mail and Face-to-Face Survey Methods: New Zealand Health Professionals. Marketing Bulletin, 5(4).

McKinney, M. L. (2002). Urbanization, Biodiversity, and Conservation. Bioscience, 52(10), 883-890.

McKinney, M. L. (2006). Urbanization as a major cause of biotic homogenization. Biological Conservation, 127, 247-260.

McKinney, M. L. (2008). Effects of urbanization on species richness: a review of plants and animals. Urban Ecosystems, 11, 161-176.

Meinhold, J. L. and Malkus, A. J. (2005). Adolescent environmental behaviors: can knowledge, attitudes and self-efficacy make a difference? Environment and Behavior, 37(4), 511-532.

Melles, S. J. (2005). Urban Bird Diversity as an Indicator of Human Social Diversity and Economic Inequality in Vancouver, British Columbia. Urban Habitats, 3(1), 25-48.

Melles, S., Glenn, S., and Martin, K. (2003). Urban Bird Diversity and Landscape Complexity: Species- 
environment Associations Along a Multiscale Habitat Gradient. Conservation Ecology, 7(1), 5.

Meyer, W. B., and Turner, B. L. (1992). Human population growth and land-use/cover change. Annual Review of Ecology and Systematics, 23, 39-61.

Millennium Ecosystem Assessment (2005). Millennium ecosystem assessment: biodiversity synthesis. World Resources Institute, Washington, D.C., USA.

Miller, J. R. (2005). Biodiversity conservation and the extinction of experience. TRENDS in Ecology and Evolution, 20(8), 430-434.

Miller, J. R. (2006). Restoration, reconciliation, and reconnecting with nature nearby. Biological Conservation, 127, 356-361.

Miller, J. R., and Hobbs, R. J. (2002). Conservation where people live and work. Conservation Biology 16(2), 330-337.

Mitchell, R., and Popham, F. (2009). Greenspace, urbanity and health: relationships in England. Journal of Epidemiol Community Health, 61, 681-683.

Neuvonen, M., Sievanen, T., Tonnes, S., and Koskela, T. (2007). Access to green areas and the frequency of visits - A case study in Helsinki. Urban Forestry and Urban Greening 6, 235247.

Newhouse, N. (1991). Implications of attitude and behaviour research for environmental conservation. The Journal of Environmental Education, 22(1), 26-32.

Nicol, C., and Blake, R. (2000). Classification and use of open space in the context of increasing urban capacity. Planning Practice and Research, 15(3), 193-210.

Niemela, J. (1999). Ecology and urban planning. Biodiversity and Conservation, 8, 119-131.

Olsson, P., and Folke, C. (2001). Local ecological knowledge and institutional dynamics for ecosystem management: a study of Lake Racken Watershed, Sweden. Ecosystems, 4, 85-104.

Orr, D. W. (2002). Political economy and the ecology of childhood. pp 279-304 in Pilgrim, S., Smith, D., Pretty, J. (2007). A cross-regional assessment of the factors affecting ecoliteracy: implications for policy and practice. Ecological Applications, 17(6), 1742-1751.

Palomino, D., and Carrascal, L. M. (2006). Urban influence on birds at a regional scale: A case study with the avifauna of northern Madrid province. Landscape and Urban Planning 77, 276-290.

Parsons, H., Major, R. E., and French, K. (2006). Species interactions and habitat associations of birds inhabiting urban areas of Sydney, Australia. Australian Ecology, 31, 217-227.

Pauly, D. (1995). Anecdotes and the shifting baseline syndrome of fisheries. Trends in Ecology and Evolution 10, 430.

Pergams, O. R. W., and Zaradic, P. A. (2006). Is love of nature in the US becoming love of electronic media? 16-year downtrend in national park visits explained by watching movies, playing video games, internet use, and oil prices. Journal of Environmental Management, 80, 387-393.

Pergams, O. R. W., and Zaradic, P. A. (2008). Evidence for a fundamental and pervasive shift away from nature-based recreation. PNAS, 105(7), 2295-2300. 
Petty, R. E., and Cacioppo, J. T. (1981). Attitudes and persuasion: Classic and contemporary approaches. Dubuque, IA: Wm. C. Brown in Jacobson, S. K., McDuff, M. D., and Monroe, M. C. (2006). Conservation Education and Outreach Techniques. Oxford University Press, Oxford, pp. 63-84.

Pickett, S. T. A., Burch, W. R., Dalton, S. E., Foresman, T. W., Grove, J. M., and Rowntree, R. (1997). A conceptual framework for the study of human ecosystems in urban areas. Urban ecosystems, $1,185-199$.

Pickett, S. T. A., Cadenasso, M. L., Grove, J. M., Nilon, C. H., Pouyat, R. V., Zipperer, W. C., and Costanza, R. (2001). Urban ecological systems: Linking Terrestrial Ecological, Physical, and Socioeconomic Components of Metropolitan Areas. Annual Review of Ecological Systems 32, 127-157.

Pickett, S. T. A., and Cadenasso, M. L. (2006). Advancing urban ecological studies: Frameworks, concepts, and results from the Baltimore Ecosystem Study. Austral Ecology 31, 114-125.

Pickett, S. T. A., Cadenasso, M. L., Grove, J. M., Groffman, P. M., Band, L. E., Boone, C. G., Burch, W. R., Grimmond, S. B., Hom, J., Jenkins, J. C., Law, N. L., NIlon, C. H., Pouyat, R. V., Szlavecz, K., Warren, P. S., and Wilson, M. A. (2008). Beyond Urban Legends: An Emerging Framework of Urban Ecology, as Illustrated by the Baltimore Ecosystem Study. Bioscience, 58(2), 139-150.

Pilgrim, S., Cullen, L., Smith, D., and Pretty, J. (2008). Ecological Knowledge is Lost in Wealthier Communities and Countries. Environmental Science and Technology, 42(4), 1004-1009.

Pilgrim, S., Smith, D., and Pretty, J. (2007). A cross-regional assessment of the factors affecting ecoliteracy: implications for policy and practice. Ecological Applications, 17(6), 1742-1751.

Pretty, J., Peacock, J., Sellens, M., and Griffin, M. (2005). The mental and physical health outcomes of green exercise. International Journal of Environmental Health Research, 15, 319-337.

Pyle, R. M. (2003). Nature matrix: reconnecting people and nature. Oryx, 37(2), 206-214.

Quilan, M. B., and Quilan, R. J. (2007). Modernization and medicinal plant knowledge in a Caribbean horticultural village. Medicinal Anthropology Quarterly, 21(2), 169-192.

Redford, K. H., and Sanderson, S. E. (2000). Extracting Humans from Nature. Conservation Biology, 14(5), 1362-1364.

Redman, C. L., Grove, J. M., and Kuby, L. H. (2004). Integrating Social Science into the Long-Term Ecological Research (LTER) Network: Social Dimensions of Ecological Change and Ecological Dimensions of Social Change. Ecosystems, 7, 161-171.

Reyes-Garcia, V., Vadez, V., Byron, E., Apaza, L., Leonard, W. R., Perez, E., and Wilkie, D. (2005). Market Economy and the Loss of Folk Knowledge of Plant Uses: Estimates from the Tsimane' of the Bolivian Amazon. Current Anthropology, 46(4), 651-656.

Rickman, J. K., and Connor, E. F. (2003). The effect of urbanization on the quality of remnant habitats for leaf-mining Lepidoptera on Quercus agrifolia. Ecography, 26, 777-787.

Roach, W. J., Heffernan, J. B., Grimm, N. B., Arrowsmith, J. R., and Eis, C. (2008). Unintended consequences of urbanization for aquatic ecosystems: A case study. Bioscience, 58(8), 715-727. 
Rogan, R., O'Connor, M., and Horwitz, P. (2005). Nowhere to hide: Awareness and perceptions of environmental change, and their influence on relationships with place. Journal of Environmental Psychology, 25, 147-158.

Rollinson, D. J., O'Leary, R., and Jones, D. N. (2003). The practice of wildlife feeding in suburban Brisbane. Corella 27, 52-59.

Rudd, H., Vala, J., and Schaefer, V. (2002). Importance of backyard habitat in a comprehensive biodiversity conservation strategy: A connectivity analysis of urban green spaces. Restoration Ecology, 10(2), 368-375.

Sanderson, S. (2002). The future of conservation. Foreign Affairs, 81, 162-173.

Sandstrom, U. G., Angelstam, P., and Khakee, A. (2006a). Urban comprehensive planning - identifying barriers for the maintenance of functional habitat networks. Landscape and Urban Planning, $75,43-57$.

Sandstrom, U. G., Angelstam, P., Mikusinski, G. (2006b). Ecological diversity of birds in relation to the structure of urban green space. Landscape and Urban Planning, 77, 39-53.

Savard, J-P. L., Clergeau, P., and Mennechez, G. (2000). Biodiversity concepts and urban ecosystems. Landscape and Urban Planning, 48, 131-142.

Schneider, I. E., Salk, R. (2002). Information needs and experience preferences of birders and watchable wildlife participants. Staff Paper Series 165, Department of Forest Resources. College of Natural Resources, University of Minnesota.

Schultz, P. W. (2000). Empathizing With Nature: The Effects of Perspective Taking on Concern for Environmental Issues. Journal of Social Sciences, 56(3), 391-406.

Schultz, P. W., Gouvela, V. V., Cameron, L. D., Tankha, G., Schmuck, P., and Franeck. M. (2005). Values and their Relationship to Environmental Concern and Conservation Behaviour. Journal of Cross-Cultural Psychology, 36(4), 457-475.

Schwartz, M. W., Jurjavcic, N. L., and O'Brien, J. M. (2002). Conservation's disenfranchised Urban Poor. Bioscience 52(7), 601-606.

Shea, K., Chesson, P. (2002). Community ecology theory as a framework for biological invasions. Trends in Ecology and Evolution, 17, 170-176.

Shochat, E., Warren, P. S., Faeth, S. H., McIntyre, N. E., and Hope, D. (2006). From patterns to emerging processes in mechanistic urban ecology. Trends in Ecology and Evolution, 21(4), $186-191$.

Statistics New Zealand (2005). New Zealand rural / urban profile: Historical context. Statistics New Zealand (Web Page). Accessed July 2008 from http://www.stats.govt.nz/publications/businessperformanceenergyandagriculture/urban-ruralprofile/historical-context.aspx

Statistics New Zealand (2008). Quickstats about Wellington City. Statistics New Zealand (Web Page). Accessed July 2008 from http://www.stats.govt.nz/Census/2006CensusHomePage/QuickStats/ AboutAPlace/SnapShot.aspx $?$ id=2000047\&type=ta\&ParentID=1000009

Stenhouse, R. N. (2004). Fragmentation and internal disturbance of native vegetation reserves in the 
Perth metropolitan area, Western Australia. Landscape and Urban Planning, 68, 389-401.

Stern, P. (2000).Toward a coherent theory of environmentally significant behaviour. Journal of Social Issues, 56(3), 407-424.

Tajima, K., 2003. New estimates of the demand for urban green space: implications for valuing the environmental benefits of Boston's Big Dig project. Journal of Urban Affairs 25 (5), 461-655.

Takahashi, K. (2008). Greenspace Depletion in Tokyo, Japan. Unpublished Masters thesis, College of Arts and Science, Ohio University, USA.

Tarrant, M. A., Bright, A. D., and Cordell, K. H. (1997). Attitudes Toward Wildlife Species Protection: Assessing Moderating and Mediating Effects in the Value-Attitude Relationship. Human Dimensions of Wildlife, 2(2), 1-20.

Turner, W. R., Nakamura, T., and Dinetti, M. (2004). Global Urbanization and the Separation of Humans from Nature. Bioscience, 54(6), 585-590.

Turpie, J., K. (2003). The existence value of biodiversity in South Africa: how interest, experience, knowledge, income and perceived level of threat influence local willingness to pay. Ecological Economics, 46(2), 199-216.

Tzoulas, K., Korpela, K., Venn, S., Yli-Pelkonen, V., Kazmierczak, A., Niemela, J., and James, P. (2007). Promoting ecosystem and human health in urban areas using Green Infrastructure: A literature review. Landscape and Urban Planning, 81, 167-178.

United Nations (2004). World Urbanisation prospects: The 2004 revision. Department of economic and Social Affairs, Population Division, 2004. (Web Page). Accessed August 2008 from http://www.un.org/esa/population/publications/WPP2004/2004Highlights_finalrevised.pdf

United Nations (2007). World population prospects: the 2006 revision population data base (Web Page). Accessed August 2008 from http://esa.un.org/unpp/p2k0data.asp

Van Heezik, Y., Symth, A., and Mathieu, R. (2008). Diversity of native and exotic birds across an urban gradient in a New Zealand city. Landscape and Urban Planning, 87, 223-232.

Van Herzele, A., and Wiedemann, T. (2003). A monitoring tool for the provision of accessible and attractive urban green spaces. Landscape and Urban Planning, 63, 109-126.

Vinton, J. G. (2008). Avian species abundance and richness in a variably urbanised landscape in Wellington City, New Zealand. Victoria University of Wellington, Masters Thesis.

Vlek, C., and Steg, L. (2007). Human Behaviour and Environmental Sustainability: Problems, Driving Forces, and Research Topics. Journal of Social Issues, 63(1), 1-19.

Voeks, R. A., and Leony, A. (2004). Forgetting the forest: assessing medicinal plant erosion in Eastern Brazil. Economic Botany, 58, 294-306.

de Vries, S., Verheij, R. A., Groenewegen, P. P., and Spreeuwenberg, P. (2003). Natural environmentshealthy environments? An exploratory analysis of the relationship between greenspace and health. Environment and Planning A, 35, 1717-1731.

Wellington City Council (1998). Capital Spaces. Open space strategy for Wellington (Web page). Accessed April 52009 from http://wellington.govt.nz/plans/policies/capitalspaces/pdfs/capitalspacespolicy.pdf 
Wellington City Council (2008). About Wellington - facts and figures overview (Web page). Accessed April 52009 from http://www.wellington.govt.nz/aboutwgtn/glance/index.html

Wellington City Council (2009). Parks and Garden Services (Web page). Accessed Sep 52009 from http://www.wellington.govt.nz/services/prksgrdnsserv/freeplants/freeplants.html

White, J. G., Antos, M. J., Fitzsimons, J. A., and Palmer, G. C. (2005). Non-uniform bird assemblages in urban environments: the influence of streetscape vegetation. Landscape and Urban Planning, 71, 123-135.

Whittaker, D., Manfredo, M. J., Fix, P. J., Sinnott, R., Miller, S., and Vaske, J. J. (2001). Understanding Beliefs and Attitudes about an Urban Wildlife Hunt near Anchorage, Alaska. Wildlife Society Bulletin, 29(4), 1114-1124.

Yli-Pelkonen, V., and Niemela, J. (2005). Linking ecological and social systems in cities: urban planning in Finland as a case. Biodiversity and Conservation, 14, 1947-1967. 


\section{Appendix 1}

\section{Urban Wildlife and Ecological Knowledge in Wellington Survey - Questions (not in original} formatting)

1. How would you rate your own knowledge about bird species in your neighbourhood?

Please tick $(\checkmark)$ the appropriate box.
Poor
Fair
Good
$\square$ Very Good
Excellent

2. Without using any references or talking to other people, write down as many bird species as you can in five minutes. From this list, place a cross ( $\mathrm{x})$ next to the birds that you think you would be able to recognise. Place a tick $(\checkmark)$ next to the birds that are native to New Zealand.

3. List the bird species that you have commonly seen or heard in your local neighbourhood within the last year. From this list, place a tick $(\checkmark)$ next to the birds that you think are native to New Zealand.

4. Have you noticed any change in the number of birds in your neighbourhood during the last year?

Yes, the number of birds has increased

Yes, the number of birds has decreased

No change

Not sure 
5. In general, how easy or difficult is it for you to get to a local park or other green space in your area?

Very Difficult

Difficult

Neither

Easy

Very easy

Don't know

6. How often did you visit a local park or reserve in the last year?

Not at all $\quad \longrightarrow$ (Skip to 8)

Once or twice a year

About once a month

Two to three times a month

About once a week or more

7. Which park(s) or reserve(s) did you visit most regularly in 2007?

park / reserve

8. How often did you visit a park or reserve outside Wellington in the last year?

Not at all $\longrightarrow \quad$ (Skip to 10)

Once or twice a year

About once a month

Two to three times a month

About once a week or more

9. Which park(s) or reserve(s) outside of Wellington did you visit most regularly in the last year? 
The following section is concerned with outdoor pursuits

10. How often do you participate in outdoor recreation activities?

\section{Not at all $\longrightarrow$ (Skip to 12)}

$\square$ Once or twice a year

About once a month

Two to three times a month

About once a week or more

11. Which outdoor recreation activities do you participate in?

Tick as many boxes as apply.

$\square$ Tramping
$\square \quad$ Hunting
$\square \quad$ Fishing
$\square \quad$ Camping
$\square \quad$ Climbing
$\square \quad$ Outdoor Photography
$\square \quad$ Swimming / Surfing
$\square \quad$ Four-wheel driving
$\square \quad$ Other(s). Please specify

12. Do you belong to any of the following?

A sports club. If so, which type of sport?

$\square$ A hobby or interest group. Please specify

$\square$ A community or voluntary group 
13. Write the name of the bird species pictured in the blank spaces provided, or tick the 'don't know' box if unsure.

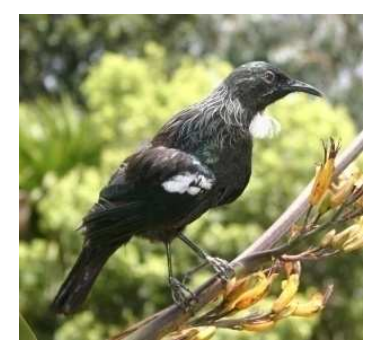

Bird 1

Don't know

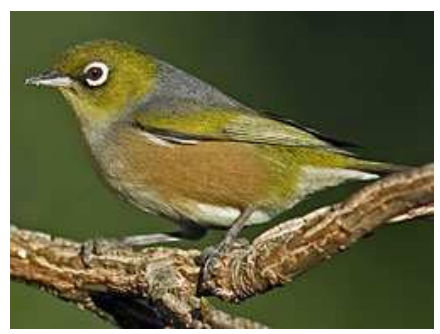

Bird 3

Don't know

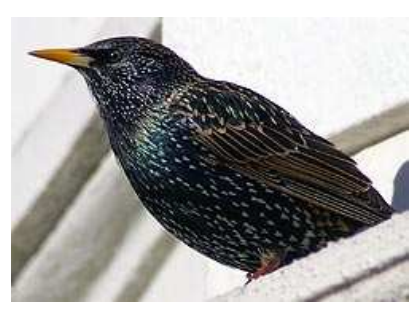

Bird 5

Don't know

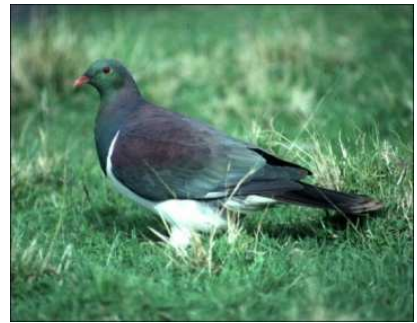

Bird 2

Don't know

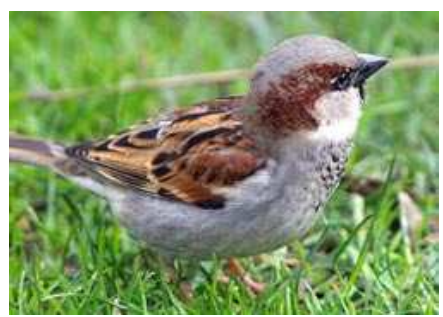

Bird 4

Don't know

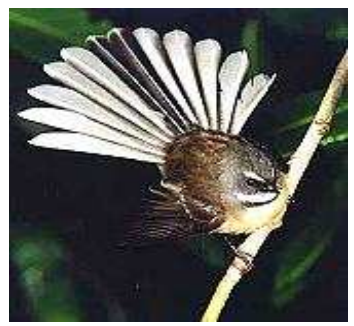

Bird 6

Don't know 


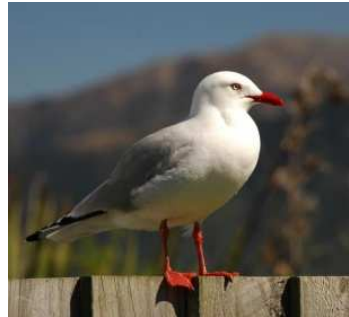

Bird 7

Don't know

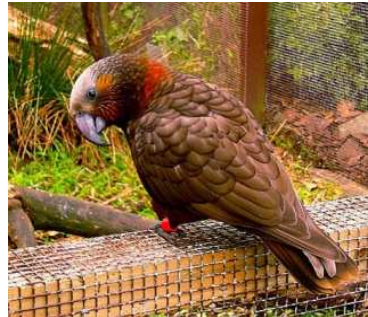

Bird 8

Don't know

14. To what extent do you agree or disagree with the following statements? Please tick the box that most applies for each statement

\begin{tabular}{|c|c|c|c|c|c|}
\hline & $\begin{array}{l}\text { Strongly } \\
\text { disagree }\end{array}$ & Disagree & $\begin{array}{l}\text { Neither } \\
\text { agree nor } \\
\text { disagree }\end{array}$ & Agree & $\begin{array}{c}\text { Strongly } \\
\text { agree }\end{array}$ \\
\hline $\begin{array}{l}\text { Green spaces are important habitat for } \\
\text { birds }\end{array}$ & & & & & \\
\hline $\begin{array}{l}\text { Birds are an annoyance in my } \\
\text { neighbourhood }\end{array}$ & & & & & \\
\hline $\begin{array}{l}\text { I am satisfied with the amount of green } \\
\text { space in my neighbourhood }\end{array}$ & & & & & \\
\hline $\begin{array}{l}\text { A decline in native bird species is not of } \\
\text { concern to humans }\end{array}$ & & & & & \\
\hline $\begin{array}{l}\text { Seeing birdlife in Wellington city is a } \\
\text { pleasant experience for me }\end{array}$ & & & & & \\
\hline $\begin{array}{l}\text { Hearing birdlife in Wellington city is a } \\
\text { pleasant experience for me } \\
\text { Seeing exotic birds gives me greater } \\
\text { pleasure than seeing native bird species }\end{array}$ & & & & & \\
\hline
\end{tabular}




\begin{tabular}{l|l|l|l|l|l|}
\hline $\begin{array}{l}\text { The parks in Wellington city are not } \\
\text { important as habitat for birds }\end{array}$ & & & & & \\
\hline $\begin{array}{l}\text { I would support measures to help } \\
\text { increase native bird populations in } \\
\text { Wellington }\end{array}$ & & & & & \\
\hline $\begin{array}{l}\text { The health of bird populations in } \\
\text { Wellington is important to me }\end{array}$ & & & & & \\
\hline
\end{tabular}

15. Which description below best describes the outside area of your current property? Please tick the relevant box. Private means that the outdoors area is not shared with other apartments/flats/houses.

Has no outdoors area

Has outdoors area which is shared between multiple apartments / houses

Has private outdoors area, containing garden space

Has private outdoors area, containing no garden space

Don't know

16. Do you have a pet at this address?

No

Yes - Dlease specify

17. Green space is defined as being an area devoted to gardens, park area, or vegetation. At this current address, how would you describe the level of green space on your property?

No green space available

\section{(Skip to 19)}

Small area of green space, not large enough to grow trees

Some green space, with trees

Large area of green space 
18. On the property where you currently live, have you planted any trees or plants to encourage bird-life?

No

No, but would do so if had the opportunity

Yes Pleaste specify what you've planted

19. Have you, whilst living at this address, placed food outside specifically for birds to eat?

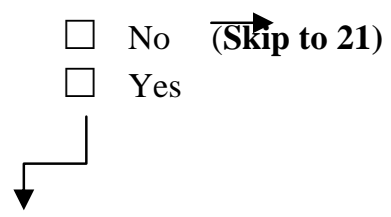

20. (If Yes) What is the food given for the birds?

How is this food delivered to the birds?

Which bird species were you targeting?

21. Are there any other steps you have taken to encourage bird activity?

Tick all the boxes that apply

Keeping pets indoors at night

Placing a bell on a cat

Minimising pesticide and/or herbicide use

Maintaining nest boxes

Maintaining bird baths

Other. Please specify

22. To what extent do you agree or disagree with the following statements? Please tick the box that most applies for each statement 


\begin{tabular}{|c|c|c|c|c|c|c|}
\hline & $\begin{array}{l}\text { Strongly } \\
\text { disagree }\end{array}$ & Disagree & $\begin{array}{c}\text { Neither } \\
\text { agree nor } \\
\text { disagree }\end{array}$ & Agree & $\begin{array}{c}\text { Strongly } \\
\text { agree }\end{array}$ & $\begin{array}{l}\text { Don't } \\
\text { know }\end{array}$ \\
\hline $\begin{array}{l}\text { Some bird species in New } \\
\text { Zealand were originally } \\
\text { from another country }\end{array}$ & & & & & & \\
\hline $\begin{array}{l}\text { Birds are more vocal at } \\
\text { certain times of the day }\end{array}$ & & & & & & \\
\hline $\begin{array}{l}\text { Some birds are better } \\
\text { adapted to avoiding } \\
\text { predators than others }\end{array}$ & & & & & & \\
\hline $\begin{array}{l}\text { The introduction of exotic } \\
\text { pest species has led to a } \\
\text { decrease in native bird } \\
\text { species in New Zealand }\end{array}$ & & & & & & \\
\hline $\begin{array}{l}\text { Planting trees and plants } \\
\text { can attract certain bird } \\
\text { species }\end{array}$ & & & & & & \\
\hline $\begin{array}{l}\text { Birds generally nest on th } \\
\text { ground in New Zealand }\end{array}$ & & & & & & \\
\hline $\begin{array}{l}\text { Some New Zealand birds } \\
\text { fly to other parts of the } \\
\text { world at certain times of } \\
\text { the year }\end{array}$ & & & & & & \\
\hline
\end{tabular}

The following questions concern general information

23. Are you?

Male

Female

24. Please tick the relevant age group to which you belong
$15-25$
$26-35$
$36-50$
$51-70$ 
Over 70

25. Which ethnic group do you belong to?

$\square$ New Zealand European
$\square$ Maori
$\square$ Samoan
$\square$ Cook Island Maori
$\square$ Tongan
$\square$ Niuean
$\square$ Chinese
$\square$ Indian
$\square$ other. Please state

26. How long have you lived at this current address?

number of years

27. Which country were you born in?

Country

28. How long have you lived in New Zealand?

Less than one year

One year to just under two years

Two years to just under five years

Five years to just under ten years

Ten years or more

29. What is your highest educational qualification?

No formal qualifications

Fifth or sixth form qualification (School Certificate passes, NCEA Level 1 or 2, Sixth Form Certificate, or University Entrance prior to 1986)

High school qualification (University Bursary Entrance exam, scholarship, Higher School Certificate, National Certificate Level 3 or 4, Overseas School Qualifications) 
Bachelor degree or vocational qualification (New Zealand certificate, National Diploma, Trade certificate, apprenticeship)

$\square$ Postgraduate degree (Honours, Masters, $\mathrm{PhD}$ )

$\square$ Other. Please specify

30. Which describes your annual personal income before tax?
Loss
Zero income
Less than $\$ 10,000$
$\$ 10,001-\$ 20,000$
$\$ 20,001-\$ 30,000$
$\$ 30,001-\$ 40,000$
$\$ 40,001-\$ 50,000$
$\$ 50,001-\$ 60,000$
$\$ 60,001-\$ 70,000$
$\$ 70,001$ - $\$ 100,000$
$\$ 100,001$ or more
Don't know 
Appendix 2. Bi-variate Correlation Matrix - Spearmans Coefficients.

\begin{tabular}{|c|c|c|c|c|c|c|c|c|c|c|c|c|c|c|c|c|c|c|c|c|}
\hline & Age & Inc. & Educ & Green & $\begin{array}{l}\text { Out } \\
\text { Rec }\end{array}$ & $\begin{array}{l}\text { Reg } \\
\text { Park }\end{array}$ & $\begin{array}{l}\text { Local } \\
\text { Park }\end{array}$ & $\begin{array}{l}\text { Access } \\
\text { green }\end{array}$ & $\begin{array}{l}\text { Bird } \\
\text { div. }\end{array}$ & $\begin{array}{l}\text { Geo } \\
\text { Type }\end{array}$ & $\begin{array}{l}\text { Sp. } \\
\text { Club }\end{array}$ & $\begin{array}{l}\text { Hobby } \\
\text { Group }\end{array}$ & $\begin{array}{l}\text { Comm } \\
\text { Group }\end{array}$ & $\begin{array}{l}\text { Know } \\
\text { Local }\end{array}$ & $\begin{array}{l}\text { Know } \\
\text { Gen }\end{array}$ & $\begin{array}{l}\text { Know } \\
\text { ID }\end{array}$ & $\begin{array}{l}\text { Tree } \\
\text { plant }\end{array}$ & $\begin{array}{l}\text { Bird } \\
\text { Feed }\end{array}$ & $\begin{array}{l}\text { Nat } \\
\text { gen }\end{array}$ & $\begin{array}{l}\text { Nat } \\
\text { Loc }\end{array}$ \\
\hline Age & - & & & & & & & & & & & & & & & & & & & \\
\hline Income & $.15^{* *}$ & - & & & & & & & & & & & & & & & & & & \\
\hline Education & & $\begin{array}{l}.22 \\
1\end{array}$ & - & & & & & & & & & & & & & & & & & \\
\hline Green Sp. & & & & - & & & & & & & & & & & & & & & & \\
\hline Out Rec. & & & & & - & & & & & & & & & & & & & & & \\
\hline Reg. Park & & & $.16^{* *}$ & & & - & & & & & & & & & & & & & & \\
\hline Loc. Park & & & $.11^{*}$ & & & & - & & & & & & & & & & & & & \\
\hline Access Gr. & & & & $.14^{* *}$ & $.15^{* *}$ & $.14^{* *}$ & $.29 * *$ & - & & & & & & & & & & & & \\
\hline Diversity & & & & & & & & $.12^{*}$ & - & & & & & & & & & & & \\
\hline Geo tyoe & & & & $.39 * *$ & & & & $-.15^{* *}$ & $-.38^{* *}$ & - & & & & & & & & & & \\
\hline Sports Club & & & & $-.12^{*}$ & $.27^{* *}$ & & & & & & - & & & & & & & & & \\
\hline Hobby C. & $.20^{* *}$ & & & & & & & & & & & - & & & & & & & & \\
\hline Comm Gp & & & & $.14^{* *}$ & & & & $.10^{*}$ & & & & $.16^{* *}$ & - & & & & & & & \\
\hline Know-loc & $.35^{* *}$ & & & $.21^{* *}$ & & $.11^{*}$ & & & $-.4^{* *}$ & & & & $.11^{*}$ & - & & & & & & \\
\hline Know-gen & & & $.16^{* *}$ & $.11^{*}$ & & $.21^{* *}$ & $.13^{* *}$ & & & & & & $.14^{* *}$ & $.44^{* *}$ & - & & & & & \\
\hline Know-id & & & $.12^{* *}$ & $.13^{* *}$ & & $.19 * *$ & $.15^{* *}$ & $.12^{*}$ & & & & $.14^{* *}$ & $.13^{*}$ & $.46^{* *}$ & $.50^{* *}$ & - & & & & \\
\hline Tree plant & $.31^{* *}$ & & & $.17^{* *}$ & & & $.11^{*}$ & & & & $.12^{*}$ & & $.13^{*}$ & $.33^{* *}$ & $.16^{* *}$ & $.18^{* *}$ & - & & & \\
\hline Bird feeding & $.16^{* *}$ & & & $.18^{* *}$ & & & . & $.12^{* *}$ & $-.10^{*}$ & $\begin{array}{l}- \\
.15^{* *}\end{array}$ & & & & $.28^{* *}$ & & $.10^{*}$ & $.20^{* *}$ & - & & \\
\hline Native gen & & & $.11^{*}$ & & & $.12^{*}$ & $.13^{* *}$ & & & & & & & $.11^{* *}$ & $.14^{* *}$ & $.28^{* *}$ & & & - & \\
\hline Native local & & & & $.15^{* *}$ & & & & & & & & & $.13^{* *}$ & & & $.17^{* *}$ & & & $\begin{array}{l}.33^{*} \\
*\end{array}$ & - \\
\hline
\end{tabular}

Note: ${ }^{* *}$ Correlation is significant at the 0.001 level (2-tailed). ${ }^{*}$ Correlation is significant at the 0.05 level 